MARCO ANTONIO ZANUSSI BARRETO

\title{
DINÂMICA LONGITUDINAL: EFEITOS DA GEOMETRIA DE SUSPENSÃO NAS MUDANÇAS DE ATITUDE DA MASSA SUSPENSA E OS ESFORÇOS NOS ELEMENTOS DA SUSPENSÃO.
}

Dissertação apresentada à Escola de Engenharia de São Carlos, da Universidade de São Paulo, como parte dos requisitos para a obtenção do Título de Mestre em Engenharia Mecânica.

Orientador: Prof. Dr. Álvaro Costa Neto.

São Carlos

2005 
DINÂMICA LONGITUDINAL: EFEITOS DA GEOMETRIA DE SUSPENSÃO NAS MUDANÇAS DE ATITUDE DA MASSA SUSPENSA E OS ESFORÇOS NOS ELEMENTOS DA SUSPENSÃO. 
À minha família, noiva e amigos. 


\section{AGRADECIMENTOS}

O presente trabalho foi realizado com o apoio do Conselho Nacional de Desenvolvimento Científico e Tecnológico CNPq-Brasil

Ao Prof. Dr. Álvaro da Costa Neto por ter propiciado a realização do trabalho e por sua amizade.

Aos professores da faculdade de engenharia industrial (FEI), Ricardo Bock, Roberto Bertolucci e Rodrigo Magnabosco, pela confiança e indicação para o programa de pósgraduação.

Aos professores e funcionários da Escola de Engenharia de São Carlos, pela ajuda recebida e afeição. 


\section{ÍNDICE DE FIGURAS}

Figura 1 - Modelo trailing-arm de Fu-Cheng Wang......................................................... 7



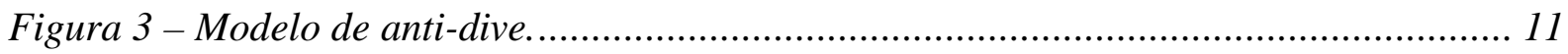



Figura 2 - Transferência de carga entre os eixos. ........................................................ 15

Figura 3 - Vista lateral da suspensão com dois braços de controle. ................................... 17

Figura 4 - Vista lateral do equivalente trailing-arm................................................... 18

Figura 5 - Cálculo da força de anti-dive ................................................................... 19







Figura 9 - Cálculo da força de anti-squat para um veículo tração traseira por eixo rígido. 22

Figura 10 - Cálculo da força de anti-squat para suspensão independente. ......................... 23

Figura 11 - Linhas de fixação para total anti-dive e anti-lift. ............................................ 32

Figura 12 - Cálculo dos esforços na suspensão............................................................... 33



Figura 1 - Linha cronológica do desenvolvimento MBS. ............................................. 45

Figura 2 - Modelo em sistema de multicorpos............................................................... 48

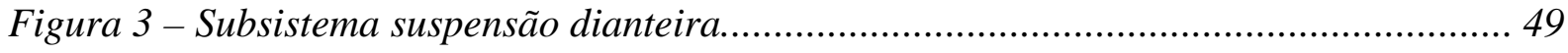

Figura 4 - Junta entre os corpos da suspensão dianteira................................................... 50

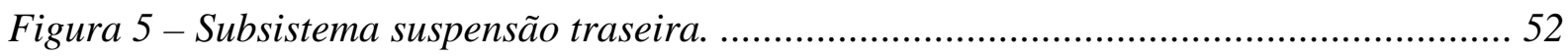

Figura 6 - Junta entre os corpos da suspensão traseira .................................................. 53




Figura 8 - Junta entre os corpos do subsistema de direção.

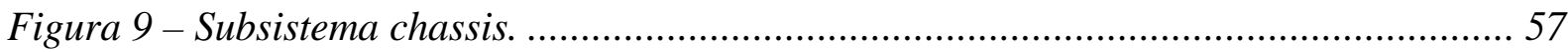

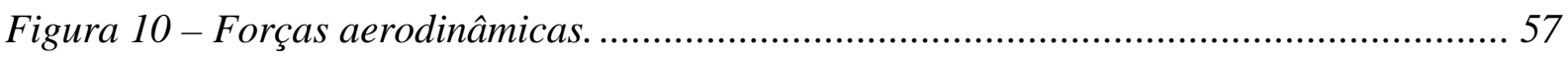

Figura 11 - Modelo roda e pneu dianteiro e traseiro....................................................... 59

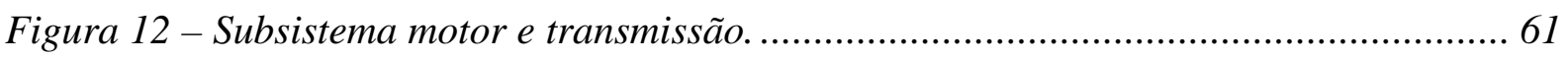

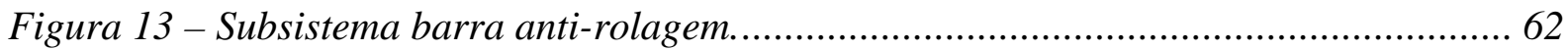

Figura 14 - Junta entre os corpos da barra anti-rolagem.............................................. 62

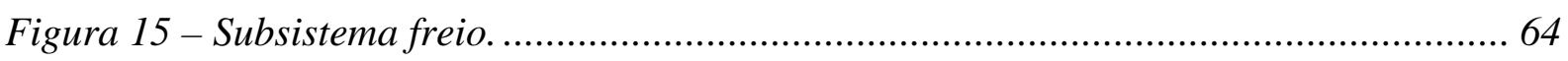

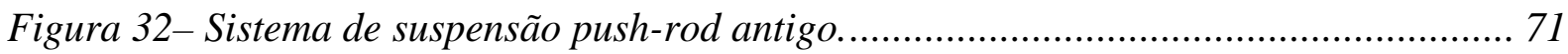

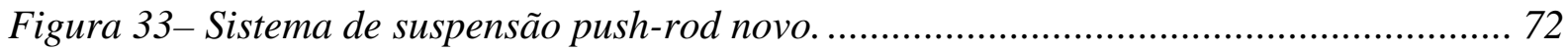

Figura 34 - Coordenadas do modelo trailing-arm............................................................ 92

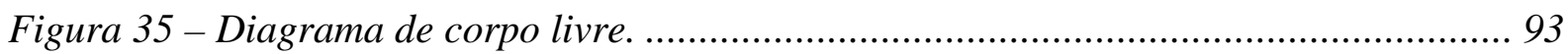




\section{ÍNDICE DE GRÁFICOS}

Gráfico 1. - Variação de dive na suspensão dianteira para $0 \%$ de anti-dive ........................ 67

Gráfico 2- Variação de dive na suspensão dianteira para $100 \%$ de anti-dive. ..................... 68

Gráfico 3- Variação de lift na suspensão traseira para $0 \%$ de anti-lift................................ 68

Gráfico 4- Variação de lift na suspensão traseira para 100\% de anti-lift. ........................... 69

Gráfico 5- Variação de squat na suspensão traseira para $0 \%$ de anti-lift............................. 70

Gráfico 6- Variação de squat na suspensão traseira para 100\% de anti-lift......................... 71

Gráfico 7- Variação de squat na nova suspensão traseira para $0 \%$ de anti-lift.................... 73

Gráfico 8- Variação de squat na nova suspensão traseira para $100 \%$ de anti-lift. ............... 73

Gráfico 9- Variação do comprimento do equivalente trailing-arm para $0 \%$ de anti-lift........ 74

Gráfico 10- Variação do comprimento do equivalente trailing-arm para 100\% de anti-lift.. 75

Gráfico 11- Variação do comprimento do equivalente trailing-arm para $100 \%$ de anti-lift

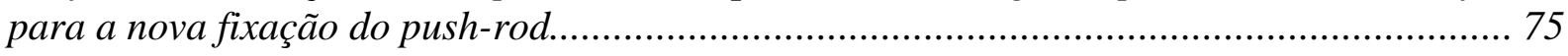

Gráfico 12 - Deslocamento angular do veiculo em aceleração......................................... 77

Gráfico 13 - Deslocamento vertical do veiculo em aceleração. ......................................... 77

Gráfico 14-Deslocamento angular para o veiculo em aceleração com nova fixação do pushrod.

Gráfico 15 - Deslocamento angular para o veiculo em aceleração com nova fixação do pushrod......

Gráfico 16 - Deslocamento angular para o veiculo em desaceleração. 80

Gráfico 17 - Deslocamento vertical para o veiculo em desaceleração. 80

Gráfico 18-Deslocamento angular para o veiculo em desaceleração com nova suspensão. 81

Gráfico 19- Deslocamento vertical para o veiculo em desaceleração com a nova suspensão.

Gráfico 20 - Variação do comprimento do amortecedor traseiro em aceleração.

Gráfico 21 - Variação do comprimento do amortecedor traseiro em aceleração, com a nova suspensão. 
Gráfico 22 - Variação do comprimento do amortecedor traseiro em desaceleração.

84

Gráfico 23 - Variação do comprimento do amortecedor traseiro em desaceleração, com a nova suspensão. 


\section{ÍNDICE DE TABELAS}

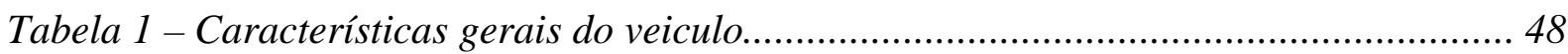

Tabela 2 - Descrição das juntas na suspensão dianteira................................................. 50

Tabela 3 - Descrição das juntas na suspensão traseira...................................................... 53

Tabela 4 - Descrição das juntas do subsistema direção.................................................... 56

Tabela 5 - Características do subsistema roda pneu .............................................................. 58

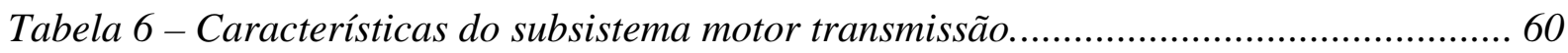

Tabela 7 - Descrição das juntas do subsistema barra anti-rolagem.................................. 63

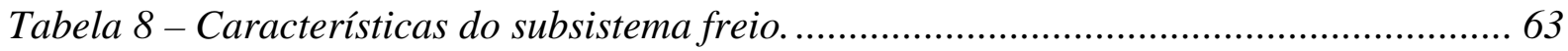




\section{ÍNDICE GERAL}

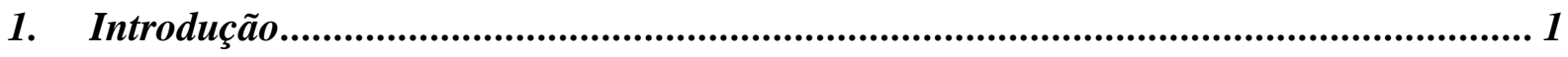

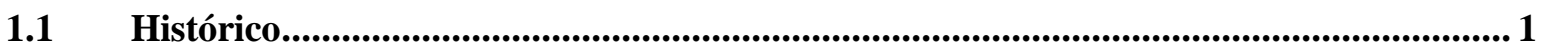





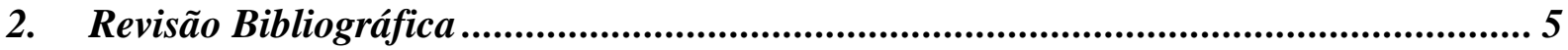

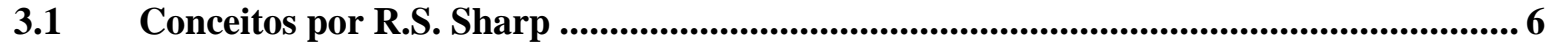

3.2 Modelo dinâmico Bidimensional de Fu-Cheng Wang ......................................................... 7





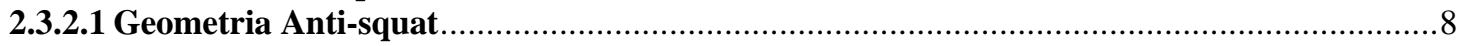

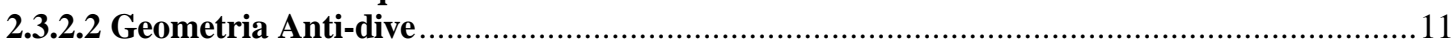

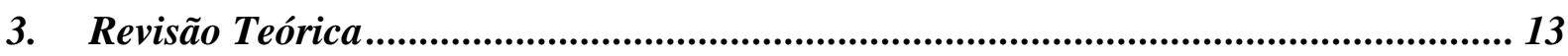

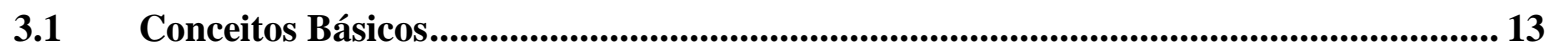

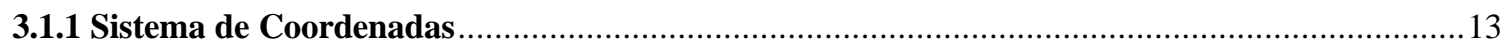

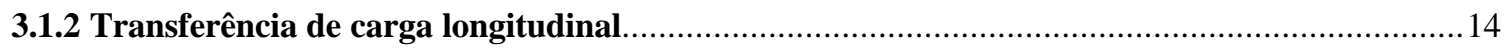

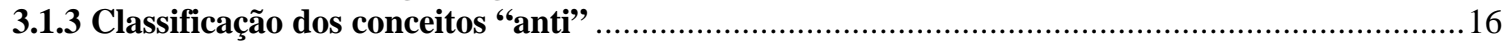

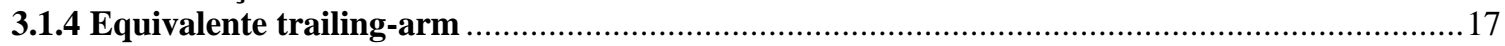

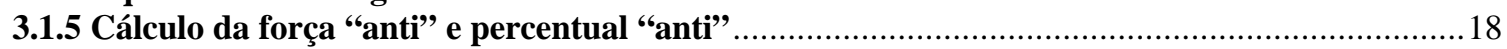

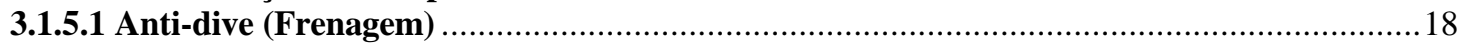

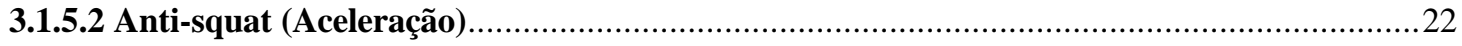

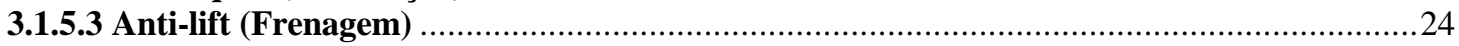

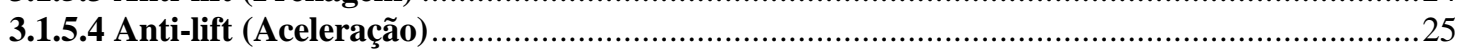

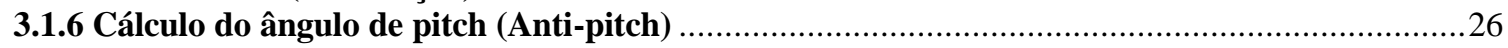

3.1.6.1 Tração traseira independente e tração traseira por eixo rígido ……...............................2.

3.1.6.2 Tração dianteira independente e tração dianteira por eixo rígido ...................................28

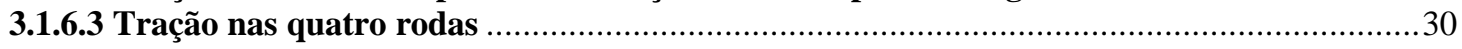

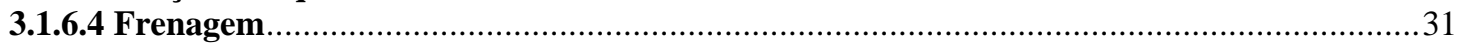

3.1.7 Cálculo dos esforços nos elementos de suspensão

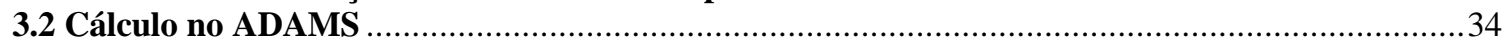

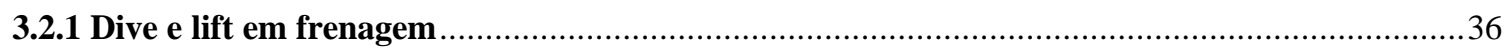



3.2.3 Percentual de anti-dive e anti-lift em frenagem ..................................................................... 39



3.2.5 Comprimento e ângulo do equivalente trailing-arm .................................................................... 42

4. Modelo do veiculo em sistema de multicorpos (MBS)........................................... 45

4.1 Histórico............................................................................................................................................... 45

4.2 Modelo em sistema de multicorpos do veículo ...............................................................47

















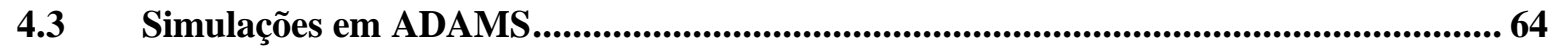


5. Resultados e Análises ...............................................................................................6 66

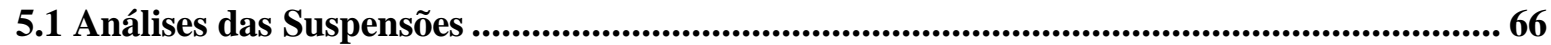

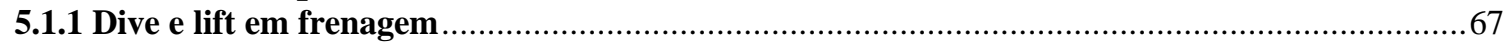



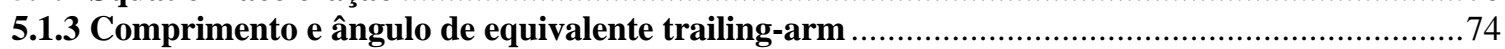

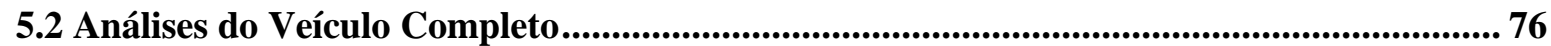

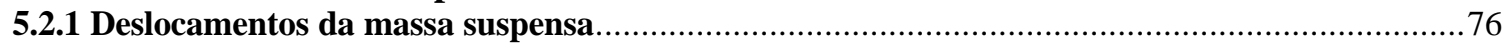

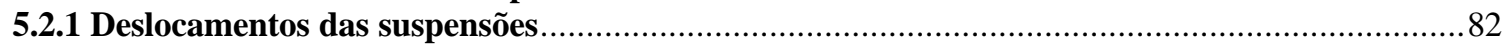

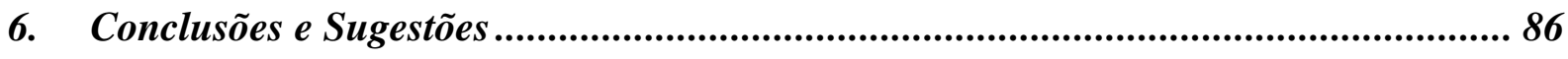

7. Referências Bibliográficas ........................................................................................ 88

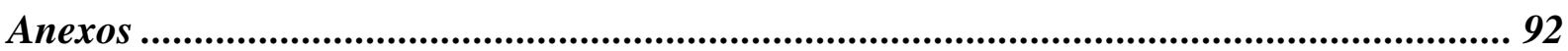

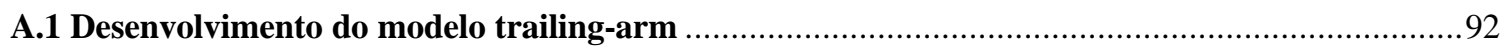

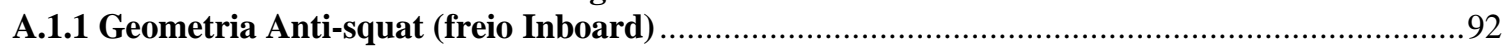

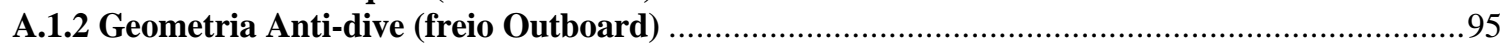

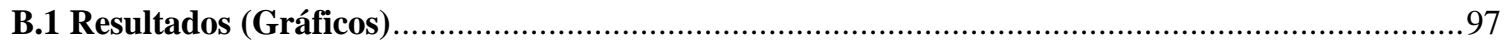



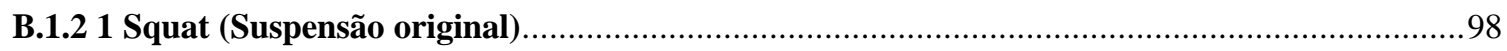

B.1.2.2 Squat (Suspensão com alteração no push-rod) .......................................................... 100

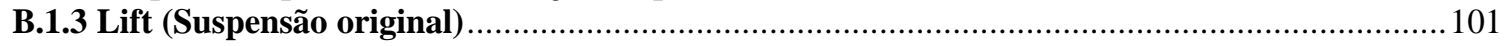

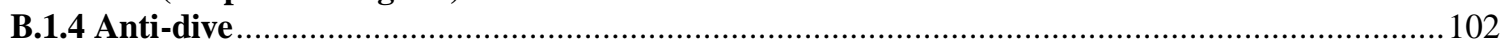

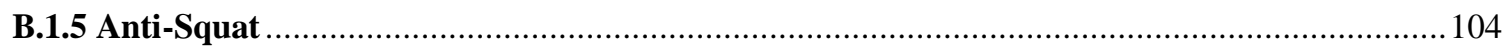

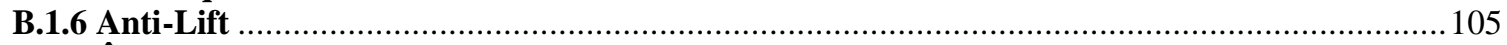

B.1.7 Ângulo do Equivalente trailing-arm (suspensão traseira original) .................................... 106

B.1.8 Ângulo do Equivalente trailing-arm (suspensão traseira com alteração no push-rod)...........108

B.1.9 Comprimento do Equivalente trailing-arm (suspensão traseira original) ............................109

B.1.10 Comprimento do Equivalente trailing-arm (suspensão traseira com alteração no push-rod) 


\section{LISTA DE SÍMBOLOS}

F - Força de desaceleração.

W - Peso do Veiculo.

$a_{l}$ - Aceleração ou desaceleração longitudinal.

$\mathrm{H}$ - Altura do CG.

L - Distancia entre os eixos.

$\Delta W$ - Variação de carga entre os eixos.

$F_{f}-$ Força de frenagem.

$\mathrm{p}$ - Percentual de frenagem no eixo dianteiro.

$\mathrm{x}_{1}$ - Altura do centro instantâneo lateral em relação ao solo para suspensão dianteira.

$\mathrm{y}_{1}$ - Distância do centro instantâneo ao centro da roda dianteira para suspensão dianteira.

$\phi_{\mathrm{df}}-$ Ângulo formado pela linha que sai do ponto de contato do pneu até o centro instantâneo de rotação lateral com a coordenada $\mathrm{y}_{1}$.

r - Altura do solo ao centro da roda.

x - Altura do centro instantâneo lateral em relação ao solo para suspensão traseira.

y2 - Distância do centro instantâneo ao centro da roda dianteira para suspensão traseira.

$F_{t}-$ Força de tração.

$\phi_{\mathrm{sr}}-$ Ângulo formado pela linha que sai do ponto de contato do pneu até o centro instantâneo de rotação lateral com a coordenada $y_{2}$.

$\theta_{\mathrm{df}}-$ Ângulo formado pela linha que sai do centro da roda dianteira até o centro instantâneo de rotação lateral com a coordenada $\mathrm{y}_{1}$.

$\theta_{\text {sr }}-$ Ângulo formado pela linha que sai do centro da roda traseira até o centro instantâneo de rotação lateral com a coordenada y2. 
$\theta_{\mathrm{lf}}-$ Ângulo formado pela linha que sai do centro da roda dianteira até o centro instantâneo de rotação lateral com a coordenada $\mathrm{y}_{1}$.

$\theta_{\text {lr }}-$ Ângulo formado pela linha que sai do centro da roda traseira até o centro instantâneo de rotação lateral com a coordenada $\mathrm{y}_{2}$.

g - aceleração da gravidade.

$\mathrm{F}_{\mathrm{mr}}$ - Força na mola traseira.

$\mathrm{k}_{\mathrm{r}}$ - rigidez da mola traseira.

$\delta_{\mathrm{r}}-$ deformação da mola traseira.

$\mathrm{F}_{\mathrm{mf}}-$ Força na mola dianteira.

$\mathrm{k}_{\mathrm{f}}$ - rigidez da mola dianteira.

$\delta_{\mathrm{f}}-$ deformação da mola dianteira.

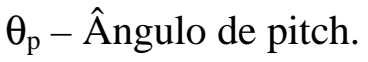

$q$ - Fração da força total de tração desenvolvida no eixo dianteiro.

$\mathrm{F}_{\mathrm{tf}}-$ Força de tração no eixo dianteiro.

$\mathrm{F}_{\mathrm{tr}}-$ Força de tração no eixo traseiro.

$F_{y}$ - Força de tração no solo.

$F_{x}$ - Força de reação vertical no solo causada pelas componentes verticais das forças nos braços de controle.

$\mathrm{P}_{1}$ - Força no braço de controle superior.

$\mathrm{P}_{2}$ - Força de controle no braço inferior.

$\theta_{1}-$ Ângulo formado pelo braço superior de controle com uma linha horizontal que passa pelo ponto superior da manga de eixo.

$\theta_{2}$ - Ângulo formado pelo braço inferior de controle com uma linha horizontal que passa pelo ponto inferior da manga de eixo.

$Z_{1}$ - Distância entre o ponto superior e inferior da manga de eixo. 
$\mathrm{Z}_{2}$ - Distância entre o ponto inferior da manga de eixo e o solo.

x - Altura do centro instantâneo de rotação.

y - Distância do centro da roda ao centro instantâneo de rotação.

$F_{1}$ - Força de tração no eixo dianteiro.

$\mathrm{F}_{2}$ - Força de tração no eixo traseiro.

$\mathrm{m}_{\mathrm{s}}$ - Massa suspensa.

$\mathrm{I}_{1}$ - Inércia do eixo dianteiro.

$\mathrm{I}_{2}$ - Inércia do eixo traseiro.

$\mathrm{N}_{1}$ - Força normal no eixo dianteiro.

$\mathrm{N}_{2}$ - Força normal no eixo traseiro.

$\mathrm{m}_{1}-$ Massa no eixo dianteiro.

$\mathrm{m}_{2}$ - Massa no eixo traseiro. 


\section{RESUMO}

BARRETO, M. A. Z. (2005). Dinâmica Longitudinal: Efeitos da Geometria de Suspensão nas Mudanças de Atitude da Massa Suspensa e Esforços nos Elementos de Suspensão. São Carlos 2004. 103p. Dissertação (Mestrado) - Escola de Engenharia de São Carlos, Universidade de São Paulo.

Este trabalho tem como objetivo estudar a influência da geometria de suspensão do veiculo nas atitudes da massa suspensa. Apresenta um confronto entre obras e autores e esta segmentada em três partes; onde na primeira parte são definidos os conceitos básicos como dive, squat, lift, anti-dive, anti-squat, anti-lift e equivalente trailing-arm; na segunda parte são apresentadas as limitações e os novos conceitos definidos por R. S. Sharp e na terceira parte é apresentado o modelo dinâmico bidimensional introduzido por Fu-Cheng Wang. Apresenta um modelo virtual em sistema de multi-corpos desenvolvido no programa ADAMS, com todos os subsistemas que compõe um veículo completo. Inova ao trazer como objeto de estudo um veiculo de competição (fórmula SAE) que possui como particularidade o sistema de suspensão push-rod. Surpreende com os resultados obtidos, pois, contrariam os conceitos básicos encontrados na maioria dos livros.

Palavras-chave: Modelagem de veículos; Dinâmica longitudinal; Anti-dive; Anti-squat; Anti-lift, Transferência de carga longitudinal; Dive; Lift; Squat; Pitch; Equivalente trailing-arm; Fórmula SAE; Push-rod; Multicorpos; ADAMS Car. 


\begin{abstract}
BARRETO, M. A. Z. (2005). Longitudinal Dynamics: Effects of the geometry suspension on the sprung mass attitude and the effort on elements suspensions. São Carlos 2004. 103 p. Dissertação (Mestrado) - Escola de Engenharia de São Carlos, Universidade de São Paulo.
\end{abstract}

This work has objective study the influence of suspension geometry on the sprung mass attitudes. It presents a confrontation among works and authors and this segmented in three parts; where in the first part the basic concepts are defined, dive, squat, lift, anti-dive, antisquat, anti-lift and equivalent trailing-arm; in the second part the limitations are presented and the new concepts are defined for R. S. Sharp and in the third part are presented the bidimensional dynamic model introduced by $\mathrm{Fu}$-Cheng Wang. It presents a virtual model in system of multi-bodies developed in the program ADAMS, with all the subsystems that composes a complete vehicle. It innovates when bringing such object to study one vehicle of competition (formula SAE) that it has a particularity suspension system push-rod. It surprises with results because it's opposite of the basic concepts which is present in the majority of books.

Key-Word: Modeling of vehicles; longitudinal dynamics; Anti-dive; Anti-squat; Anti-lift; Longitudinal load transference; Dive; Lift; Squat; Pitch; Equivalent trailing-arm; Formula SAE; Push-rod; Multibody; ADAMS Car 


\section{Introdução}

\subsection{Histórico}

A concepção do primeiro automóvel ocorreu por volta de 1769, quando o militar francês Nicolas Joseph Cugnot construiu um triciclo movido a vapor com o propósito de locomover equipamentos de guerra. Ele foi seguido por James Watt em 1784, e por Richard Trevithick que em 1802 desenvolveu uma carruagem a vapor que fazia viagem de Cornwall para Londres, as carruagens a vapor tiveram seu fim devido à sua baixa capacidade de carga comparada com os trens. Em 1886, surgiram os primeiros automóveis movidos à gasolina cujos méritos são dados a Karl Benz e Gottlieb Daimler, que trabalharam em seus projetos independentemente. (GILLESPIE, 1992, p.1-2).

A evolução do sistema de suspensão não esta relacionado somente à evolução do automóvel, os primeiros sistemas de suspensão equipavam carruagens do século 18 e 19 para melhorar o conforto dos passageiros, pois as estradas eram de baixa qualidade. Conhecimentos relacionados à qualidade do sistema foram adquiridos, mas não foi publicado nenhum material técnico a respeito nesse período. (DIXON, 1996). 
O primeiro automóvel movido à gasolina, originado em 1886 por Gottlieb Daimler, usou um par de feixes de mola em cada eixo dispostos nos extremos, fixando o eixo na parte de baixo da mola e o chassi na parte de cima.

O surgimento da mola helicoidal ocorreu devido ao surgimento da meia suspensão, que teve um maior uso nas suspensões independentes dianteiras após a segunda guerra mundial, e foi usada em conjunto com feixe de molas no eixo traseiro durante algum tempo. (DIXON, 1996).

Com o passar dos tempos muitos trabalhos foram desenvolvidos relacionando o sistema de suspensão com, o pneumático, o sistema de direção e com o pavimento. Um estudo muito importante foi feito por Bradley e Allen em 1930, que investigaram as propriedades de aderência da superfície de rodagem em testes de frenagem. (DIXON, 1996).

Nos últimos tempos com o auxilio do computador os sistemas de suspensão são analisados com maiores detalhes, com programas de multicorpos é possível analisar as características da suspensão com seus elementos elásticos como também suas características no estudo do modelo do veiculo completo.

\subsection{Motivação para o trabalho}

Quando o veículo está sob efeitos de aceleração ou desaceleração a massa suspensa tende a mudar de atitude, essa mudança de atitude pode causar diversas alterações, por exemplo, mudança de carga nos eixos dianteiro e traseiro, mudança na altura da massa suspensa, mudança nos parâmetros da suspensão como ângulo de cambagem, ângulo de caster e ângulo de convergência e até mesmo sensações de desconforto aos passageiros. (SHARP, 1999, p. 23-36). 
A mudança de carga nos eixos pode afetar o controle do veiculo, por exemplo, em aceleração aonde existe uma transferência da carga do eixo dianteiro para o eixo traseiro, diminuindo a força de contato do pneu com o pavimento no eixo dianteiro podendo gerar uma ausência momentânea de controle.

O conhecimento da altura da massa suspensa é muito importante, pois, ela determina a posição de impacto do veiculo em colisão, essa que pode ser diferente dependendo da desaceleração ou aceleração em que o veiculo se encontra, e pode ser determinante em caso de colisão com pedestres. (SHARP, 1999, p. 23-36).

Outro fator relevante é que os movimentos da massa suspensa podem ser desconfortáveis às pessoas que estão dentro do veiculo. Movimentos bruscos podem trazer sensações de insegurança ao condutor, por exemplo, quando estiver em uma frenagem brusca. (SHARP, 1999, p. 23-36).

Além dos fatos relacionados acima o trabalho foi motivado ao constatar que a maioria dos livros apresenta apenas uma visão quase-estática e simplificada sobre o tema.

\subsection{Objetivo}

O presente trabalho tem como objetivo estudar a influência da geometria da suspensão do veículo na mudança de atitude da massa suspensa, quando o veículo esta sobre influencia de aceleração e desaceleração longitudinal.

O estudo é do tipo comparativo que apresenta um confronto teórico entre autores e esta segmentado em algumas partes aonde, na primeira parte é feita uma revisão dos principais conceitos, na segunda parte é apresentado um modelo com quatro graus de 
liberdade e que possui as características dinâmicas longitudinais similares a de um modelo completo que é apresentado na terceira parte do trabalho.

O modelo a ser estudado é de um veiculo de competição conhecido como FORMULA SAE, a escolha desse ocorreu devido às suas características de performance e por verificar a escassez de literaturas nacionais que analisam esses tipos de veículos. Equipes nacionais de competição movimentam milhões de reais por ano, aonde grande parte de suas tecnologias são importadas.

Para o estudo é usado o programa ADAMS (sigla de Automatic Dynamic Analysis of Mechanical Systems), que é uma ferramenta computacional que simula as características dinâmicas do veículo utilizando as teorias de MBS (sigla de Multy Body Systems). 


\section{Revisão Bibliográfica}

Um dos trabalhos mais citados, que estuda a influência da dinâmica longitudinal nas mudanças de atitude da massa suspensa, é o Bastow D. -1974 que faz uma análise da geometria da suspensão nos efeitos de squat e dive do veículo. Os conceitos apresentados em seu trabalho são considerados, por muitos autores, base para o entendimento. . Sua teoria e os conceitos básicos são desenvolvidos no próximo capitulo.

Durante muitos anos análises simplificadas foram predominante, até que em 1999 (Sharp R. S.) apresentou um trabalho com diferentes visões e criticas. Ele analisou as influências da geometria da suspensão nos efeitos de squat e dive com a ajuda de um programa de multicorpos (AutoSim).

Em $2001 \mathrm{Fu}$-Cheng Wang apresentou em seu trabalho um modelo com quatro graus de liberdade que tem características dinâmicas logintudinais similares à de um veículo completo. 


\subsection{Conceitos por R.S. Sharp}

Em 1999 R. S. Sharp apresentou em seu trabalho criticas sobre os conceitos usados até então, pois eles tratam apenas de casos especiais em que às características do sistema são encontradas pelo método simplificado do equilíbrio e os casos mais gerais são parcialmente entendidos através de interpolação qualitativa de casos especiais. Assim numerou as seguintes deficiências:

1) As características são tratadas de maneira quase-estática e não dinamicamente.

2) A análise de equilíbrio simplificada é marcante e implica em restrições sobre os movimentos verticais do corpo, que é causada pela solução do problema de equilíbrio não apresentando as características reais.

3) Somente casos especiais são tratados publicamente.

Para a solução das deficiências encontradas, Sharp utilizou um programa de MBS (Multy Body Systems, AutoSim) aonde foi criado um modelo para estudos dinâmico. O modelo utilizava uma diferente abordagem em que a geometria de suspensão foi definida em termos de relações matemáticas que determinavam o movimento do cubo de roda relativo ao corpo do veículo. A primeira relação envolve o movimento longitudinal do centro da roda vinculado ao seu movimento vertical quando a suspensão move em seu grau de liberdade vertical. A segunda relação envolve o movimento vertical da roda devido a rotação do cubo de roda.

O trabalho termina concluindo que a restrição do movimento de pitch é obtido através de características cinemáticas, a restrição do movimento de pitch é acompanhada do movimento vertical do veículo, o idealismo de $100 \%$ anti-pitch se torna impossível devido a mudanças que ocorrem na geometria da suspensão quando em movimento e que as suspensões com alta restrição do movimento de pitch se tornam menos suaves. 


\subsection{Modelo dinâmico Bidimensional de Fu-Cheng Wang}

\subsubsection{Modelo trailing-arm}

Continuando a apresentação dos trabalhos mais importantes será abordado o trabalho de Fu-Cheng Wang. Baseado em que a geometria de suspensão trailing-arm é a solução convencional para o entendimento dos problemas de dive e squat durante aceleração ou frenagem, Fu-Cheng Wang apresentou o modelo trailing-arm, figura (1).

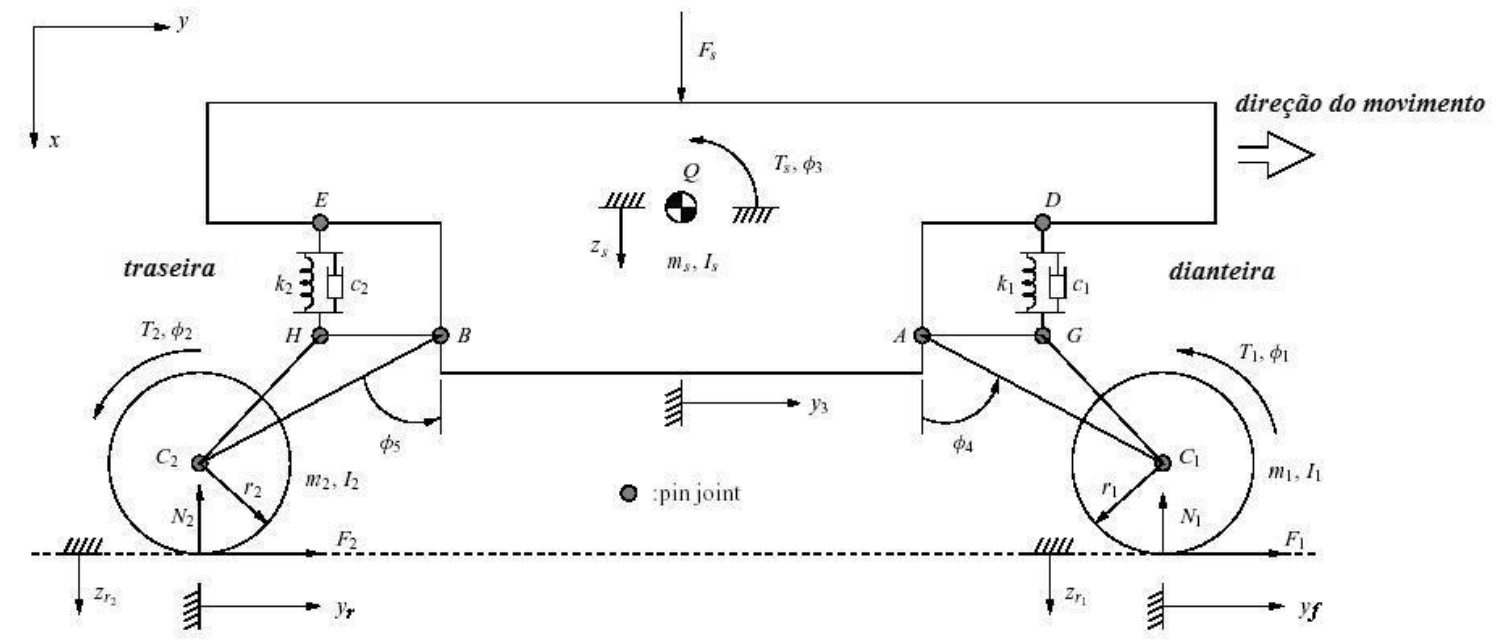

Figura 1 - Modelo trailing-arm de Fu-Cheng Wang.

FONTE: - FU-CHENG WANG, 2001, p. 17-30.

A figura (1) ilustra o modelo trailing-arm, aonde a roda dianteira é conectada a massa suspensa através do trailing-arm $\mathrm{AC}_{1}$ e a roda traseira pelo trailing-arm $\mathrm{BC}_{2}$. Para simular aceleração e frenagem são aplicados os torques $T_{1}$ e $T_{2}$ sobre as rodas e correspondem as forças $F_{1}$ e $F_{2}$ que são aplicadas no ponto de contato pneu pavimento e não possuem escorregamento na rolagem. No caso de tração independente e sistema de freio inboard é aplicado o torque de reação correspondente sobre a massa suspensa. 


\subsubsection{Geometria de Anti-squat e Anti-dive}

Nessa seção serão apresentadas as condições para o perfeito anti-dive e anti-squat. Para simplificar a análise os pneus serão considerados incompressíveis. A idéia básica é encontrar a geometria de suspensão na qual a massa suspensa não possua movimento de pitch. A abordagem leva em consideração os valores de massa e inércia das rodas.

\subsubsection{Geometria Anti-squat}

A geometria de total anti-squat é encontrada posicionando os pontos da suspensão trailing-arm de modo que a massa suspensa permaneça com altura constante e sem movimento de pitch quando o veículo estiver em aceleração. É possível verificar que, para total anti-squat não ocorre variação na geometria de suspensão assim é possível assumir que $\mathrm{y}_{\mathrm{f}}=\mathrm{y}_{\mathrm{r}}=\mathrm{y}_{\mathrm{s}}=\mathrm{y}$, figura 1 , e as forças na suspensão seriam zero (mola e amortecedor). Os pontos $\mathrm{P}_{1}$ e $\mathrm{P}_{2}$ representam o ponto de contato do pneu com o pavimento. Não será considerado o escorregamento entre o pneu e o pavimento. Os torques de aceleração $T_{1}$ e $T_{2}$ são transferidos do motor e os torques de reação são aplicados à massa suspensa. São introduzidas as forças e torques de D'Alembert e a correspondente condição de equilíbrio. 


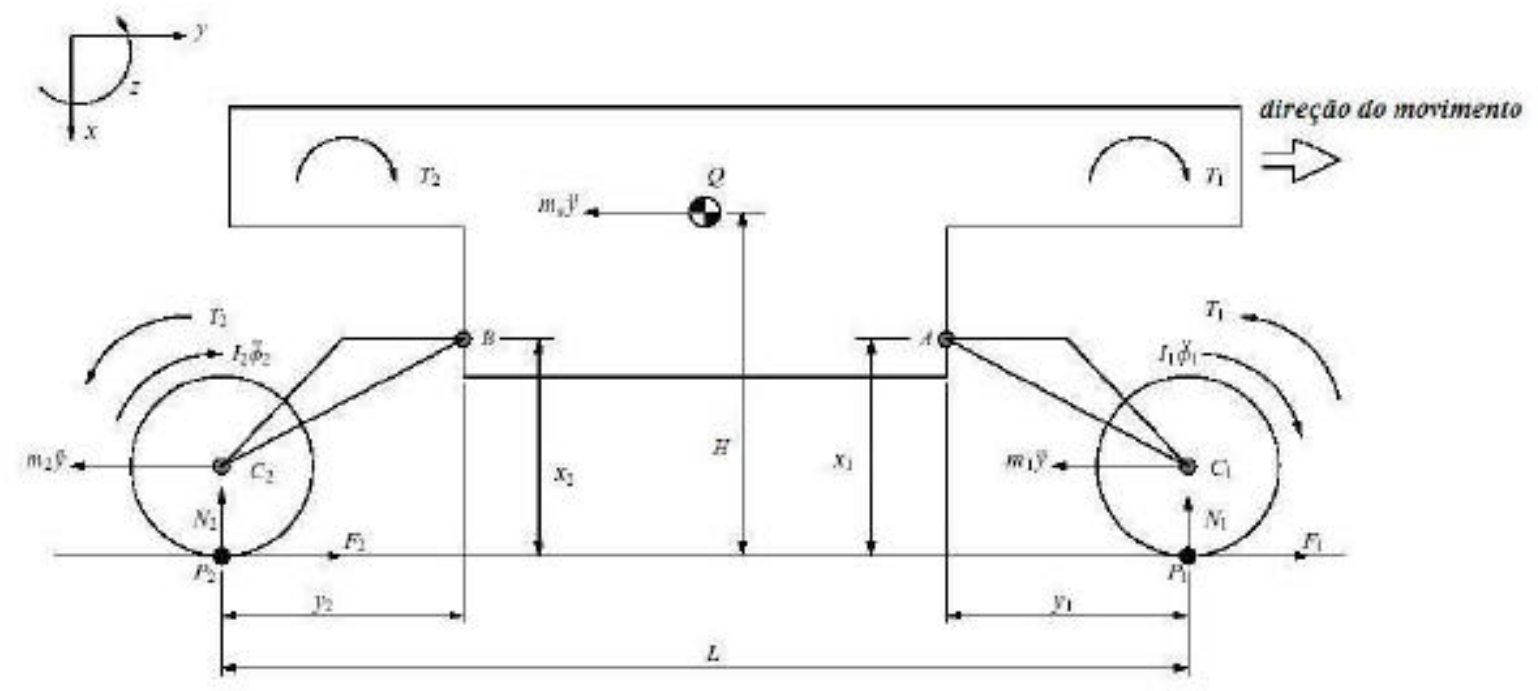

Figura 2 - Modelo de anti-squat.

FONTE: - FU-CHENG WANG, 2001, p. 17-30.

Supondo que a razão das forças de aceleração seja $\left(F_{1} / F_{2}\right)=q /(1-q)$, então a aceleração em y é dada por:

$$
\ddot{y}=\frac{F_{1}+F_{2}}{m_{1}+m_{2}+m_{s}}
$$

É possível expressar $\mathrm{F}_{1}$ e $\mathrm{F}_{2}$ como:

$$
\begin{gathered}
F_{1}=q M_{x} \ddot{y} \\
F_{2}=(1-q) M_{x} \ddot{y}
\end{gathered}
$$

Em que:

$$
M_{x}=m_{1}+m_{2}+m_{s}
$$

Fazendo a somatória dos momentos em relação ao ponto $\mathrm{P}_{2}$ para todo o sistema tem-se:

$$
N_{1} L+m_{s} \ddot{y} H+m_{1} \ddot{y} r_{1}+m_{2} \ddot{y} r_{2}+\frac{I_{1}}{r_{1}} \ddot{y}+\frac{I_{2}}{r_{2}} \ddot{y}=0
$$


Assim $\mathrm{N}_{1}$ pode ser escrito como:

$$
N_{1}=-M_{y} \ddot{y}
$$

Aonde:

$$
M_{y}=\frac{1}{L}\left(m_{s} H+m_{1} r_{1}+m_{2} r_{2}+\frac{I_{1}}{r_{1}}+\frac{I_{2}}{r_{2}}\right)
$$

Aplicando a segunda lei de Newton na direção vertical para todo sistema tem-se:

$$
N_{2}=-N_{1}=M_{y} \ddot{y}
$$

Fazendo a somatória dos momentos em relação a ponto A para a roda dianteira, tem-se:

$$
F_{1} x_{1}+N_{1} y_{1}-m_{1} \ddot{y}\left(x_{1}-r_{1}\right)-I_{1} \ddot{\phi}_{1}+T_{1}=0
$$

Que é equivalente a:

$$
q M_{x}\left(x_{1}-r_{1}\right)-M_{y} y_{1}-m_{1}\left(x_{1}-r_{1}\right)=0
$$

Fazendo a somatória dos momentos em relação ao ponto B para a roda traseira, tem-se:

$$
F_{2} x_{2}+N_{2} y_{2}-m_{2} \ddot{y}\left(x_{2}-r_{2}\right)-I_{2} \ddot{\phi}_{2}+T_{2}=0
$$

Que é equivalente a:

$$
(1-q) M_{x}\left(x_{2}-r_{2}\right)-M_{y} y_{2}-m_{2}\left(x_{2}-r_{2}\right)=0
$$

As equações (2.10) e (2.12) são suficientes para as propriedades de anti-squat, assim é possível calcular a posição do equivalente trailing-arm para eliminar o movimento de squat durante a aceleração. É possível verificar que existem quatro parâmetros $\left(\mathrm{x}_{1} ; \mathrm{y}_{1} ; \mathrm{x}_{2} ; \mathrm{y}_{2}\right)$ com somente duas equações o que significa que se tem dois graus de liberdade para determinar a condição de anti-squat. 


\subsubsection{Geometria Anti-dive}

O propósito da geometria de anti-dive é conter o movimento de rotação da massa suspensa durante a frenagem. Se considerar a razão das forças de frenagem $\left(F_{1} / F_{2}\right)=p /(1-p)$, e substituir nas equações (2.10) e (2.12) $q$ por $p$, tem-se as condições suficientes de total antidive para freios inboard. Assim aqui será tratado somente o caso de anti-dive para freio outboard. Com sistema de freio outboard os torques $\mathrm{T}_{1}$ e $\mathrm{T}_{2}$ de reação na massa suspensa desaparece, figura 3.

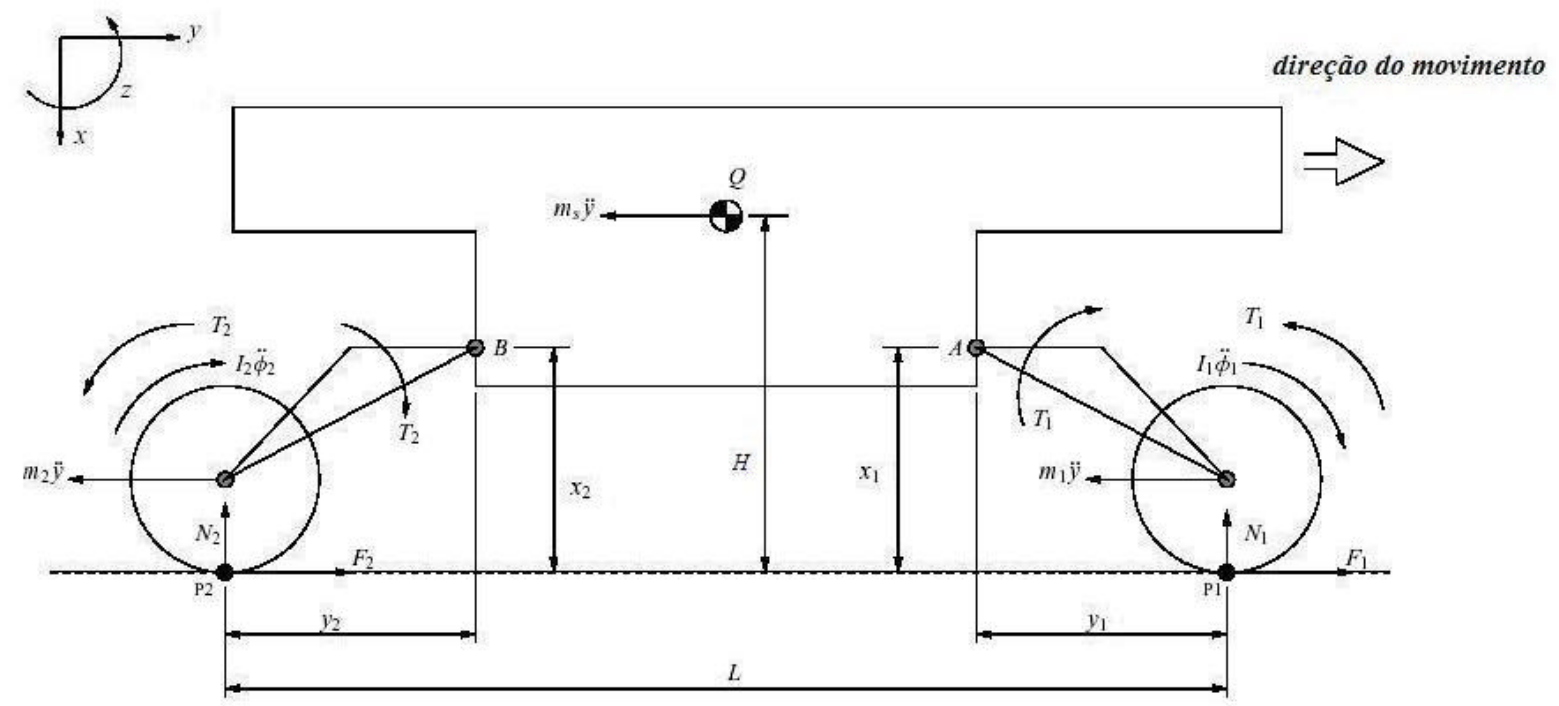

Figura 3 - Modelo de anti-dive.

FONTE: - FU-CHENG WANG, 2001, p. 17-30.

Supondo que a razão de frenagem seja $\left(\mathrm{F}_{1} / \mathrm{F}_{2}\right)=\mathrm{p} /(1-\mathrm{p})$, então a aceleração será a mesma da equação (2.1). Assim $\mathrm{F}_{1}$ e $\mathrm{F}_{2}$ ficam:

$$
\begin{gathered}
F_{1}=p M_{x} \ddot{y} \\
F_{2}=(1-p) M_{x} \ddot{y}
\end{gathered}
$$

Aonde $\mathrm{M}_{\mathrm{x}}$ é dada pela equação (2.4), é importante notar que a aceleração nesse caso é negativa como as forças $\mathrm{F}_{1}$ e $\mathrm{F}_{2}$. 
Fazendo a somatória dos momentos em relação ao ponto $\mathrm{P}_{2}$ para todo o sistema e aplicando a segunda lei de Newton na direção vertical para todo o sistema tem-se, equação (2.5) e (2.8) respectivamente.

Fazendo a somatória dos momentos em relação a ponto A para a roda dianteira, tem-se:

$$
F_{1} x_{1}+N_{1} y_{1}-m_{1} \ddot{y}\left(x_{1}-r_{1}\right)-I_{1} \ddot{\phi}_{1}=0
$$

Que é equivalente a:

$$
p M_{x}\left(x_{1}-r_{1}\right)-M_{y} y_{1}-m_{1}\left(x_{1}-r_{1}\right)+\frac{I_{1}}{r_{1}}=0
$$

Fazendo a somatória dos momentos em relação ao ponto B para a roda traseira, tem-se:

$$
F_{2} x_{2}+N_{2} y_{2}-m_{2} \ddot{y}\left(x_{2}-r_{2}\right)-I_{2} \ddot{\phi_{2}}=0
$$

Que é equivalente a:

$$
(1-p) M_{x}\left(x_{2}-r_{2}\right)-M_{y} y_{2}-m_{2}\left(x_{2}-r_{2}\right)+\frac{I_{2}}{r_{2}}=0
$$

Combinando as equações (2.10), (2.12), $(2,16)$ e $(2.18)$, é possível encontrar as posições, para a geometria equivalente trailing-arm, possui total anti-squat e total anti-dive e total anti-pitch. 


\section{Revisão Teórica}

O capitulo de revisão teórica expõe os conceitos básicos comumente apresentados nos livros. Inicia apresentando noções como: sistema de coordenadas, transferência de carga e equivalente trailing-arm, prossegue com as definições das geometrias anti e seus respectivos equacionamentos e finaliza expondo o método de cálculo no software ADAMS/CAR.

\subsection{Conceitos Básicos}

\subsubsection{Sistema de Coordenadas}

Nos estudos de dinâmica veicular é comum a representação das massas do veículo em apenas uma massa concentrada em seu centro de gravidade. Ao centro de gravidade é fixo um sistema de coordenadas ortogonais como referência para os movimentos do veículo, seguindo o sistema de coordenadas SAE tem-se: (GILESPIE, 1992, p. 7-8).

$\mathrm{x}$, velocidade longitudinal.

$\mathrm{y}$, velocidade lateral. 

$\mathrm{z}$, velocidade vertical.
p, velocidade de Rolamento.
q, velocidade de Arfagem.
r, velocidade de Guinada.

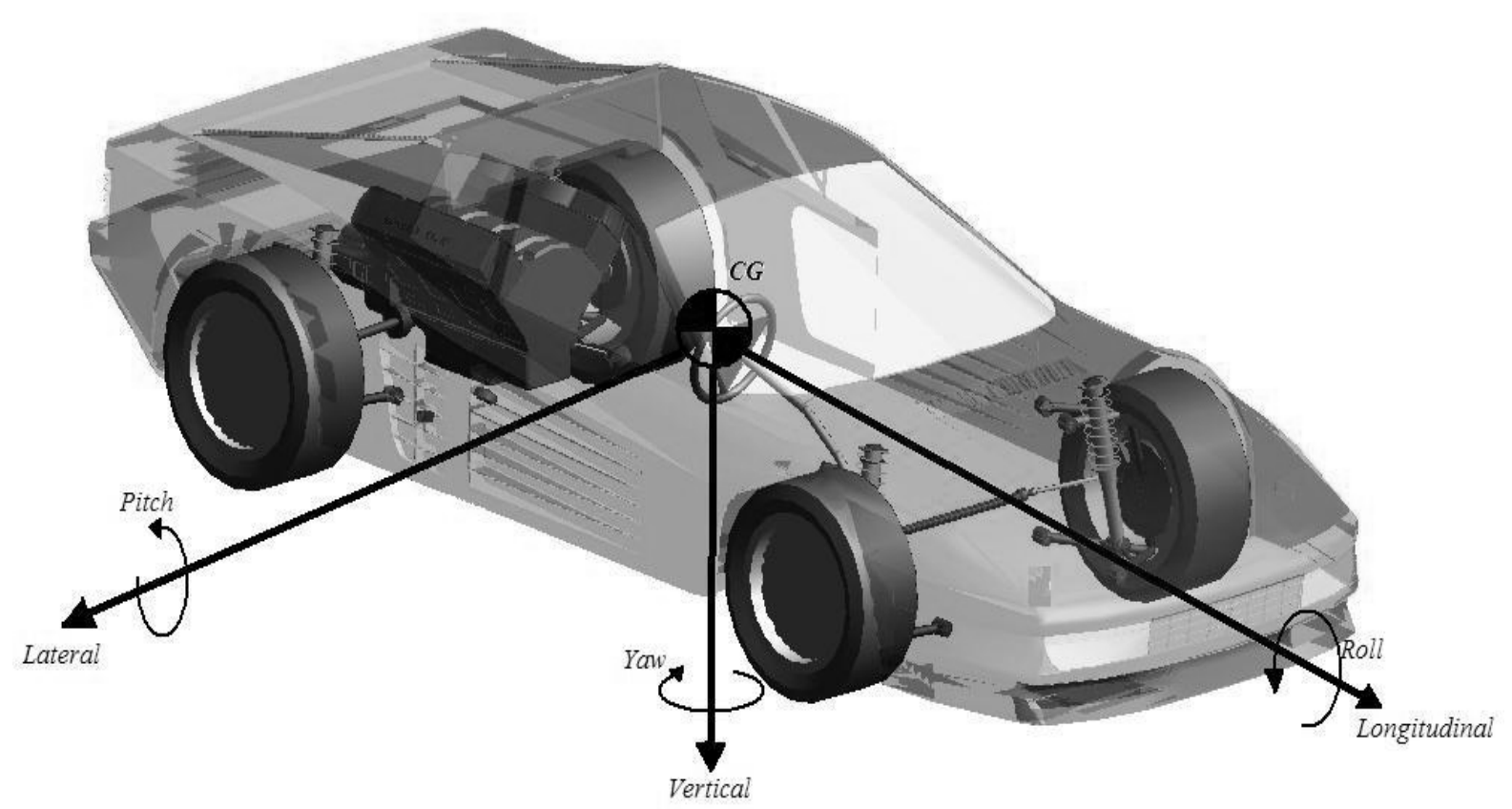

Figura 4 - Sistema de coordenadas SAE.

O presente trabalho tem como objetivo o estudo da influência da geometria da suspensão, quando o veiculo esta sobre efeitos longitudinais de aceleração ou desaceleração, nos movimentos verticais e rotacionais (pitch) da massa suspensa.

\subsubsection{Transferência de carga longitudinal}

Os efeitos longitudinais de aceleração e desaceleração sobre o veículo geram transferência de carga entre os eixos dianteiro e traseiro. A transferência de carga é expressa 
em função da força total de aceleração ou desaceleração, da altura do CG e da distância entre eixos. (MILLIKEN, 1995, p.617-620).

Analisando o veiculo em desaceleração é possível verificar a transferência de carga na figura (2):

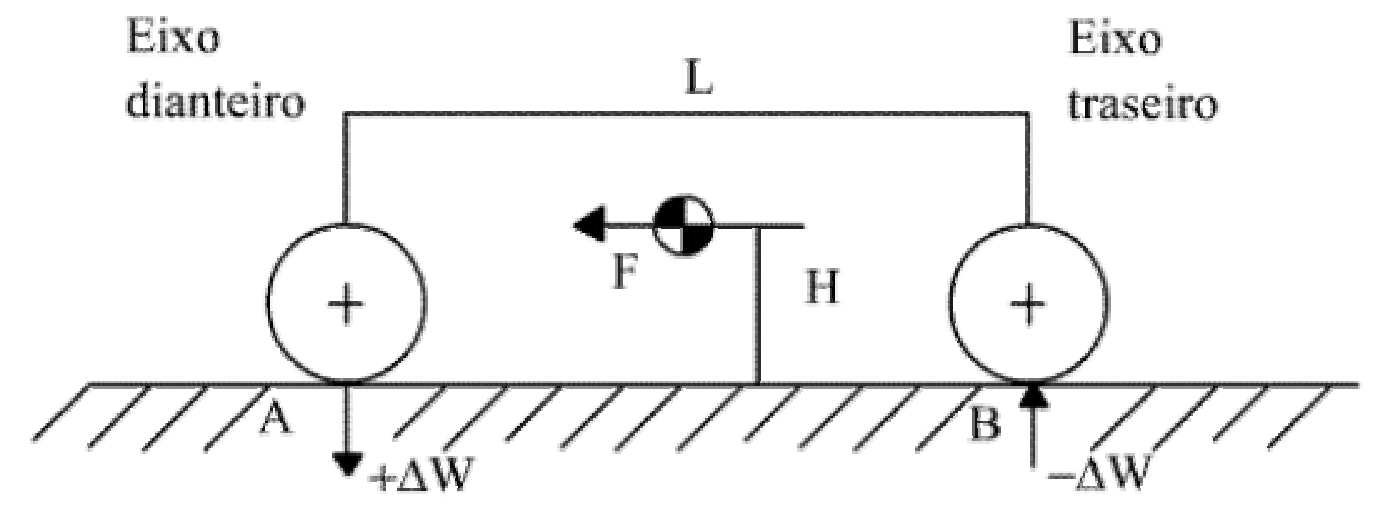

Figura 5 - Transferência de carga entre os eixos.

FONTE: MILLIKEN, 1995, p.617.

A força de desaceleração pode ser expressa como:

$$
F=W \cdot\left(\frac{a_{l}}{g}\right)
$$

A carga transferida é obtida fazendo a somatória de momentos no ponto A.

$$
\Delta W=W \cdot\left(\frac{a_{l}}{g}\right) \cdot\left(\frac{H}{L}\right)
$$

Para o veiculo em aceleração a transferência de carga ocorre do eixo dianteiro para o eixo traseiro, passando através do eixo, das rodas e principalmente através da suspensão aonde pode comprimir ou estender seus elementos. 


\subsubsection{Classificação dos conceitos "anti”"}

Quando o veiculo está sobre efeitos de aceleração, ocorre a compressão da suspensão traseira e o alongamento da suspensão dianteira o que implica no movimento do veiculo conhecido como "squat". Neste movimento o alongamento da suspensão dianteira é denominado de "lift" e a compressão da suspensão traseira é denominada de "squat".

Quando o veiculo esta sobre efeitos de desaceleração, ocorre a compressão da suspensão dianteira e o alongamento da suspensão traseira o que implica no movimento do veiculo conhecido como “dive”. Neste movimento o alongamento da suspensão traseira é denominado de "lift” e a compressão da suspensão dianteira é denominada de “dive”.

E a combinação dos movimentos da suspensão dianteira e traseira causam o movimento de rotação conhecido como “pitch”.

Esses movimentos podem ser amenizados e até anulados dependendo do projeto da geometria de suspensão, que atua em oposição à transferência de carga. As geometrias de suspensão conhecidas com “anti” são classificas: (MILLIKEN, 1995, p.617-620).

“Anti-dive”, geometria na suspensão dianteira que reduz sua compressão durante frenagem.

“Anti-lift", geometria na suspensão dianteira que reduz seu alongamento quando o veiculo esta sobre aceleração e possui tração dianteira.

“Anti-lift”, geometria na suspensão traseira que reduz seu alongamento durante a frenagem.

“Anti-squat”, geometria na suspensão traseira que reduz sua compressão quando o veiculo esta sobre aceleração e possui tração traseira.

“Anti-pitch", geometria na suspensão traseira e dianteira que reduz o movimento angular da massa suspensa quando o veiculo esta acelerando ou desacelerando. 
É importante enfatizar que os efeitos "anti” na geometria não mudam o estado constate de transferência de carga (regime permanente). (MILLIKEN, 1995, p. 617-620).

\subsubsection{Equivalente trailing-arm}

A geometria "anti" pode ser facilmente entendida reconhecendo que todas as suspensões são funcionalmente equivalentes a trailing-arm, considerando as reações de força e momento sobre a massa suspensa do veiculo.(GILLESPIE, 1992, p.248-249).

Para verificar essa proposta é necessário analisar a vista lateral da geometria de suspensão. Em uma suspensão com duplo braço de controle é possível verificar o local da fixação do equivalente trailing-arm, figuras 3 e 4 .

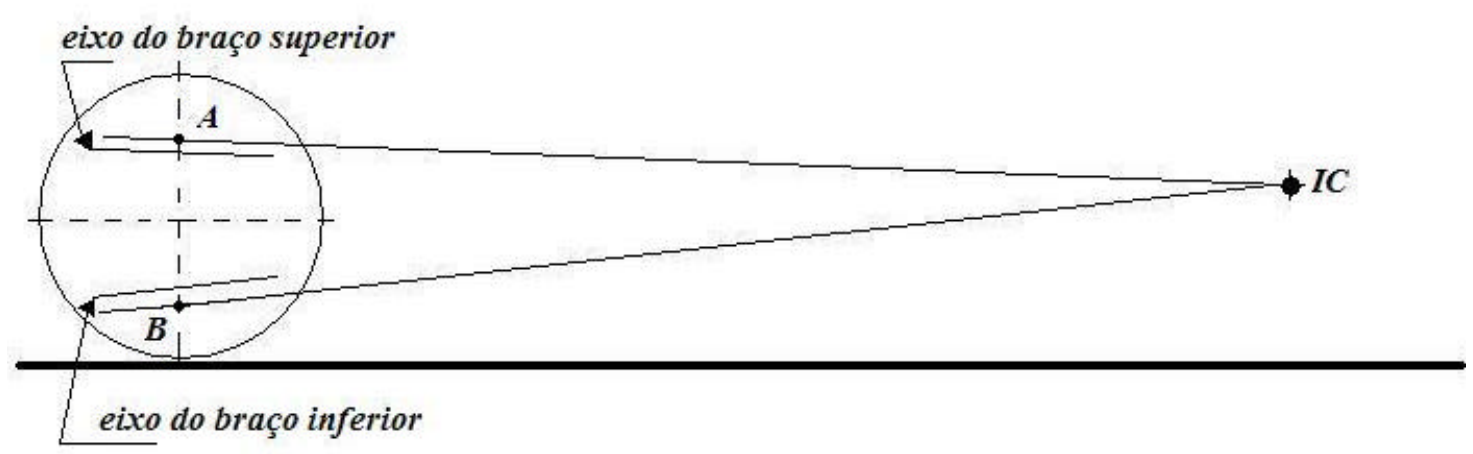

Figura 6 - Vista lateral da suspensão com dois braços de controle.

FONTE: GILLESPIE, 1992, p.249-250. 


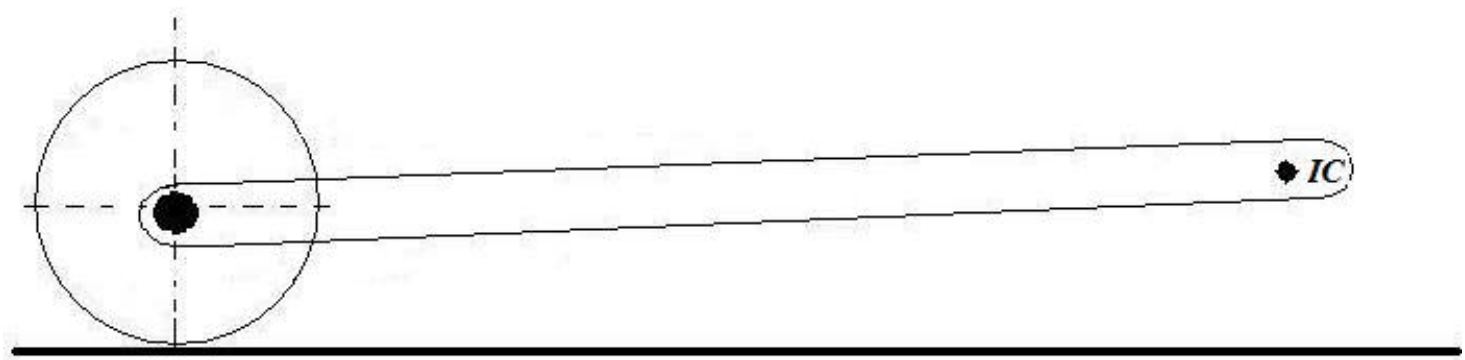

Figura 7 - Vista lateral do equivalente trailing-arm.

FONTE: GILLESPIE, 1992, p.249-250.

Os pontos A e B são os pontos externos do braço superior e inferior respectivamente. O ponto IC “centro instantâneo de rotação” representa o ponto imaginário de fixação do braço virtual a massa suspensa do veiculo aonde são transferidas forças providas do ponto de contato do pneu com o pavimento.

A prova matemática do equivalente trailing-arm é apresentada na seção $2.1 .7 \mathrm{em}$ conjunto com o cálculo dos esforços na suspensão.

\subsubsection{Cálculo da força "anti" e percentual "anti"}

\subsubsection{Anti-dive (Frenagem)}

Utilizando os conceitos anteriores é possível calcular a força que atua contra a transferência de carga nas suspensões com geometria "anti". Na figura 5 é apresentado um esquema para o cálculo da força de anti-dive. 

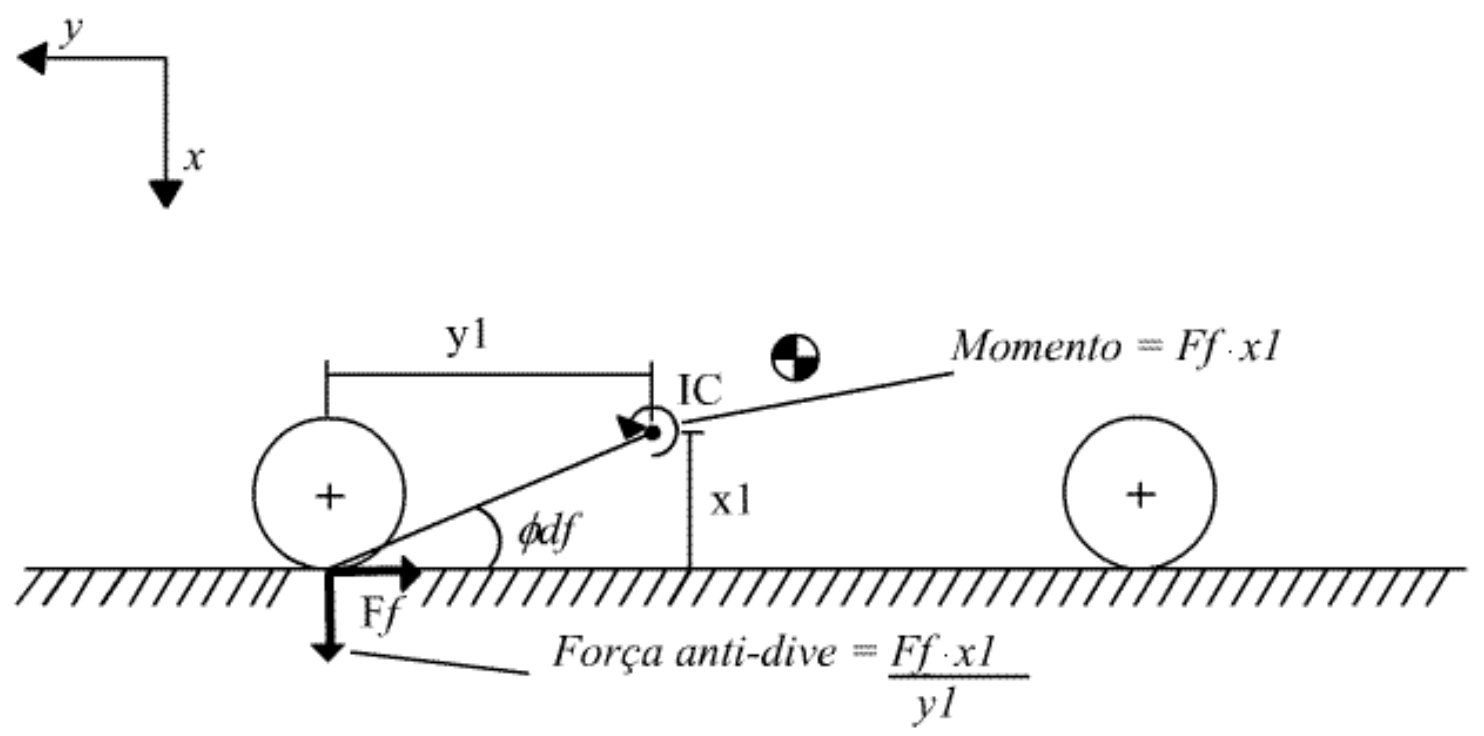

Figura 8 - Cálculo da força de anti-dive.

FONTE: MILLIKEN, 1995, p.617.

Para o cálculo da força de anti-dive é considerado a força de frenagem no eixo dianteiro do veiculo, a altura do solo e a distância do eixo dianteiro ao centro instantâneo IC.

Sendo $\boldsymbol{p}$ percentual de frenagem no eixo dianteiro e $\boldsymbol{F} \boldsymbol{f}=\boldsymbol{F}$. $\boldsymbol{p}$ é possível verificar:

$$
\text { Força anti-dive }=\frac{W \cdot\left(\frac{a_{l}}{g}\right) \cdot(p) \cdot\left(x_{1}\right)}{y_{1}}
$$

Conhecendo a força de anti-dive é possível expressar a característica anti-dive em termos de percentual.

$$
\begin{gathered}
\% \text { anti-dive }=(\text { anti-dive força }) /(\text { transferência de carga }) \\
\% \text { anti }- \text { dive }=\frac{\left[W \cdot\left(\frac{a_{l}}{g}\right) \cdot(p) \cdot\left(\frac{x_{1}}{y_{1}}\right)\right]}{\left[W \cdot\left(\frac{a_{l}}{g}\right) \cdot\left(\frac{H}{L}\right)\right]}
\end{gathered}
$$

De acordo com a figura 5 é possível verificar que:

$$
\tan \phi d f=\left(\frac{x_{1}}{y_{1}}\right)
$$


Assim obtendo:

$$
\text { \%anti }- \text { dive }=(p) \cdot(\tan \phi d f) \cdot\left(\frac{L}{H}\right)
$$

As equações anteriores são validas somente para sistemas de freios conhecidos como "outboard", aqueles que não são ligados à massa suspensa do veiculo, figura 6 .

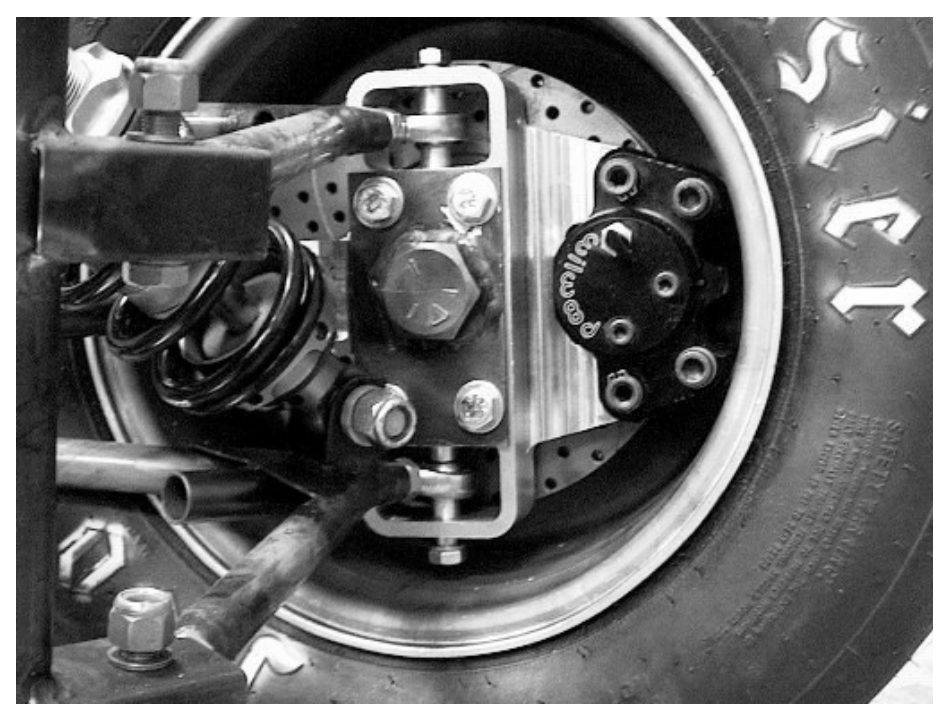

Figura 9 - Sistema de freio outboard.

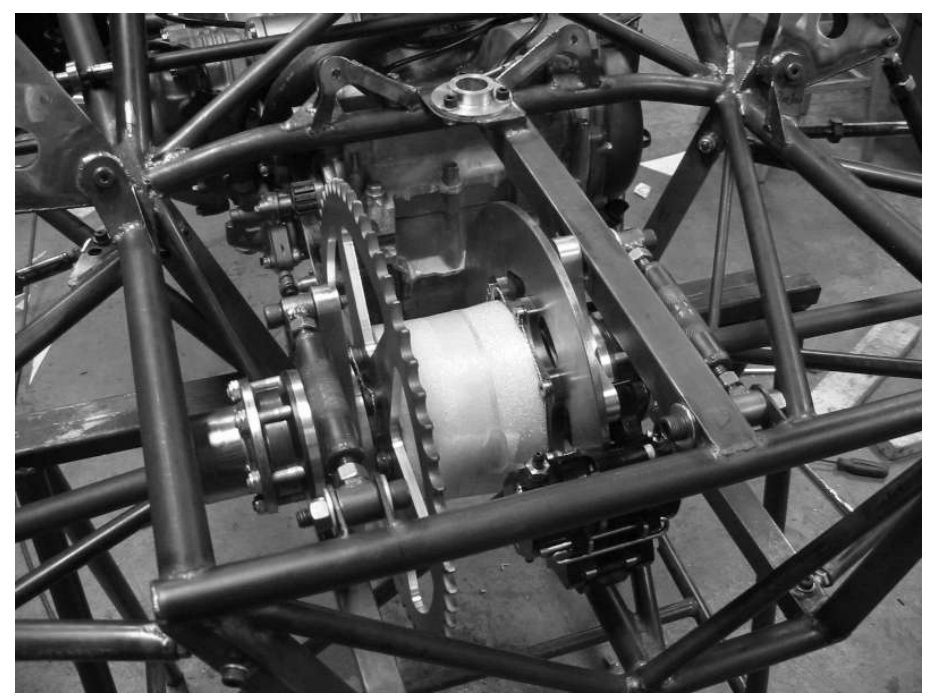

Figura 10 - Sistema de freio inboard.

Para sistemas de freio conhecido como "inboard", figura 7, as equações mudam, pois aparece um torque de reação na massa suspensa. Os freios inboard são aqueles que estão ligados diretamente a massa suspensa. 


$$
\text { Torque de reação }=\left[W \cdot\left(\frac{a_{l}}{g}\right) \cdot(p) \cdot(r)\right]
$$

O torque de reação atua contra o momento gerado pela geometria da suspensão assim a força de anti-dive para sistemas de freio inboard fica:

$$
\text { \%anti-dive }=\frac{\left\{W \cdot\left(\frac{a_{l}}{g}\right) \cdot(p) \cdot\left[\frac{\left(x_{1}-r\right)}{y_{1}}\right]\right\}}{\left[W \cdot\left(\frac{a_{l}}{g}\right) \cdot\left(\frac{H}{L}\right)\right]}
$$

Sabendo que:

$$
\tan \theta d f=\left(\frac{x_{1}-r}{y_{1}}\right)
$$

Obtém-se:

$$
\text { \%anti-dive }=(p) \cdot(\tan \theta d f) \cdot\left(\frac{L}{H}\right)
$$

O ângulo ?df pode ser facilmente entendido através de uma representação visual na figura 8.

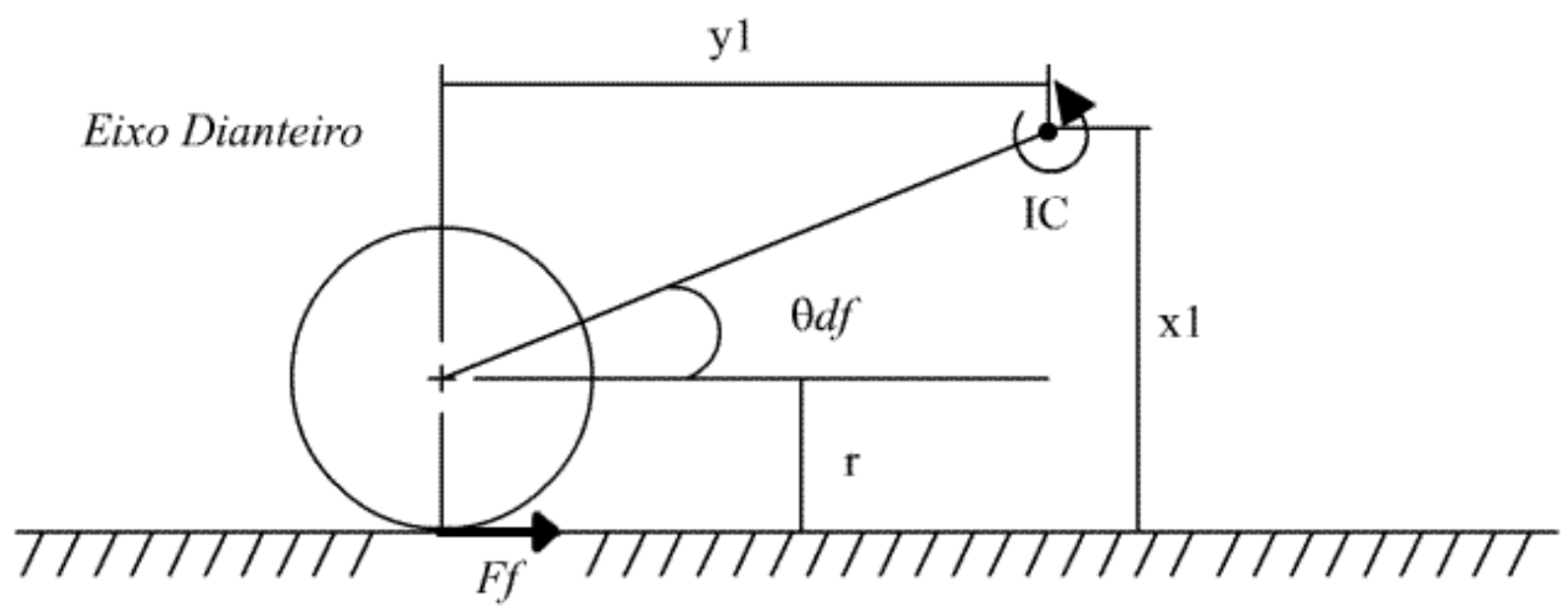

Figura 11 - Sistema de freio Inboard.

FONTE: MILLIKEN, 1995, p.617. 


\subsubsection{Anti-squat (Aceleração)}

Seguindo a mesma sequiência de cálculo, usado para geometria anti-dive, é obtida a força e o percentual para suspensão com geometria anti-squat. Quando o veiculo possui tração traseira por eixo rígido o cálculo é semelhante ao da geometria anti-dive para freio outboard. É importante salientar que tração por eixo rígido não impõe torque à massa suspensa, pois ele não é ligado rigidamente a mesma.

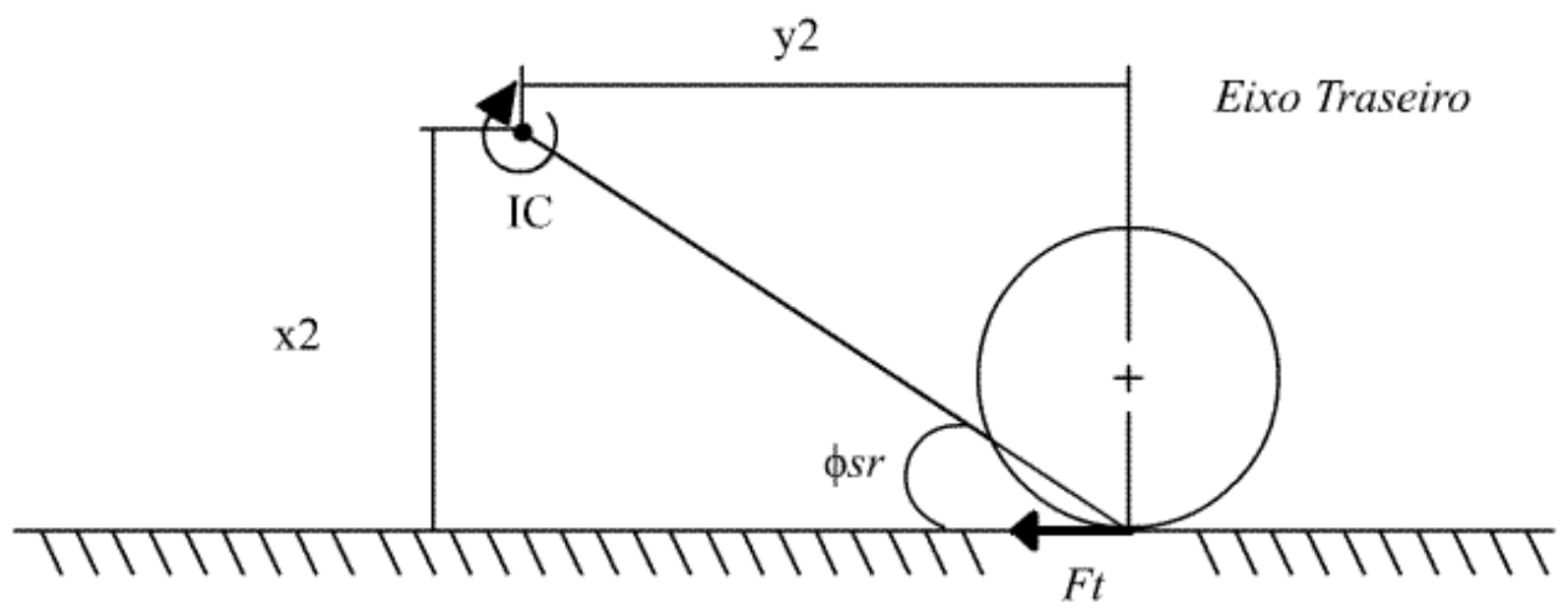

Figura 12 - Cálculo da força de anti-squat para um veículo tração traseira por eixo rígido.

FONTE: MILLIKEN, 1995, p.617.

Através da figura (9) é possível verificar:

$$
\begin{gathered}
\text { Força.anti-squat }=F t \cdot\left(\frac{x_{2}}{y_{2}}\right) \\
\tan \phi s r=\left(\frac{x_{2}}{y_{2}}\right)
\end{gathered}
$$

Semelhante ao cálculo do percentual de anti-dive para freio outboard é obtido o percentual de anti-squat na suspensão traseira para eixo rígido:

$$
\% \text { anti-squat }=(\text { anti-squat força }) /(\text { transferência de carga })
$$


Assim:

$$
\text { \%anti }- \text { squat }=\frac{\left[\left(F_{t}\right) \cdot\left(\frac{x_{2}}{y_{2}}\right)\right]}{\left[W \cdot\left(\frac{a_{l}}{g}\right)\left(\frac{H}{L}\right)\right]}
$$

Fazendo a força de tração igual à massa vezes a aceleração.

$$
F_{t}=W \cdot\left(\frac{a_{l}}{g}\right)
$$

É possível simplificar a equação 3.15.

$$
\% \text { anti }- \text { squat }=\frac{\tan \phi s r}{\left(\frac{H}{L}\right)}
$$

Para veículos com tração traseira independente, o cálculo da força de anti-squat é semelhante ao cálculo da força de anti-dive para freios inboard, pois, o diferencial montado sobre o veiculo impõe um torque sobre a massa suspensa, que é dado pela equação (3.8).

Através da figura (10) é possível verificar:

$$
\begin{gathered}
\text { Força.anti-squat }=F t \cdot\left(\frac{x_{2}-r}{y_{2}}\right) \\
\tan \theta s r=\left(\frac{x_{2}-r}{y_{2}}\right)
\end{gathered}
$$

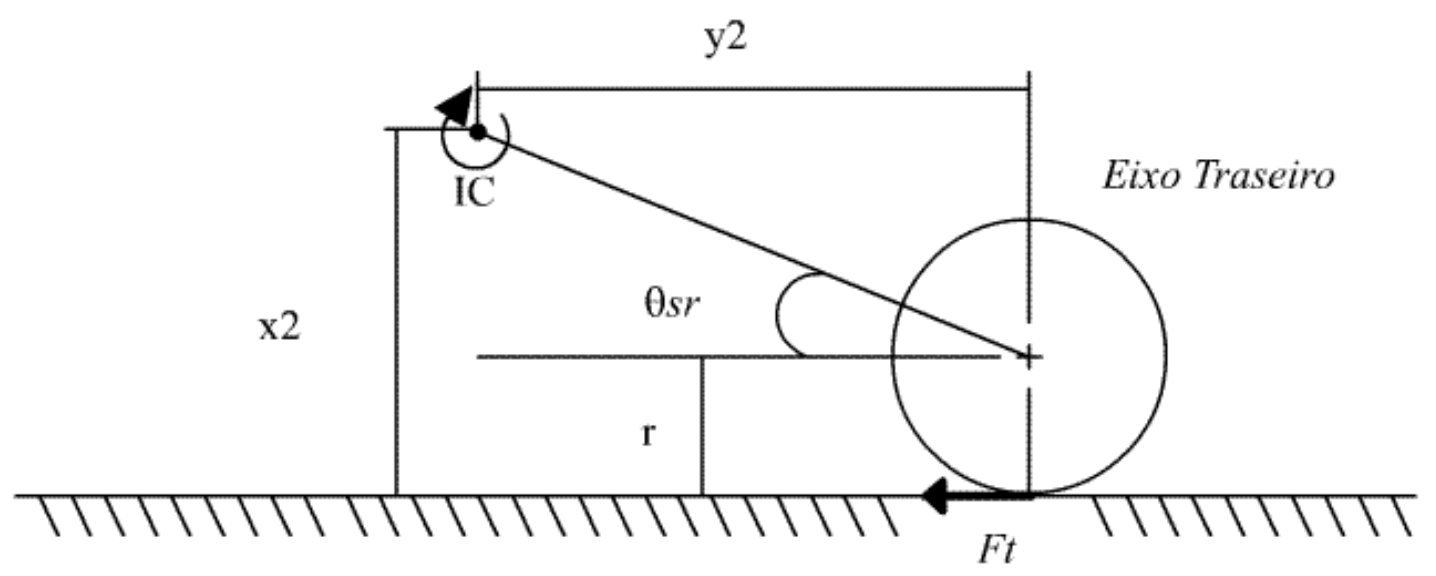

Figura 13 - Cálculo da força de anti-squat para suspensão independente.

FONTE: MILLIKEN, 1995, p.617. 
Semelhante ao cálculo do percentual de anti-dive para freio inboard é obtido o percentual de anti-squat na suspensão traseira independente:

$$
\% \text { anti-squat }=(\text { anti-squat força }) /(\text { transferência de carga })
$$

Assim:

$$
\text { \%anti }- \text { squat }=\frac{\left[\left(F_{t}\right) \cdot\left(\frac{x_{2}-r}{y_{2}}\right)\right]}{\left[W \cdot\left(\frac{a_{l}}{g}\right) \cdot\left(\frac{H}{L}\right)\right]}
$$

Conhecendo a força de tração, equação 16, é possível simplificar a equação (3.21).

$$
\% \text { anti }-s q u a t=\frac{\tan \theta s r}{\left(\frac{H}{L}\right)}
$$

\subsubsection{Anti-lift (Frenagem)}

Quando o veiculo está desacelerando o cálculo da força de anti-lift na suspensão traseira é semelhante ao cálculo da força de anti-squat. Para obter as equações de força e percentual de anti-lift para um veiculo com sistema de freio inboard basta substituir nas equações (3.18) e (3.21) Ft por F(1-p), em que, (1-p) é o percentual de frenagem no eixo traseiro.

$$
\text { Força.anti }- \text { lift }=F(1-p) \cdot\left(\frac{x_{2}-r}{y_{2}}\right)
$$




$$
\text { \%anti }- \text { lift }=\frac{\left[(F(1-p)) \cdot\left(\frac{x_{2}-r}{y_{2}}\right)\right]}{\left[W \cdot\left(\frac{a_{l}}{g}\right) \cdot\left(\frac{H}{L}\right)\right]}
$$

E para veículos com sistema de outboard as equações de força e percentual de anti-lift são obtidas substituindo Ft por F(1-p) nas equações (3.12) e (3.15) respectivamente.

$$
\begin{gathered}
\text { Força.anti-lift }=F(1-p) \cdot\left(\frac{x_{2}}{y_{2}}\right) \\
\% \text { anti }- \text { lift }=\frac{\left[(F(1-p)) \cdot\left(\frac{x_{2}}{y_{2}}\right)\right]}{\left[W \cdot\left(\frac{a_{l}}{g}\right)\left(\frac{H}{L}\right)\right]}
\end{gathered}
$$

\subsubsection{Anti-lift (Aceleração)}

Para um veículo tração dianteira independente a força de anti-lift é dada por:

$$
\begin{gathered}
\text { Força.anti }- \text { lift }=F t \cdot\left(\frac{x_{1}-r}{y_{1}}\right) \\
\tan \theta l f=\left(\frac{x_{1}-r}{y_{1}}\right)
\end{gathered}
$$

Semelhante aos cálculos anteriores:

$$
\% \text { anti-lift }=(\text { anti-lift força }) /(\text { transferência de carga })
$$

Assim:

$$
\text { \%anti }- \text { lift }=\frac{\left[\left(F_{t}\right) \cdot\left(\frac{x_{1}-r}{y_{1}}\right)\right]}{\left[W \cdot\left(\frac{a_{l}}{g}\right) \cdot\left(\frac{H}{L}\right)\right]}
$$


Conhecendo a força de tração, equação (3.16), é possível simplificar a equação (3.30).

$$
\% \text { anti }- \text { lift }=\frac{\tan \theta l f}{\left(\frac{H}{L}\right)}
$$

Para obter as equações de força e percentual de anti-lift na suspensão dianteira para veículos com tração por eixo rígido basta fazer $\mathbf{r}$ igual a zero, assim anulando a parcela referente ao torque de reação na massa suspensa.

\subsubsection{Cálculo do ângulo de pitch (Anti-pitch)}

\subsubsection{Tração traseira independente e tração traseira por eixo rígido}

Conhecendo a transferência de carga e a força gerada pela geometria de suspensão é possível determinar o ângulo de arfagem "pitch" do veiculo.

Para um veiculo acelerando com tração traseira independente é possível verificar que a troca de carga na suspensão traseira é igual à carga transferida menos as forças geradas pela geometria de suspensão anti-squat.

$$
\Delta W=W \cdot\left(\frac{a_{l}}{g}\right) \cdot\left(\frac{H}{L}\right)-F_{t} \cdot\left(\frac{x_{2}-r}{y_{2}}\right)
$$

Fazendo uma análise simplifica, a troca de carga na suspensão será igual à força gerada pela deformação da mola traseira.

$$
F_{M r}=k_{r} \delta_{r}=W \cdot\left(\frac{a_{l}}{g}\right) \cdot\left(\frac{H}{L}\right)-F_{t} \cdot\left(\frac{x_{2}-r}{y_{2}}\right)
$$


Na suspensão dianteira a deformação ocorrerá somente pela transferência de carga, pois não existe nenhuma força aplicada no ponto de contato do pneu com o pavimento no eixo dianteiro.

$$
F_{M f}=k_{f} \boldsymbol{\delta}_{f}=-W\left(\frac{a_{l}}{g}\right)\left(\frac{H}{L}\right)
$$

O ângulo de pitch do veiculo é simplificado pela soma das deflexões nas suspensões dianteira e traseira e dividindo pelo entre eixos do veiculo. (GUILLESPIE, 1992, p.248-256).

$$
\theta_{p}=\frac{\delta_{r}-\delta_{f}}{L}=\frac{W}{k_{r}} \cdot\left(\frac{a_{l}}{g}\right) \cdot\left(\frac{H}{L^{2}}\right)-\frac{F_{t}}{L} \cdot\left(\frac{x_{2}-r}{y_{2}}\right) \cdot \frac{1}{k_{r}}+\frac{W}{k_{f}} \cdot\left(\frac{a_{l}}{g}\right) \cdot\left(\frac{H}{L^{2}}\right)
$$

Simplificando:

$$
\theta_{p}=\frac{W}{L} \cdot\left(\frac{a_{l}}{g}\right) \cdot\left[\left(\frac{H}{L}\right) \cdot \frac{1}{k_{r}}-\left(\frac{x_{2}-r}{y_{2}}\right) \cdot \frac{1}{k_{r}}+\frac{1}{k_{f}} \cdot\left(\frac{H}{L}\right)\right]
$$

A partir da equação (3.36) é possível mostrar que o ângulo de pitch será zero quando a seguinte condição for satisfeita, equação (3.37). (GUILLESPIE, 1992, p.248-256).

$$
0=\left[\left(\frac{H}{L}\right) \cdot \frac{1}{k_{r}}-\left(\frac{x_{2}-r}{y_{2}}\right) \cdot \frac{1}{k_{r}}+\frac{1}{k_{f}} \cdot\left(\frac{H}{L}\right)\right]
$$

Assim:

$$
\left(\frac{x_{2}-r}{y_{2}}\right)=\left(\frac{H}{L}\right)+\left(\frac{H}{L}\right) \cdot \frac{k_{r}}{k_{f}}
$$

O primeiro termo à direita da equação (3.34) corresponde à condição em que a geometria de $100 \%$ de anti-squat é obtida, ela define uma linha que sai do ponto no centro da roda traseira do veiculo até o ponto na altura do CG sobre o eixo dianteiro, assim localizar o ponto de fixação da suspensão trailing-arm ou do centro instantâneo IC do equivalente trailing-arm sobre essa linha será obtido total de anti-squat. A relação $\left(\mathrm{x}_{2}-\mathrm{r} / \mathrm{y}_{2}\right)=(\mathrm{H} / \mathrm{L})$ pode ser verificada combinando as equações (3.23) e (3.26) e fazendo o percentual de anti-squat 
igual a 1. A condição de total anti-squat não implica em anular o movimento de pitch, pois, a suspensão dianteira ira estender devido a transferência de carga. (GUILLESPIE, 1992, p.248256).

Através da equação (3.38) completa é obtida a relação de total de anti-pitch. Quando a fixação da suspensão trailing-arm ou do centro instantâneo IC do equivalente trailing-arm está localizada na linha que liga o ponto no centro da roda traseira até o ponto sobre o CG do veiculo é obtido $100 \%$ de anti-pitch. Isso implica que a suspensão traseira subirá compensando a suspensão dianteira, assim o veiculo permanece nivelado, porém ocorrendo o deslocamento vertical do veiculo. (GUILLESPIE, 1992, p.248-256).

As equações para o cálculo do ângulo de pitch quando o veiculo possuir tração traseira por eixo rígido são obtidas fazendo $\mathbf{r}$ igual a zero nas equações anteriores, assim anulando a parcela referente ao torque de reação sobre a massa suspensa. (GUILLESPIE, 1992, p.248-256).

\subsubsection{Tração dianteira independente e tração dianteira por eixo rígido}

Seguindo a seqüência lógica empregada para veículos com tração traseira independente é possível obter as equações de total anti-pitch e total anti-lift para um veículo com tração dianteira independente. Assim a troca de carga na suspensão dianteira fica:

$$
\Delta W=-W \cdot\left(\frac{a_{l}}{g}\right) \cdot\left(\frac{H}{L}\right)-F_{t} \cdot\left(\frac{x_{1}-r}{y_{1}}\right)=k_{f} \delta_{f}
$$


E na suspensão traseira:

$$
\Delta W=W\left(\frac{a_{l}}{g}\right) \cdot\left(\frac{H}{L}\right)=k_{r} \delta_{r}
$$

O ângulo de pitch pode ser determinado pela soma da deflexão das suspensões dividindo pelo entre eixos do veiculo.

$$
\theta_{p}=\frac{\delta_{r}-\delta_{f}}{L}=\frac{W}{k_{r}} \cdot\left(\frac{a_{l}}{g}\right) \cdot\left(\frac{H}{L^{2}}\right)+\frac{F_{t}}{L} \cdot\left(\frac{x_{1}-r}{y_{1}}\right) \cdot \frac{1}{k_{f}}+\frac{W}{k_{f}} \cdot\left(\frac{a_{l}}{g}\right) \cdot\left(\frac{H}{L^{2}}\right)
$$

A partir da equação anterior é possível mostrar que o ângulo de pitch será zero quando a seguinte condição for satisfeita:

$$
0=\left[\left(\frac{H}{L}\right) \cdot \frac{1}{k_{r}}-\left(\frac{x_{1}-r}{y_{1}}\right) \cdot \frac{1}{k_{r}}+\frac{1}{k_{f}} \cdot\left(\frac{H}{L}\right)\right]
$$

Assim:

$$
\left(\frac{x_{1}-r}{y_{1}}\right)=-\left(\frac{H}{L}\right)-\left(\frac{H}{L}\right) \cdot \frac{k_{f}}{k_{r}}
$$

O sinal negativo na equação anterior indica que a fixação da suspensão trailingarm deve ficar atrás do eixo dianteiro. A linha de fixação da suspensão trailing-arm ou do centro instantâneo IC do equivalente trailing-arm, para total anti-lift sai do ponto no centro da roda dianteira até o ponto na altura do CG no eixo traseiro. A linha de fixação da suspensão trailing-arm ou do centro instantâneo IC do equivalente trailing-arm, para total anti-pitch é obtida do ponto no centro da roda dianteira até o ponto sobre o CG do veículo.

As equações para o cálculo do ângulo de pitch quando o veiculo possuir tração dianteira por eixo rígido são obtidas fazendo $\mathbf{r}$ igual a zero nas equações anteriores, assim anulando a parcela referente ao torque de reação sobre a massa suspensa. 


\subsubsection{Tração nas quatro rodas}

O cálculo do ângulo de pitch para um veículo com tração nas quatro rodas, difere dos anteriores, pois, existem forças atuando simultaneamente nos eixos dianteiro e traseiro.

$$
F_{t f}=F q \text { e } F_{t r}=F(1-q)
$$

Aonde $\mathbf{q}$ representa a fração da força de tração total, desenvolvida pelo eixo dianteiro. Para um veiculo com suspensão dianteira e traseira independentes, a troca de carga na suspensão dianteira é igual:

$$
\Delta W=W \cdot\left(\frac{a_{l}}{g}\right) \cdot\left[-\left(\frac{H}{L}\right)-\left(\frac{x_{1}-r}{y_{1}}\right) q\right]=k_{f} \boldsymbol{\delta}_{f}
$$

E a troca de carga na suspensão traseira é igual:

$$
\Delta W=W\left(\frac{a_{l}}{g}\right)\left[\left(\frac{H}{L}\right)-\left(\frac{x_{2}-r}{y_{2}}\right)(1-q)\right]=k_{r} \delta_{r}
$$

O ângulo de pitch é simplificado pela soma da deflexão das suspensões dividindo pelo entre eixos do veiculo.

$$
\theta_{p}=\left\{\frac{W}{k_{r} L}\left(\frac{a_{l}}{g}\right)\left[\left(\frac{H}{L}\right)-\left(\frac{x_{2}-r}{y_{2}}\right)(1-q)\right]\right\}+\left\{\frac{W}{k_{f} L}\left(\frac{a_{l}}{g}\right)\left[\left(\frac{H}{L}\right)+\left(\frac{x_{1}-r}{y_{1}}\right) q\right]\right\}
$$

Assim o ângulo de pitch será igual a zero quando:

$$
0=\left\{\frac{1}{k_{r}}\left[\left(\frac{H}{L}\right)-\left(\frac{x_{2}-r}{y_{2}}\right)(1-q)\right]\right\}+\left\{\frac{1}{k_{f}}\left[\left(\frac{H}{L}\right)+\left(\frac{x_{1}-r}{y_{1}}\right) q\right]\right\}
$$

Através da equação (3.48) é possível verificar que a performance de anti-squat, anti-lift e anti-pitch dependem da combinação das propriedades do veículo como, geometria de suspensão, rigidez da suspensão e da distribuição da força de tração.

As equações, para veículos com tração dianteira e traseira por eixo rígido, podem ser obtidas fazendo $\mathbf{r}$ igual a zero. 


\subsubsection{Frenagem}

A equação do ângulo de pitch, para um veículo desacelerando com sistema de freio inboard, é semelhante à encontrada para um veículo acelerando com tração independente nas quatro rodas. A diferença é que ao invés de usar a fração da força total de tração desenvolvida pelo eixo dianteiro q é usado o percentual de frenagem desenvolvida no eixo dianteiro p. A equação para um veículo desacelerando com sistema de freio outboard é obtida fazendo $\mathbf{r}$ igual a zero.

Para veículos com sistema de freio outboard é possível mostrar que, total anti-dive e anti-lift é obtido quando as seguintes relações são asseguradas:

Suspensão dianteira (anti-dive):

$$
\left(\frac{x_{1}}{y_{1}}\right)=\frac{H}{p L}
$$

Suspensão traseira (anti-lift):

$$
\left(\frac{x_{2}}{y_{2}}\right)=\frac{H}{(1-p) L}
$$

Assim para obter total anti-dive na suspensão dianteira a fixação da suspensão trailing-arm ou do centro instantâneo IC do equivalente trailing-arm deve estar sobre a linha que sai do ponto de contato do pneu dianteiro com o pavimento e que passa pelo ponto na altura do CG do veiculo e na distância relativa ao pneu dianteiro definida por $L p$. Para obter total anti-lift a fixação da suspensão trailing-arm ou do centro instantâneo IC do equivalente trailing-arm de estar na linha que sai do ponto de contato do pneu traseiro com o pavimento e passa no ponto na altura do CG do veículo na distância relativa ao pneu traseiro definida por (1-p)L, figura (11). 


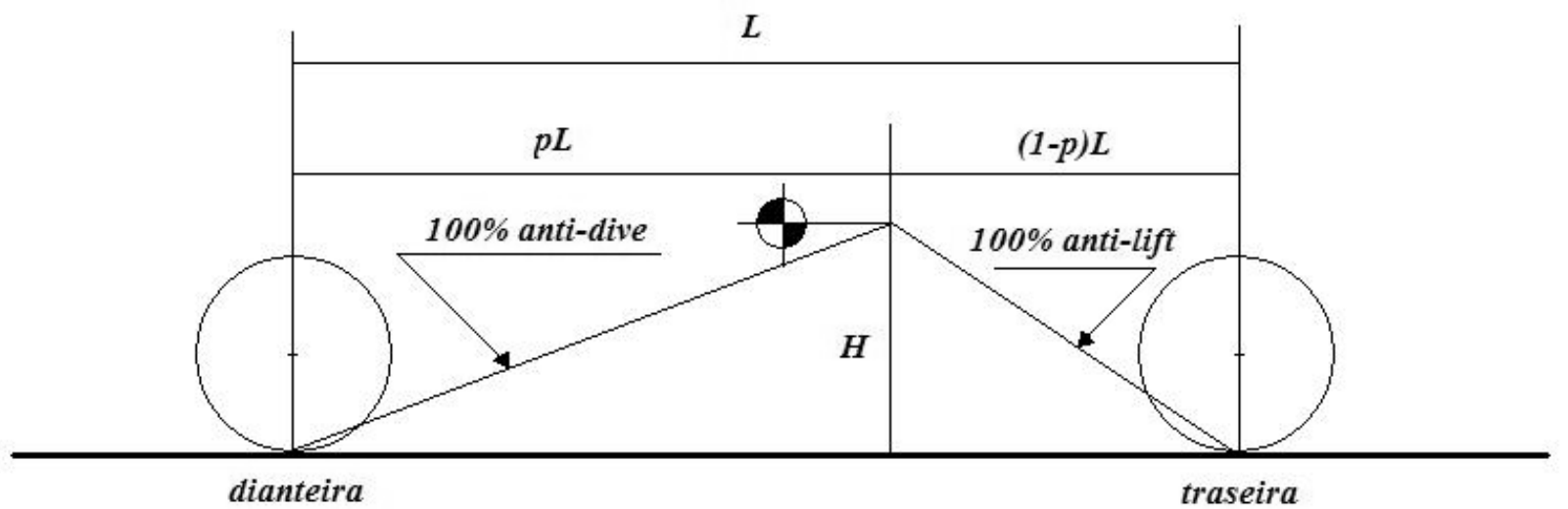

Figura 14 - Linhas de fixação para total anti-dive e anti-lift.

FONTE: - GUILLESPIE, 1992, p. 248-256.

A análise anterior pode ser feita para veículos com sistema de freio inboard levando em consideração que as linhas para total anti-dive e total anti-lift sairão do centro das rodas.

\subsubsection{Cálculo dos esforços nos elementos de suspensão}

O cálculo dos esforços nos elementos da suspensão apresentados nesse capitulo estão baseados no livro Fundamentals of Vehicle Dynamics do autor Thomas D. Gillespie. Para a análise proposta é considerado um eixo de tração controlado por dois braços sendo um inferior e o outro superior, ilustrados na figura 12. 


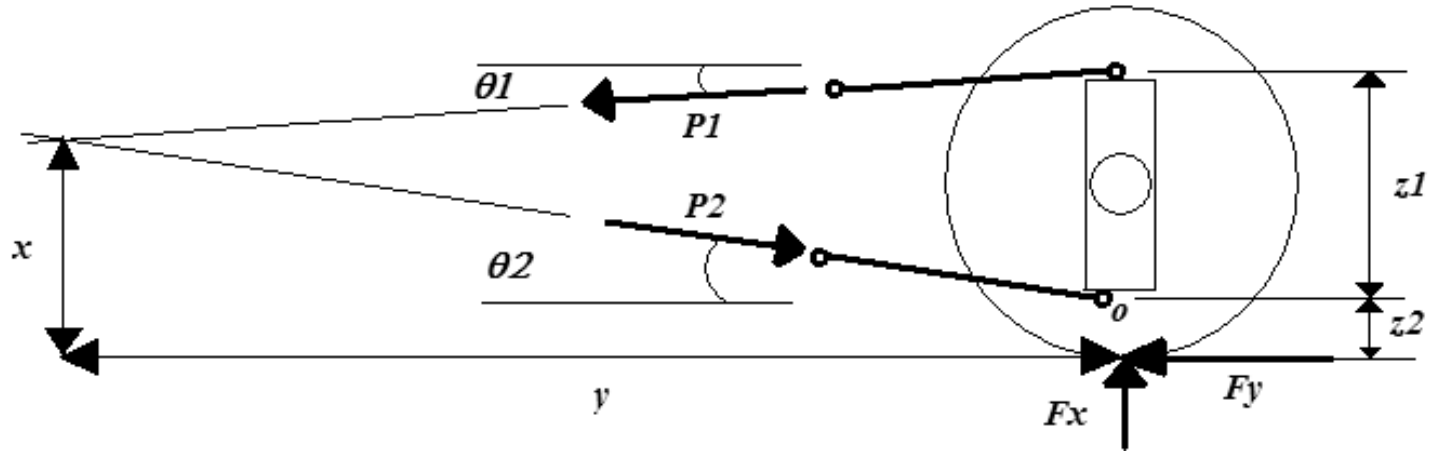

Figura 15 - Cálculo dos esforços na suspensão.

FONTE: - GUILLESPIE, 1992, p. 248-256.

Sendo $\boldsymbol{F} \boldsymbol{y}$ a força de tração no solo e $\boldsymbol{F} \boldsymbol{x}$ a força de reação vertical no solo causado pelas componentes verticais das forças nos braços de controle. A carga estática é desprezada na análise. Aplicando a segunda lei da Newton na vertical, na horizontal e a somatória dos momentos no ponto $\boldsymbol{o}$ é obtido:

$$
\begin{gathered}
F y+P_{1} \cos \theta_{1}-P_{2} \cos \theta_{2}=0 \\
F x-P_{1} \sin \theta_{1}-P_{2} \sin \theta_{2}=0 \\
F y z 2-P_{1} \cos \theta_{1} z 1=0
\end{gathered}
$$

Da equação (3.53) é possível observar:

$$
P_{1}=\frac{F y z 2}{z 1 \cos \theta_{1}}
$$

Assumindo ângulos pequenos e combinando às equações (3.51) e (3.54) tem-se:

$$
P_{2}=\frac{F y\left(1+\frac{z 2}{z 1}\right)}{\cos \theta_{2}}
$$

É geometricamente possível observar na figura 12 que: 


$$
\begin{gathered}
\tan \theta_{1}=\frac{z 2+z 1-x}{y} \\
\tan \theta_{2}=\frac{x-z 2}{y}
\end{gathered}
$$

Os esforços $\boldsymbol{P 1}$ e $\boldsymbol{P 2}$ ocorrem devido à força de tração $\boldsymbol{F y}$. Para uma situação de frenagem as equações são obtidas mudando o sentido da força $\boldsymbol{F} \boldsymbol{y}$. É possível verificar quanto maior o percentual de anti-squat, anti-lift e anti-squat os esforços $\boldsymbol{P 1}$ e $\boldsymbol{P 2}$ são maiores isso ocorre devido ao aumento dos ângulos $\theta 1$ e $\theta 2$.

Substituindo as equações (3.54) e (3.55) na equação (3.52) tem-se:

$$
F x=F y \tan \theta_{1}\left(\frac{z 2}{z 1}\right)+F y \tan \theta_{2}\left(1+\frac{z 2}{z 1}\right)
$$

Utilizando as relações geométricas, equações (3.56) e (3.57) obtêm-se:

$$
\frac{F x}{F y}=\left(\frac{x}{y}\right)
$$

A equação (3.59) é idêntica a que seria obtida se os braços de controle fossem substituídos por apenas um braço ligando a roda ao corpo do veiculo, em outras palavras à equação (3.59) comprova matematicamente que toda suspensão pode ser representada por um equivalente trailing-arm.

\subsection{Cálculo no ADAMS}

Os cálculos no ADAMS são baseados na geometria de suspensão, na matriz Compliance ou em ambos. A geometria de suspensão expressa a posição e a orientação das partes da suspensão. A matriz Compliance expressa o movimento da suspensão devido a 
aplicação de um incremento de força no centro da roda. O ADAMS calcula a matriz Compliance para cada posição da suspensão através de seu movimento.

A matriz compliance [C] do sistema é definida como a derivada parcial do deslocamento pela respectiva força aplicada.

$$
[C]=\frac{\partial x}{\partial F}
$$

Se assumir que o sistema é linear é possível prever o movimento do sistema devido a aplicação de uma força como entrada.

$$
\{X\}=[C]\{F\}
$$

Assim o ADAMS utiliza uma matriz 12x12 para relacionar o movimento do centro da roda direita e esquerda para uma unidade de força ou torque aplicadas no centro da roda direita e esquerda. A matriz Compliance tem a seguinte forma:

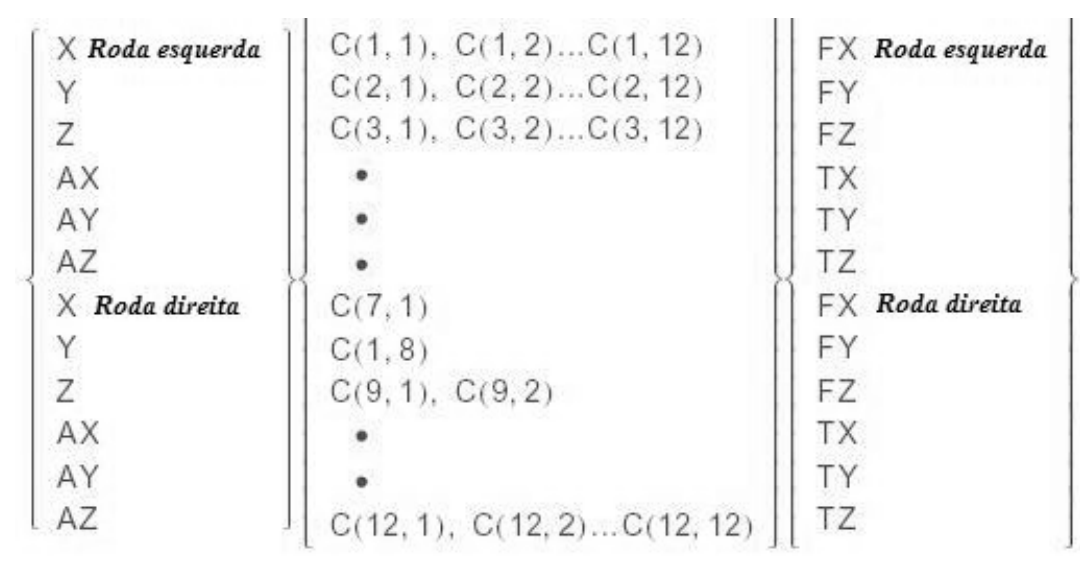

Figura 16- Matriz Compliance

Assim o elemento $\mathrm{C}(3,3)$ representa o movimento vertical do centro da roda esquerda devido a uma unidade de força vertical aplicada no centro da roda esquerda. Os outros elementos da matriz são definidos similarmente. 


\subsubsection{Dive e lift em frenagem}

O movimento de dive devido à frenagem é dado pela quantidade de compressão da suspensão dianteira por $\mathrm{G}$ de desaceleração do veiculo. $\mathrm{O}$ movimento de dive da suspensão dianteira é composto pela compressão da suspensão devido a transferência de carga mais a compressão da suspensão devido a força de frenagem. É considerado positivo o movimento de compressão da suspensão dianteira na frenagem.

O movimento de lift devido à frenagem é dado pela quantidade de extensão da suspensão dianteira por $\mathrm{G}$ de desaceleração do veiculo. $\mathrm{O}$ movimento de lift da suspensão traseira é composto pela extensão da suspensão devido à transferência de carga mais a compressão da suspensão devido à força de frenagem. É considerado positivo o movimento de extensão da suspensão traseira na frenagem.

Primeiro o ADAMS calcula a força longitudinal devido à frenagem:

$$
F_{\text {esquerda }}=F_{\text {direita }}=\frac{p}{2}
$$

E seguida à força vertical devido a transferência de peso:

$$
W_{\text {esquerda }}=W_{\text {direita }}=\frac{H}{2 L}
$$

Para o calculo do lift na suspensão traseira a transferência de peso é dada negativa. Essas forças são dadas para cada roda e por unidade total da força de frenagem.

Assim é possível calcular a deformação devido à força vertical:

$$
\begin{gathered}
Z_{\text {Wesquerda }}=W_{\text {esquerda }} C(3,3)+W_{\text {direita }} C(3,9)+\frac{W_{\text {esquerda }}}{K_{t}} \\
Z_{\text {Wdireita }}=W_{\text {esquerda }} C(9,3)+W_{\text {direita }} C(9,9)+\frac{W_{\text {direita }}}{K_{t}}
\end{gathered}
$$

E também calcular a deformação devido à força de tração: 


$$
\begin{aligned}
& Z_{\text {Fesquerda }}=F_{\text {esquerda }}\left[C(3,1)-R_{1} C(3,5)\right]+F_{\text {direita }}\left[C(3,7)-R_{1} C(3,11)\right] \\
& Z_{\text {Fdireita }}=F_{\text {esquerda }}\left[C(9,1)-R_{1} C(9,5)\right]+F_{\text {direita }}\left[C(9,7)-R_{1} C(9,11)\right]
\end{aligned}
$$

Assim o dive na suspensão dianteira e o lift na suspensão traseira são dados:

$$
\begin{gathered}
\text { dive_esquerda }=\left(Z_{\text {Fesquerda }}+Z_{\text {Wesquerda }}\right) W \\
\text { dive_direita }=\left(Z_{\text {Fdireita }}+Z_{\text {Wdireita }}\right) W
\end{gathered}
$$

Aonde R1 é o raio do pneu com carga e W é o peso do veiculo.

\subsubsection{Squat e lift em aceleração}

O movimento de lift devido à aceleração é dado pela quantidade de extensão na suspensão dianteira por $\mathrm{G}$ de aceleração. O movimento de squat devido à aceleração é dado pela quantidade de compressão na suspensão traseira por $G$ de aceleração. Ambos os movimentos variam com a força de tração, com a transferência de peso, e com torque de entrada e saída no diferencial quando o veiculo possui suspensão dependente.

Primeiro o ADAMS calcula a força de tração no ponto de contato de cada pneus:

$$
F_{\text {esquerda }}=F_{\text {direita }}=\frac{F e}{2}
$$

Depois a força vertical devido a transferência de carga:

$$
W_{\text {esquerda }}=W_{\text {direita }}=\frac{H}{2 L}
$$

As suspensões dependentes reagem ao torque de entrada e saída do diferencial, assim conhecido o torque de saída em cada pneu é possível calcular o torque de entrada no diferencial:

$$
T I=R_{1} a b s\left(F_{\text {esquerda }}+F_{\text {direita }}\right) / R_{\text {dif }}
$$


Sendo $\mathrm{B}_{\mathrm{t}}$ a bitola do veiculo, a força vertical no contato do pneu devido ao torque de entrada é dada por:

$$
V_{\text {esquerda }}=-V_{\text {direita }}=\frac{T I}{B_{T}}
$$

O torque de saída, esquerda ou direita, do diferencial é calculado como:

$$
\begin{gathered}
T O_{\text {esquerda }}=R_{1} F_{\text {esquerda }} \\
T O_{\text {direita }}=R_{1} F_{\text {direita }}
\end{gathered}
$$

Com os torques de entrada e saída o ADAMS calcula a deflexão na suspensão devido ao torque no diferencial:

$$
\begin{gathered}
Z D_{\text {esquerda }}=V T_{\text {esquerda }} C(3,1)+T O_{\text {esquerda }} C(3,5)+V T_{\text {direita }} C(3,7)+T O_{\text {direita }} C(3,11)+\frac{V T_{\text {esquerda }}}{R_{1}}(3.7 \\
Z D_{\text {esquerda }}=V T_{\text {esquerda }} C(9,1)+T O_{\text {esquerda }} C(9,5)+V T_{\text {direita }} C(9,7)+T O_{\text {direita }} C(9,11)+\frac{V T_{\text {direita }}}{R_{1}}(3.7
\end{gathered}
$$

Para suspensões independentes a deflexão devido ao toque de entrada e saída é zero.

A deflexão da suspensão devido à força de tração é calculada como:

$$
\begin{gathered}
Z_{\text {Fesquerda }}=F_{\text {esquerda }} C(3,1)+F_{\text {direita }} C(3,7) \\
Z_{\text {direita }}=F_{\text {direita }} C(9,7)+F_{\text {esquerda }} C(9,1)
\end{gathered}
$$

E a deflexão na suspensão devido a transferência de carga é dada por:

$$
\begin{gathered}
Z_{\text {Wesquerda }}=W_{\text {esquerda }} C(3,3)+W_{\text {direita }} C(3,9)+\frac{W_{\text {esquerda }}}{K_{t}} \\
Z_{\text {Wdireita }}=W_{\text {esquerda }} C(9,3)+W_{\text {direita }} C(9,9)+\frac{W_{\text {direita }}}{K_{t}}
\end{gathered}
$$

E finalmente o movimento de squat e lift por G de aceleração é dado por:

$$
\text { squat_esquerda }=\left(Z_{\text {Fesquerda }}+Z_{\text {Wesquerda }}+Z D_{\text {esquerda }}\right) M_{s} A_{g}
$$




$$
\text { squat_direita }=\left(Z_{\text {Fdireita }}+Z_{\text {Wdireita }}+Z D_{\text {direita }}\right) M_{s} A_{g}
$$

\subsubsection{Percentual de anti-dive e anti-lift em frenagem}

O percentual de anti-dive na suspensão dianteira em frenagem e o percentual de anti-lift na suspensão traseira em frenagem, são dados pela razão entre as deflexões causadas pela força e torque de frenagem pela deflexão gerada na transferência de peso. Durante a frenagem a deflexão gerada pela transferência de carga pode ser em parte cancelada pelas forças e torques de frenagem na suspensão.

Para a suspensão dianteira o percentual de anti-dive é considerado positivo quando as deflexões causadas pela força e torque de frenagem estendem a suspensão. Para a suspensão traseira o percentual de anti-lift é considerado positivo quando as deflexões causadas pela força e torque de frenagem comprimem a suspensão.

Primeiro o ADAMS calcula as forças de contato do pneu por G de desaceleração longitudinal:

$$
F_{\text {esquerda }}=F_{\text {direita }}=\frac{M_{s} A_{g} p}{2}
$$

E os torques de frenagem que reagem na suspensão são:

$$
\begin{gathered}
B T_{\text {esquerda }}=R_{1} F_{\text {esquerda }} \\
B T_{\text {direita }}=R_{1} F_{\text {direita }}
\end{gathered}
$$

$\mathrm{E}$ as forças que reagem na suspensão devido à transferência de peso são:

$$
W T_{\text {esquerda }}=\frac{M_{s} A_{g} H}{2 L}
$$




$$
W T_{\text {direita }}=\frac{M_{s} A_{g} H}{2 L}
$$

Assim a deflexão gerada pela força e torque de frenagem pode ser calculada:

$$
\begin{gathered}
Z B_{\text {esquerda }}=F_{\text {esquerda }} C(3,1)+F_{\text {direita }} C(3,7)+B T_{\text {esquerda }} C(3,5)+B T_{\text {direita }} C(3,11)+\frac{F_{\text {esquerda }}}{K_{t}}(3 . \\
Z B_{\text {direita }}=F_{\text {esquerda }} C(9,1)+F_{\text {direita }} C(9,7)+B T_{\text {esquerda }} C(9,5)+B T_{\text {direita }} C(9,11)+\frac{F_{\text {direita }}}{K_{t}}
\end{gathered}
$$

E as deflexões da suspensão devido a transferência de peso são:

$$
\begin{gathered}
Z_{\text {Wesquerda }}=W_{\text {esquerda }} C(3,3)+W_{\text {direita }} C(3,9)+\frac{W_{\text {esquerda }}}{K_{t}} \\
Z_{\text {Wdireita }}=W_{\text {esquerda }} C(9,3)+W_{\text {direita }} C(9,9)+\frac{W_{\text {direita }}}{K_{t}}
\end{gathered}
$$

E finalmente o percentual de anti-dive e anti-lift são:

$$
\begin{gathered}
\text { anti }- \text { dive }_{\text {esquerda }}=\text { anti }- \text { lift } t_{\text {esquerda }}=\frac{100 Z B_{\text {esquerda }}}{Z_{\text {Wesquerda }}} \\
\text { anti }- \text { dive }_{\text {direita }}=\text { anti }- \text { lift } t_{\text {direita }}=\frac{100 Z B_{\text {direita }}}{Z_{\text {Wdireita }}}
\end{gathered}
$$

\subsubsection{Percentual de anti-squat e anti-lift em aceleração}

O percentual de anti-lift na a suspensão dianteira em aceleração e o percentual de anti-squat na suspensão traseira em aceleração são dados pela razão entre a deflexão causada pela força e torque de tração pela deflexão causada na transferência de peso. Durante aceleração a deflexão vertical devido à transferência de carga pode em parte ser cancelada 
pela deflexão gerada pela força e torque de tração. Note que a suspensão que não possuir força ou torque de tração terá o percentual de anti-lift ou anti-squat igual a zero.

Para a suspensão dianteira o percentual de anti-lift é considerado positivo quando, a deflexão causada pela força e torque de tração age comprimindo a suspensão.Para a suspensão traseira o percentual de anti-squat é considerado positivo quando, a deflexão causada pela força e torque de tração age estendendo a suspensão.

Primeiro o ADAMS calcula a força de tração no ponto de contato do pneu:

$$
F_{\text {esquerda }}=F_{\text {direita }}=-\frac{F e}{2}
$$

Depois a força vertical devido a transferência de carga:

$$
W_{\text {esquerda }}=W_{\text {direita }}=-\frac{H}{2 L}
$$

As suspensões dependentes reagem ao torque de entrada e saída do diferencial. Conhecido o torque de saída em cada pneu é possível calcular o torque de entrada no diferencial:

$$
T I=R_{1} a b s\left(F_{\text {esquerda }}+F_{\text {direita }}\right) / R_{\text {dif }}
$$

Assim a força vertical no contato do pneu devido ao torque de entrada é:

$$
V_{\text {esquerda }}=-V_{\text {direita }}=\frac{T I}{B_{T}}
$$

O torque de saída, esquerda ou direita, do diferencial é calculado como:

$$
\begin{gathered}
T O_{\text {esquerda }}=-R_{1} F_{\text {esquerda }} \\
T O_{\text {direita }}=-R_{1} F_{\text {direita }}
\end{gathered}
$$

Com os torques de entrada e saída o ADAMS calcula a deflexão na suspensão:

$$
Z D_{\text {esquerda }}=V T_{\text {esquerda }} C(3,1)+T O_{\text {esquerda }} C(3,5)+V T_{\text {direita }} C(3,7)+T O_{\text {direita }} C(3,11)+\frac{V T_{\text {esquerda }}}{R_{1}}
$$


$Z D_{\text {esquerda }}=V T_{\text {esquerda }} C(9,1)+T O_{\text {esquerda }} C(9,5)+V T_{\text {direita }} C(9,7)+T O_{\text {direita }} C(9,11)+\frac{V T_{\text {direita }}}{R_{1}}(3.103)$

Para suspensões independentes a deflexão devido ao toque de entrada e saída é zero.

A deflexão da suspensão devido à força de tração é calculada como:

$$
\begin{gathered}
Z_{\text {Fesquerda }}=F_{\text {esquerda }} C(3,1)+F_{\text {direita }} C(3,7) \\
Z_{\text {Fdireita }}=F_{\text {direita }} C(9,7)+F_{\text {esquerda }} C(9,1)
\end{gathered}
$$

E a deflexão na suspensão devido a transferência de carga é:

$$
\begin{gathered}
Z_{\text {Wesquerda }}=W_{\text {esquerda }} C(3,3)+W_{\text {direita }} C(3,9)+\frac{W_{\text {esquerda }}}{K_{t}} \\
Z_{\text {Wdireita }}=W_{\text {esquerda }} C(9,3)+W_{\text {direita }} C(9,9)+\frac{W_{\text {direita }}}{K_{t}}
\end{gathered}
$$

Assim o percentual direito e esquerdo de anti-lift para a suspensão dianteira e o percentual direito e esquerdo de anti-squat são dados por:

$$
\begin{gathered}
\text { anti }- \text { squat }_{\text {esquerda }}=\text { anti }- \text { lift }_{\text {esquerda }}=\frac{100\left(Z_{\text {Fesquerda }}+Z_{\text {Desquerda }}\right)}{Z_{\text {Wesquerda }}} \\
\text { anti }- \text { squat }_{\text {direita }}=\text { anti }- \text { lift }_{\text {direita }}=\frac{100\left(Z_{\text {Fdireita }}+Z_{\text {Ddireita }}\right)}{Z_{\text {Wdireita }}}
\end{gathered}
$$

\subsubsection{Comprimento e ângulo do equivalente trailing-arm}

$\mathrm{O}$ equivalente trailing-arm é um braço imaginário que liga o centro da roda ao centro instantâneo de rotação lateral da suspensão. Quando o centro instantâneo de rotação esta atrás do centro da roda da suspensão dianteira o comprimento do equivalente trailing-arm 
é considerado positivo. Quando o centro instantâneo de rotação esta a frente do centro da roda da suspensão traseira o comprimento do equivalente trailing-arm é considerado positivo.

O ângulo do equivalente trailing-arm é tomado em relação a horizontal. O ângulo é positivo para o comprimento positivo quando, o braço esta inclinado para baixo em relação a linha de centro da roda. O ângulo é positivo para o comprimento negativo quando, o braço esta inclinado para cima em relação a linha de centro da roda.

A mudança na posição vertical e horizontal, e a mudança na vista lateral do centro de rotação da roda esquerda, devido a uma unidade de força no centro da roda são dados por:

$$
\begin{aligned}
& D X_{\text {esquerda }}=C(1,3) \\
& D Z_{\text {esquerda }}=C(3,3) \\
& D \phi_{\text {esquerda }}=C(5,3)
\end{aligned}
$$

O comprimento e o ângulo do equivalente trailing-arm do lado esquerdo é:

$$
\begin{gathered}
\text { Comprimento_traling }-a_{\text {esquerda }}=\frac{\left[\left(D X_{\text {esquerda }}\right)^{2}+\left(D Z_{\text {esquerda }}\right)^{2}\right]^{1 / 2}}{D \phi_{\text {esquerda }}} \\
\text { Angulo_traling }- \text { arm }_{\text {esquerda }}=\tan ^{-1} \frac{\left(D X_{\text {esquerda }}\right)}{\left(D Z_{\text {esquerda }}\right)}
\end{gathered}
$$

A mudança na posição vertical e horizontal, e a mudança na vista lateral do centro de rotação da roda direita, devido a uma unidade de força no centro da roda são dados por:

$$
\begin{aligned}
& D X_{\text {esquerda }}=C(1,3) \\
& D Z_{\text {esquerda }}=C(3,3) \\
& D \phi_{\text {esquerda }}=C(5,3)
\end{aligned}
$$

O comprimento e o ângulo do equivalente trailing-arm do lado direito são dados por:

$$
\text { Comprimento_traling }-\operatorname{arm}_{\text {direita }}=\frac{\left[\left(D X_{\text {direita }}\right)^{2}+\left(D Z_{\text {direita }}\right)^{2}\right]^{1 / 2}}{D \phi_{\text {direita }}}
$$




$$
\text { Angulo_traling }-a_{\text {direita }}=\tan ^{-1} \frac{\left(D X_{\text {direita }}\right)}{\left(D Z_{\text {direita }}\right)}
$$




\section{Modelo do veiculo em sistema de multicorpos (MBS)}

\subsection{Histórico}

A figura 16 apresenta a linha cronológica do desenvolvimento da técnica de MBS.

(BARBIERI， 2002; COSTA， 1992; SCHWERTASSER \& ROBERTSON， 1985; SCHIEHLEN \& KORTUM, 1985; SAYERS, 1990; ROSENTHAL \& SHERMAN, 1986; HUSTON, 1996).

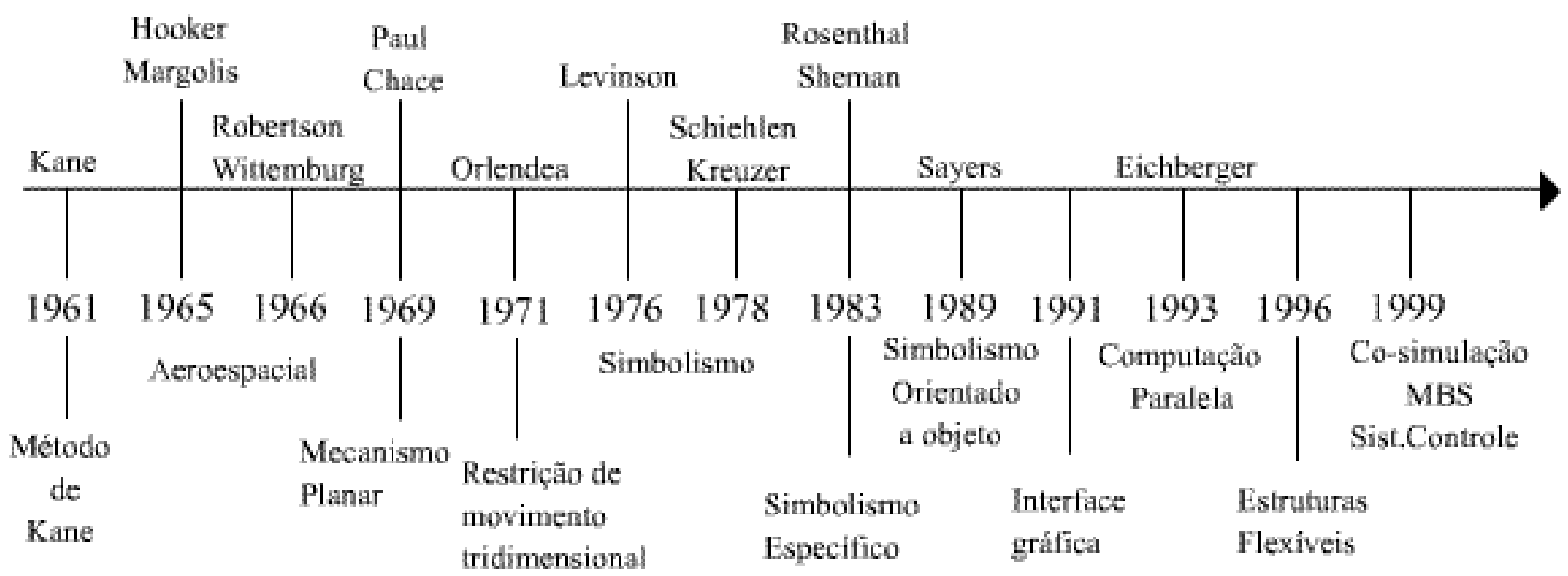

Figura 17 - Linha cronológica do desenvolvimento MBS.

FONTE: - BARBIERI, 2002, p. 163-165.

Inicialmente, Hooker e Robertson discutiram e apresentaram juntos seus propósitos para o desenvolvimento de programas de MBS na Califórnia. Após seguiram 
caminhos independentes, Hooker e Margolis, na Califórnia 1965 e Robertson e Wittenburg na Alemanha 1966, desenvolveram o formalismo para a obtenção numérica das equações de movimento tridimensionais para espaçonaves com topologia aberta. (COSTA, 1991; SCHWERTASSEK, 1985; BARBIERI, 2002).

No final dos anos 60 e início dos anos 70, Paul e Chace através de seu trabalho introduziram a abordagem de MBS nas áreas de mecânica e transportes terrestres, dificuldades encontradas no trabalho ocorreram devido aos encadeamentos cinemáticos fechados e aos vínculos holonômicos que são raramente encontrados em aplicações espaciais. Essas dificuldades foram abordadas em 1977 por Orlandea e Chace que deram origem ao programa ADAMS que aborda sistemas de diversas naturezas, resultando em grandes sistemas cuja solução necessita utilizar a técnica de matrizes esparsas.

A utilização de programas simbólicos foi introduzida por Levinson em 1976 e em seguida por Schiehlen e Kreuzer em 1978. Contudo a manipulação da linguagem simbólica requeria técnicas especiais, pois, ao gerar códigos podiam exceder os limites dos computadores.

Utilizando os métodos simplificados de manipulação simbólica, Rosenthal e Sherman em 1986 desenvolveram o programa SD/EXACT como parte de um projeto da NASA, que tinha como objetivo desenvolver códigos simples de MBS que um computador AD100 fosse capaz de calcular em tempo real. Devido aos bons resultados outros programas como Symba e AUTOSIM (SAYERS, 1989) foram desenvolvidos utilizando uma abordagem similar.

Em 1995 Chang e Huston apresentaram métodos computacionais para o estudo de impacto em sistemas de multicorpos, através do uso de equações algébricas para incrementos de velocidade (BARBIERI, 2002). Na década de 90, vários esforços de pesquisa foram direcionados para o tratamento de modelagem MBS com estruturas flexíveis (HUSTON, 
1994). Recentemente muito se evoluiu na integração entre programas de elementos finitos e programas de controles lógicos com os programas de MBS.

\subsection{Modelo em sistema de multicorpos do veículo}

Os conceitos apresentados no capitulo anterior serão verificados no estudo de um veiculo de competição formula. As características do movimento de dive e squat para esse tipo de veículo são muito importantes, pois possuem altura relativa ao solo muito pequena, altos valores de aceleração e desaceleração e grande sensibilidade aerodinâmica ao movimento de pitch.

Neste capitulo é apresentado o modelo do veículo em sistema de multicorpos, o programa utilizado para sua construção foi o ADAMS-Car (sigla de Automatic Dynamic Analysis of Mechanical Systems).

O modelo de multicorpos desenvolvido possui 22 graus de liberdade e tem toda geometria do sistema de suspensão e direção com suas características de elasticidade e tendências de esterçamento. O modelo é composto pelos subsistemas: suspensão dianteira, suspensão traseira, direção, chassis, roda e pneu dianteiro e traseiro, motor e transmissão, barras anti-rolagem dianteira e traseira e sistema de freio, que são descritos ao decorrer do capitulo, figura 17. 


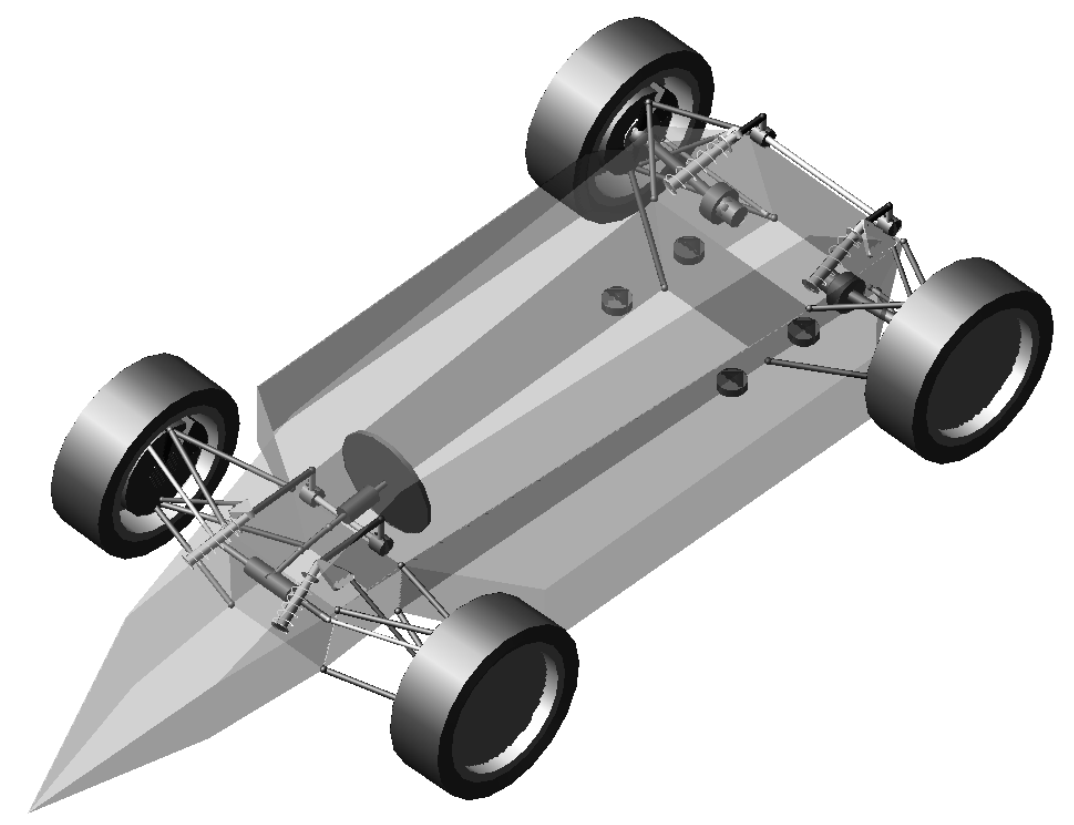

Figura 18 - Modelo em sistema de multicorpos.

As características gerais do veiculo são apresentadas na tabela 1 .

Tabela 1 - Características gerais do veiculo.

\begin{tabular}{|l|c|}
\hline \multicolumn{2}{|l|}{ Características gerais do veículo } \\
\hline Massa total & \multicolumn{1}{|c|}{$330 \mathrm{Kg}$} \\
\hline Distribuição de peso dianteiro e traseiro & $1650 \mathrm{~mm}$ \\
\hline Distância entre eixos & $1180 \mathrm{~mm}$ \\
\hline Bitola dianteira e traseira & $175 / 510-\mathrm{R} 13$ \\
\hline Pneu dianteiro e traseiro & Quatro cilindros de 600cc com \\
\hline & $82 \mathrm{hp}$. \\
\hline Motor & Cambio seqüencial de seis \\
\hline Transmissão & marchas. \\
\hline Sistema de Freio & Freio a disco nas quatro rodas. \\
\hline
\end{tabular}




\subsubsection{Subsistema suspensão dianteira}

O veículo formula estudado possui sistema de suspensão não comumente encontrado em carros de passeio, exceto em alguns carros esportivos. $\mathrm{O}$ sistema de suspensão push-rod com duplo braço de controle tem como vantagem ser compacto e leve. O sistema proporciona melhoras aerodinâmicas, pois o conjunto mola amortecedor ficar interno a carroceria.

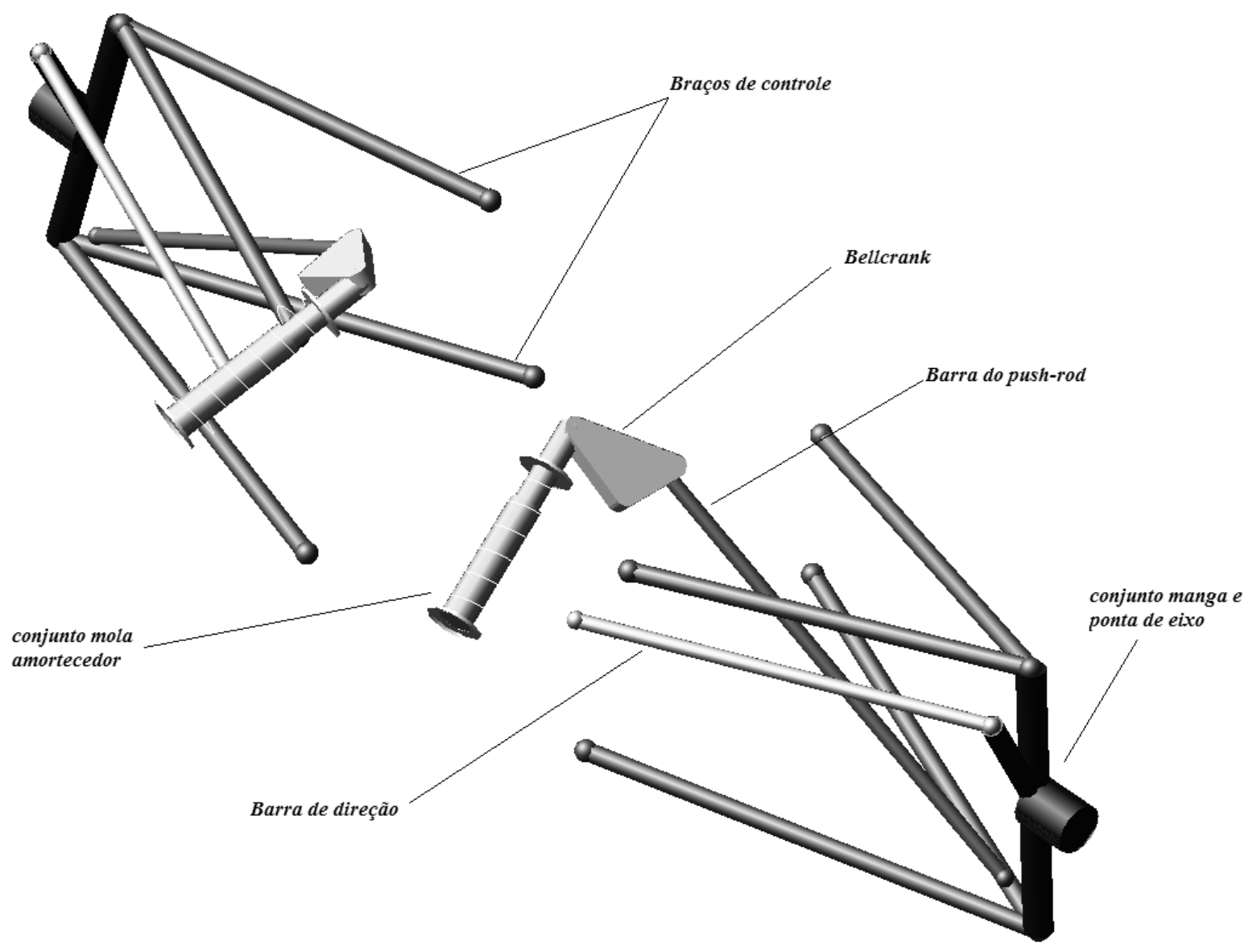

Figura 19 - Subsistema suspensão dianteira.

A figura 18 mostra o subsistema suspensão dianteira que é composto por braços de controle, barra de direção, conjunto manga e ponta de eixo, conjunto mola e amortecedor, bellcrank e barra do push-rod. 
A figura 19 apresenta as juntas do subsistema suspensão dianteira, que estão numeradas e são descritas na tabela 2 .

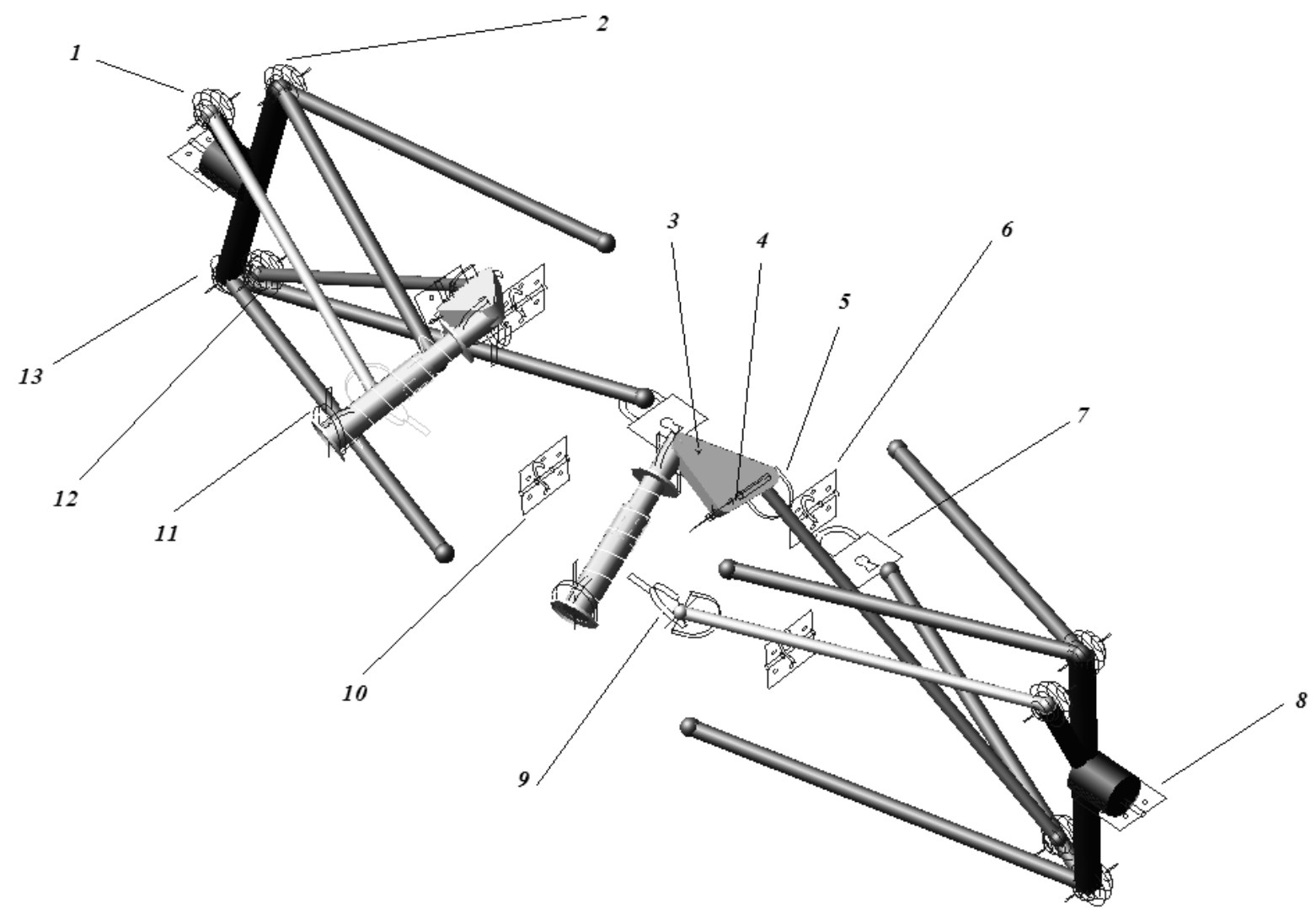

Figura 20 - Junta entre os corpos da suspensão dianteira.

Tabela 2 - Descrição das juntas na suspensão dianteira.

\begin{tabular}{|l|l|}
\hline \multicolumn{2}{|l|}{ Juntas da suspensão dianteira } \\
\hline 1 & Junta esférica para a conexão da barra de direção à manga de eixo. \\
\hline 2 & Junta esférica para conexão do braço de controle superior à manga de eixo. \\
\hline 3 & Junta cruzeta para conexão do bellcrank a conjunto mola amortecedor. \\
\hline 4 & Junta de revolução para conexão do bellcrank ao corpo do veiculo. \\
\hline 5 & Junta cruzeta para conexão do bellcrank a barra do push-rod. \\
\hline
\end{tabular}




\begin{tabular}{|l|l|}
\hline 6 & Junta de revolução para conexão do braço de controle superior ao corpo do veiculo. \\
\hline 7 & Junta fixa para a conexão da barra de torção. \\
\hline 8 & Junta de revolução para a conexão do cubo de roda no eixo. \\
\hline 9 & Junta cruzeta para a conexão da barra de direção ao subsistema direção. \\
\hline 10 & Junta de revolução para conexão do braço de controle inferior ao corpo do veiculo. \\
\hline 11 & Junta cruzeta para a conexão do amortecedor ao corpo do veiculo. \\
\hline 12 & Junta esférica para a conexão da barra do push-rod ao braço de controle inferior. \\
\hline 13 & \\
\hline
\end{tabular}

A mola e o amortecedor são modelados como elemento vetor força aonde a mola é função do deslocamento relativo das extremidades e o amortecedor é função da velocidade relativa entre as extremidades.

\subsubsection{Subsistema suspensão traseira}

Semelhante ao subsistema suspensão dianteira o subsistema suspensão traseira também usa suspensão push-rod com duplo braço de controle. A suspensão traseira é composta por braços de controle, barra de convergência, conjunto manga e ponta de eixo, conjunto mola e amortecedor, bellcrank, barra do push-rod e semi-eixo, como mostra a figura 20. 


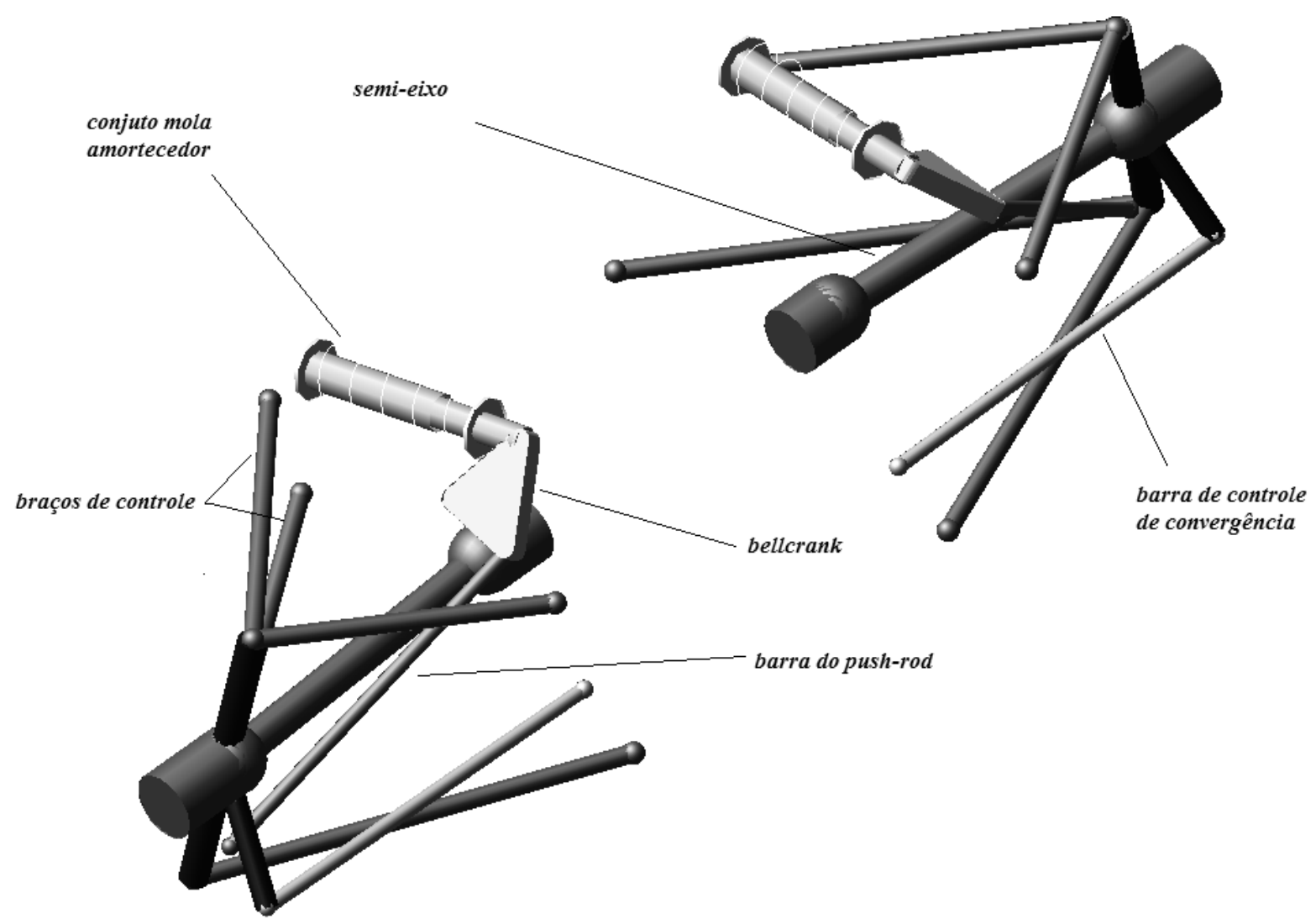

Figura 21 - Subsistema suspensão traseira.

A figura 21 apresenta as juntas de conexão do subsistema suspensão traseira. Diferente do subsistema suspensão dianteira a junta de revolução não conecta mais a ponta de eixo ao cubo de roda mais sim o da ponta do semi-eixo ao cubo de roda, por onde ira ser transmitido o torque para as rodas traseiras. A tabela 3 apresenta a descrição das juntas que compõe o subsistema suspensão traseira.

Como no subsistema suspensão dianteira a mola e o amortecedor são modelados como elemento vetor força aonde a mola é função do deslocamento relativo das extremidades e o amortecedor é função da velocidade relativa entre as extremidades. 


$$
E^{*}
$$




\begin{tabular}{|l|l|}
\hline 8 & Junta cruzeta para conexão do bellcrank a conjunto mola amortecedor. \\
\hline 9 & Junta cruzeta para conexão do bellcrank a barra do push-rod. \\
\hline 10 & Junta de revolução para a conexão da ponta do semi-eixo ao cubo de roda. \\
\hline 11 & Junta deslizante para a conexão do eixo ao diferencial. \\
\hline 12 & Junta de revolução para conexão do braço de controle superior ao corpo do veiculo. \\
\hline 13 & Junta de revolução para conexão do bellcrank ao corpo do veiculo. \\
\hline 14 & Junta cruzeta para a conexão do amortecedor ao corpo do veiculo. \\
\hline
\end{tabular}

\subsubsection{Subsistema direção}

O subsistema direção do modelo em multicorpos é composto por volante, coluna de direção, suporte da coluna de direção, pinhão, cremalheira e suporte do pinhão cremalheira.

A caixa de redução foi modelada como elemento de acoplamento, pois, o acoplamento transmite o movimento de uma junta a outra levando em consideração a relação de redução entre o pinhão e a cremalheira. A redução da direção é dada entre o movimento angular da junta de revolução do pinhão e o movimento linear da junta de translação da cremalheira. Na figura 23 são apresentadas as juntas do subsistema direção.

O movimento do sistema de direção pode ser imposto através da aplicação de um ângulo no volante ou através da aplicação de um torque no volante. Não foi incluído ao subsistema nenhum tipo de amortecimento ou rigidez. 


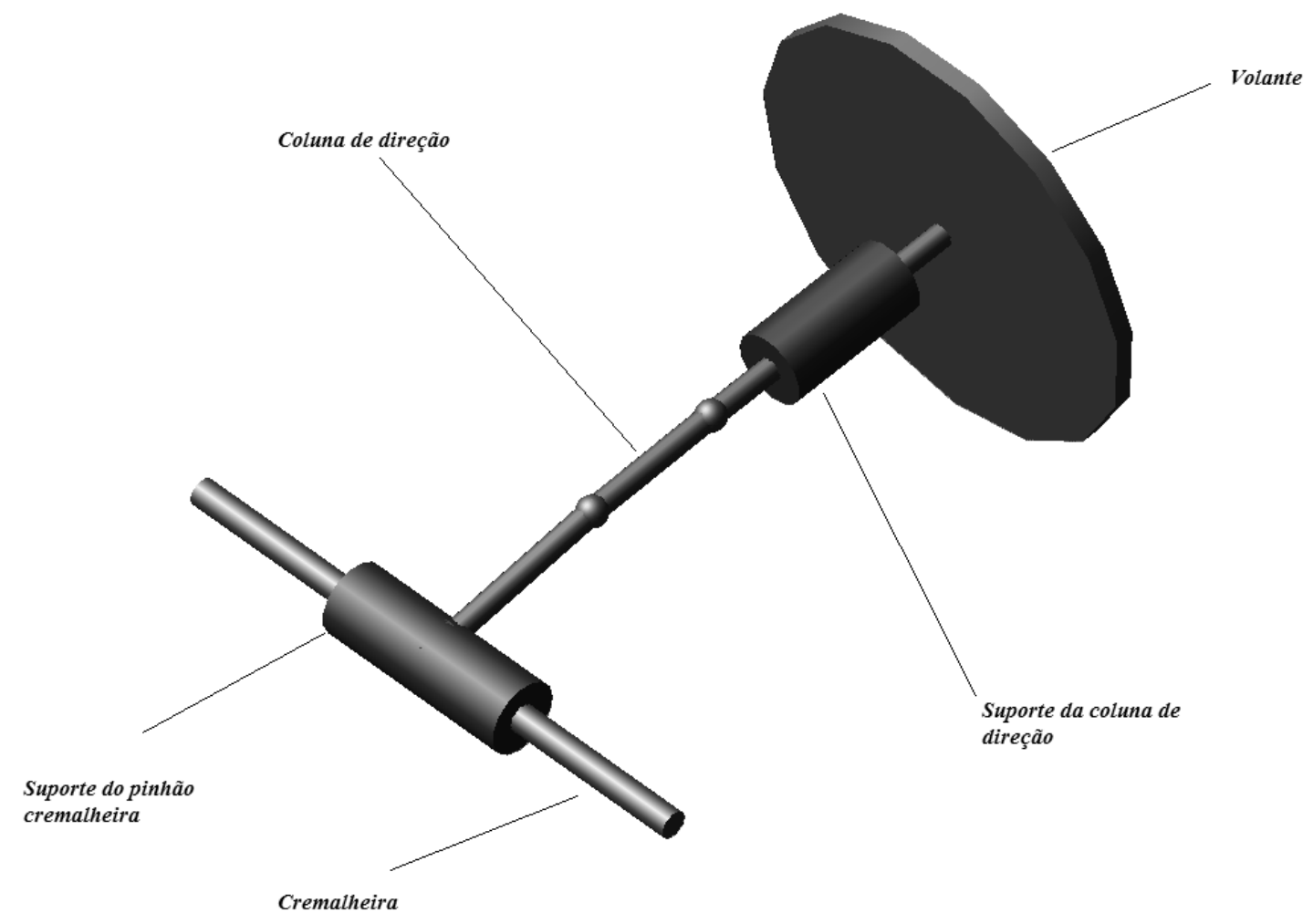

Figura 23 - Subsistema direção.

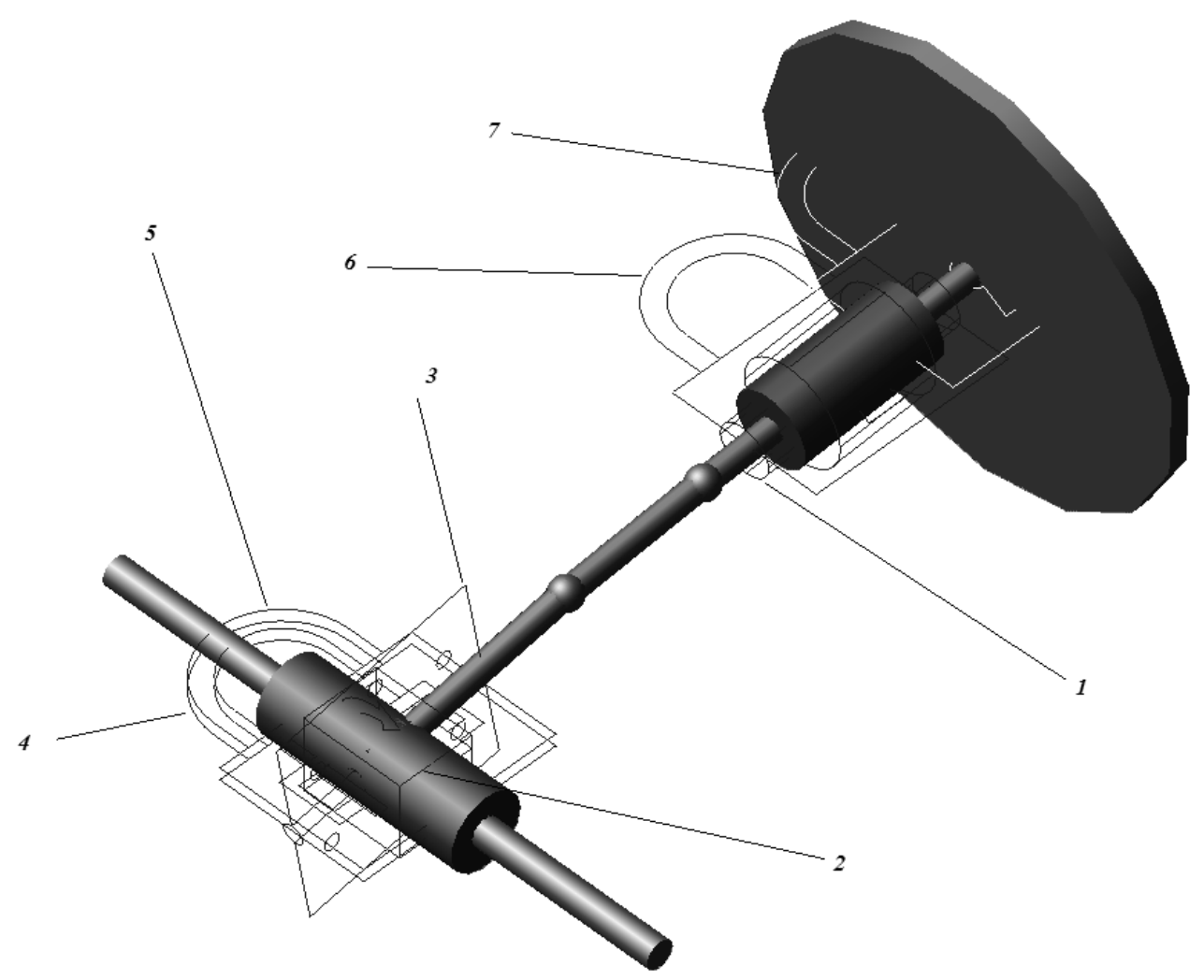

Figura 24 - Junta entre os corpos do subsistema de direção. 
Na tabela 4 são descritas as juntas entre os corpos do subsistema direção.

Tabela 4 - Descrição das juntas do subsistema direção.

\begin{tabular}{|l|l|}
\hline \multicolumn{2}{|l|}{ Juntas da suspensão traseira } \\
\hline 1 & $\begin{array}{l}\text { Junta cilíndrica para a conexão da coluna de direção ao suporte da coluna de } \\
\text { direção. }\end{array}$ \\
\hline 2 & Junta de translação para conexão do suporte do pinhão cremalheira a cremalheira. \\
\hline 3 & Junta de revolução para conexão do suporte do pinhão cremalheira ao pinhão. \\
\hline 5 & Junta fixa para conexão do suporte do pinhão cremalheira ao corpo do veiculo. \\
\hline 6 & Junta fixa para a conexão do pinhão a coluna de direção. \\
\hline 7 & Junta fixa para a conexão do suporte da coluna de direção ao corpo. \\
\hline
\end{tabular}

\subsubsection{Subsistema chassis}

O subsistema chassis é modelado como sendo um corpo rígido, tendo sua massa concentrada e momentos de inércia em relação ao centro de massa. Diferente dos outros subsistemas o subsistema chassis não possui juntas.

Os subsistemas direção, suspensão dianteira, suspensão traseira, barra anti-rolagem e conjunto motor transmissão, trocam informações e são conectados ao subsistema chassis através de comunicadores. 


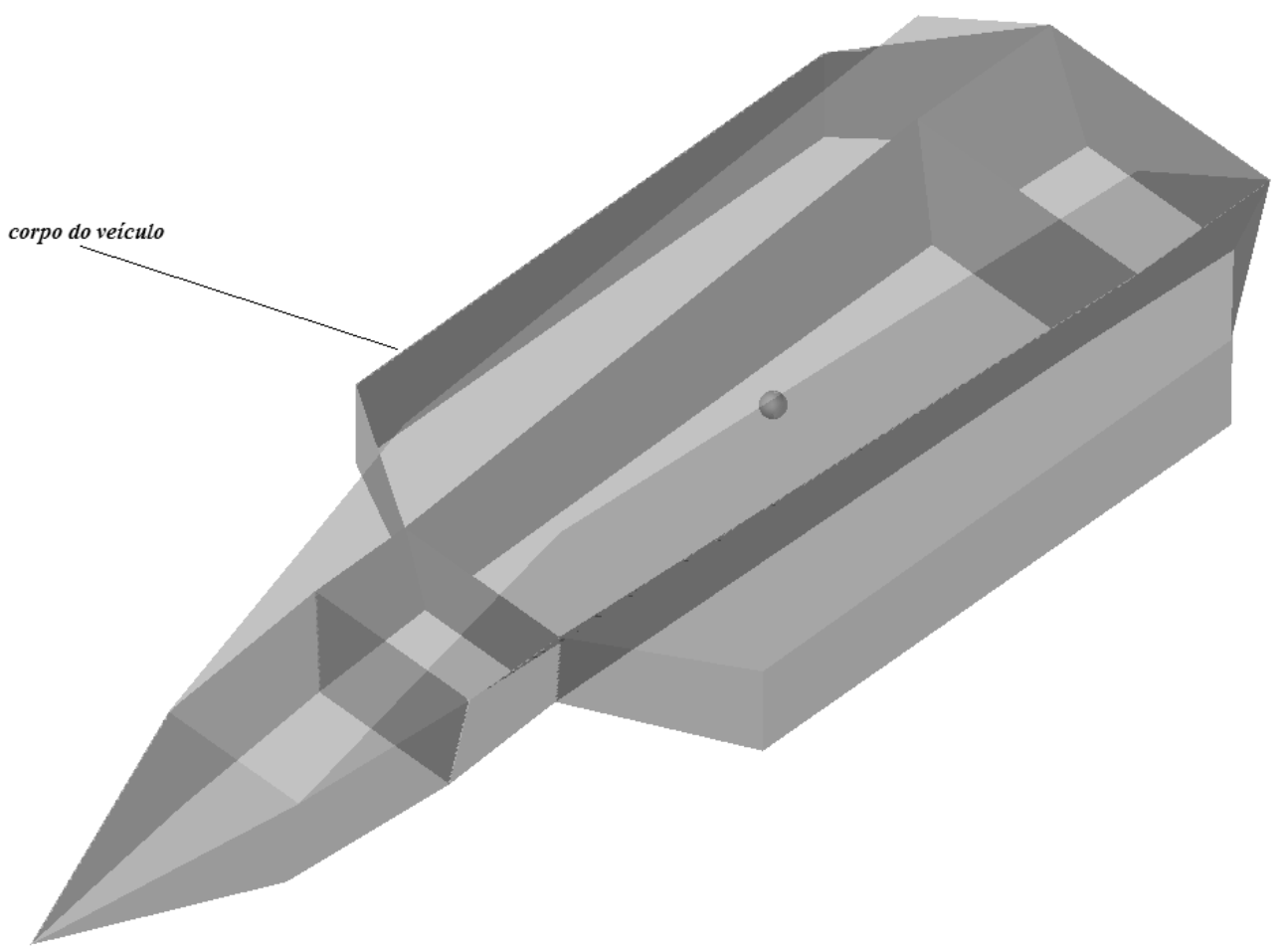

Figura 25 - Subsistema chassis.

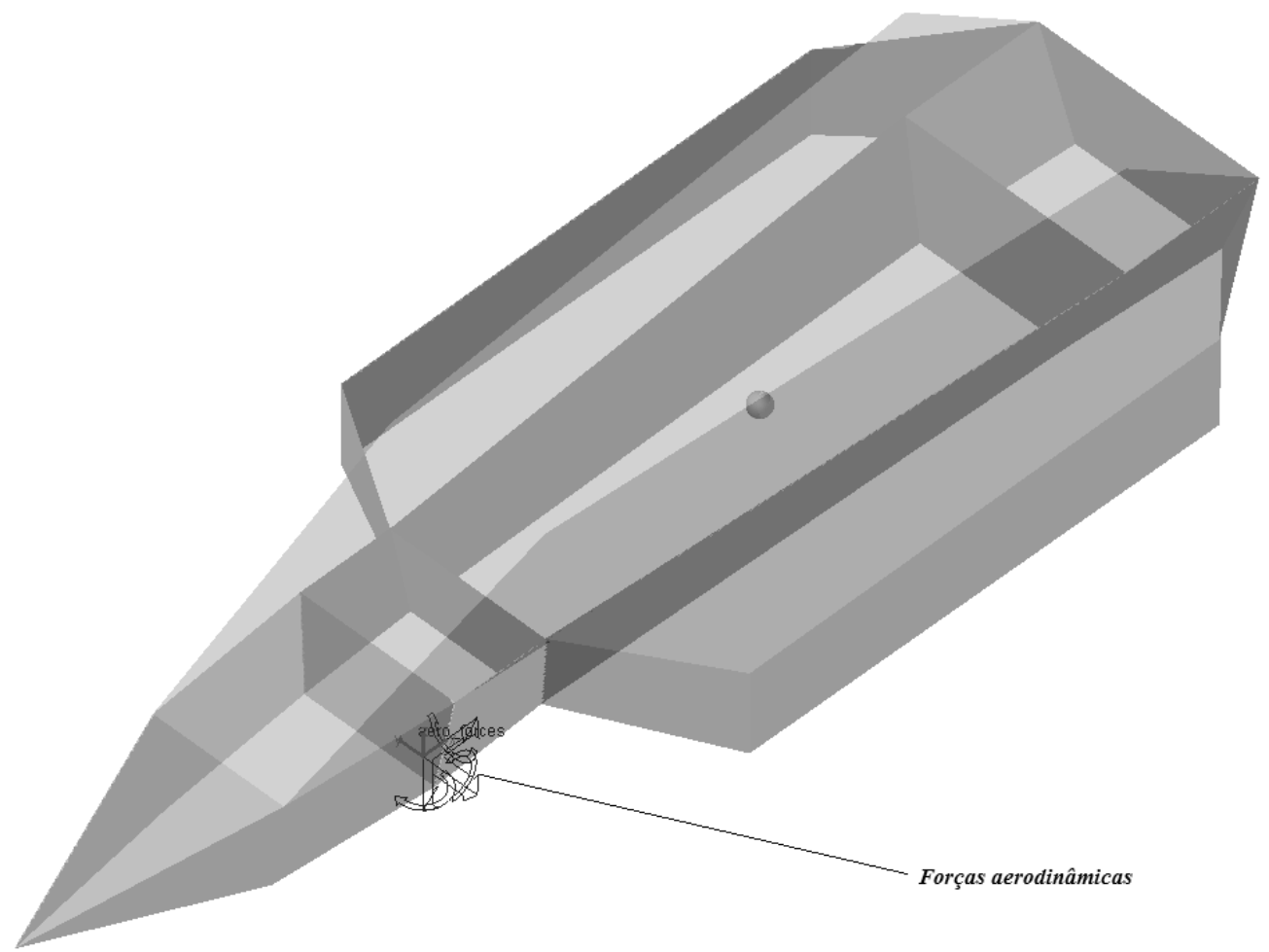

Figura 26 - Forças aerodinâmicas. 
Ao subsistema chassis são aplicados elementos de força, que poderão ou não ser função da velocidade, representando as forças aerodinâmicas sobre o veículo como apresenta a figura 25 .

\subsubsection{Subsistema roda e pneu dianteiros e traseiros}

As características do subsistema roda e pneu são listadas na tabela 5.

Tabela 5 - Características do subsistema roda pneu.

\begin{tabular}{|l|c|}
\hline \multicolumn{2}{|l|}{ Pneu e roda } \\
\hline Pressão de enchimento & $103.42 \mathrm{MPa}$ \\
\hline Largura & $175 \mathrm{~mm}$ \\
\hline Diâmetro & $249 \mathrm{~mm}$ \\
\hline Rigidez vertical & $226263.9 \mathrm{~N} / \mathrm{m}$ \\
\hline Amortecimento vertical & $250 \mathrm{Ns} / \mathrm{m}$ \\
\hline Rigidez lateral & $113131.95 \mathrm{~N} / \mathrm{m}$ \\
\hline Massa da roda & $6,5 \mathrm{~kg}$ \\
\hline
\end{tabular}

A figura 26 apresenta o modelo em ADAMS do subsistema roda e pneu dianteiro e traseiro. Os modelos possuem juntas fixas em cada roda, que conectam a roda ao cubo de roda do subsistema suspensão dianteira e traseira. 


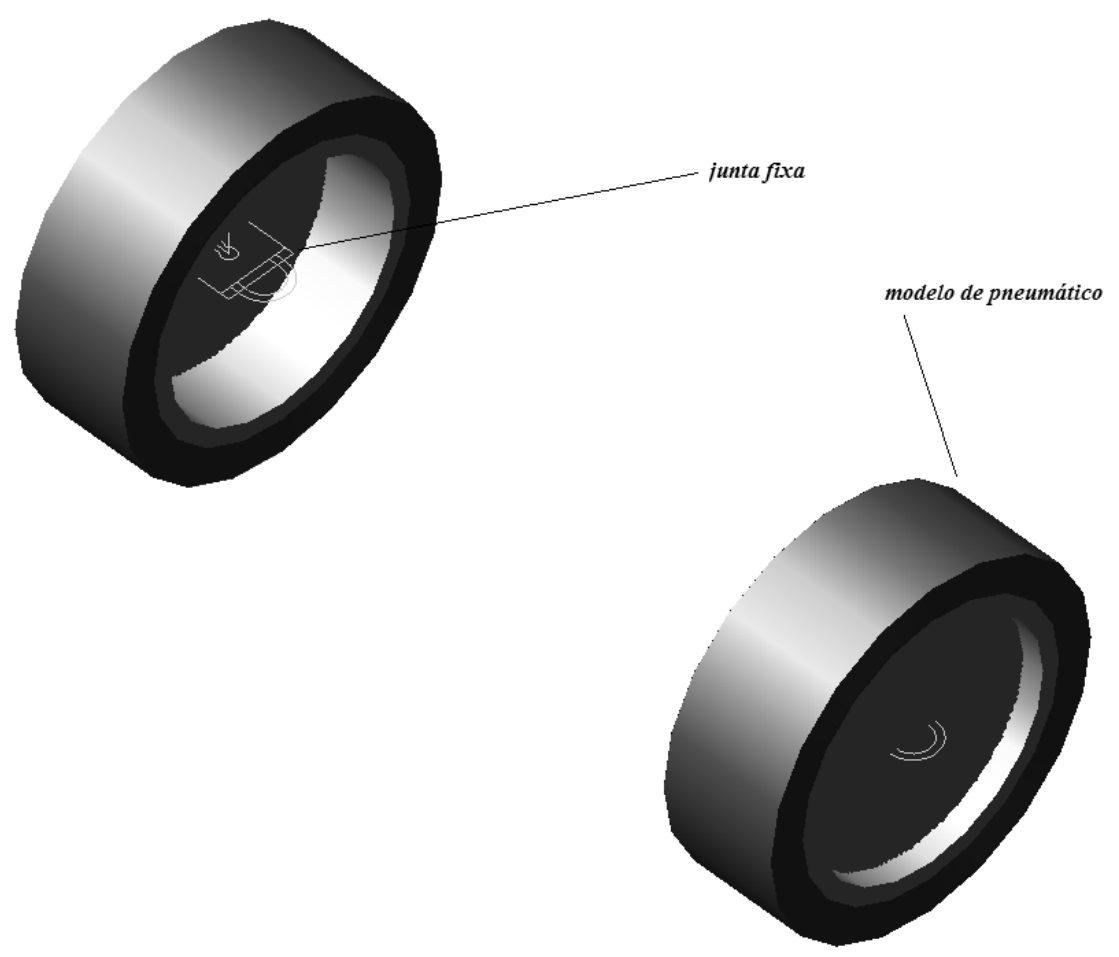

Figura 27 - Modelo roda e pneu dianteiro e traseiro.

As curvas do pneu foram fornecidas pelo fabricante que obteve seus parâmetros em varias condições de carga, orientação e movimento.

Para que seja calculadas as forças de contato do pneu com o pavimento é necessário adotar um modelo de pista, o ADAMS possui dois modelos de pista sendo o modelo 2D utilizado para manobras de dirigibilidade e o modelo 3D para simular terrenos irregulares como: buracos, ressaltos, etc. O presente trabalho assume o modelo 2D, pois não é objetivo o modelo em pistas irregulares.

\subsubsection{Subsistema motor e transmissão}

O subsistema motor e transmissão não contêm partes girantes conectadas como em uma transmissão real, pois se todas as partes do trem de força (Inércia, massa, rigidez, etc) fossem representadas aumentariam o tempo de simulação. Ele é inteiramente baseado em 
funções que representam o motor, a embreagem e a linha de transmissão. Ao subsistema motor e transmissão estão relacionadas às características apresentadas na tabela 6 .

Tabela 6 - Características do subsistema motor transmissão.

\begin{tabular}{|l|c|}
\hline \multicolumn{2}{|l|}{ Motor e transmissão } \\
\hline Amortecimento da embreagem & $9 \mathrm{e} 6 \mathrm{Ns} / \mathrm{m}$ \\
\hline Rigidez da embreagem & $1 \mathrm{e} 5 \mathrm{~N} / \mathrm{m}$ \\
\hline Torque crítico da embreagem & $100 \mathrm{Nm}$ \\
\hline Rotação limite do motor & $13500 \mathrm{rpm}$ \\
\hline Rotação mínima do motor & $2500 \mathrm{rpm}$ \\
\hline Inércia rotacional do motor & $1 \mathrm{e}-3 \mathrm{kgm}{ }^{2}$ \\
\hline Redução do diferencial & 4.25 \\
\hline Redução da $1,2,3,4,5, \mathrm{e}$ & 2,$75 ; 1,95 ; 1,5 ; 1,28 ; 1,142 \mathrm{e} 1,061$. \\
\hline marchas & \\
\hline
\end{tabular}

A figura 27 apresenta o modelo representativo do subsistema motor e transmissão aonde o motor é fixo ao chassi através de buchas que são modeladas como elementos de força com matriz de rigidez de dimensão 6x6. As curvas de força versus deslocamento translacional ou rotacional são não lineares. 


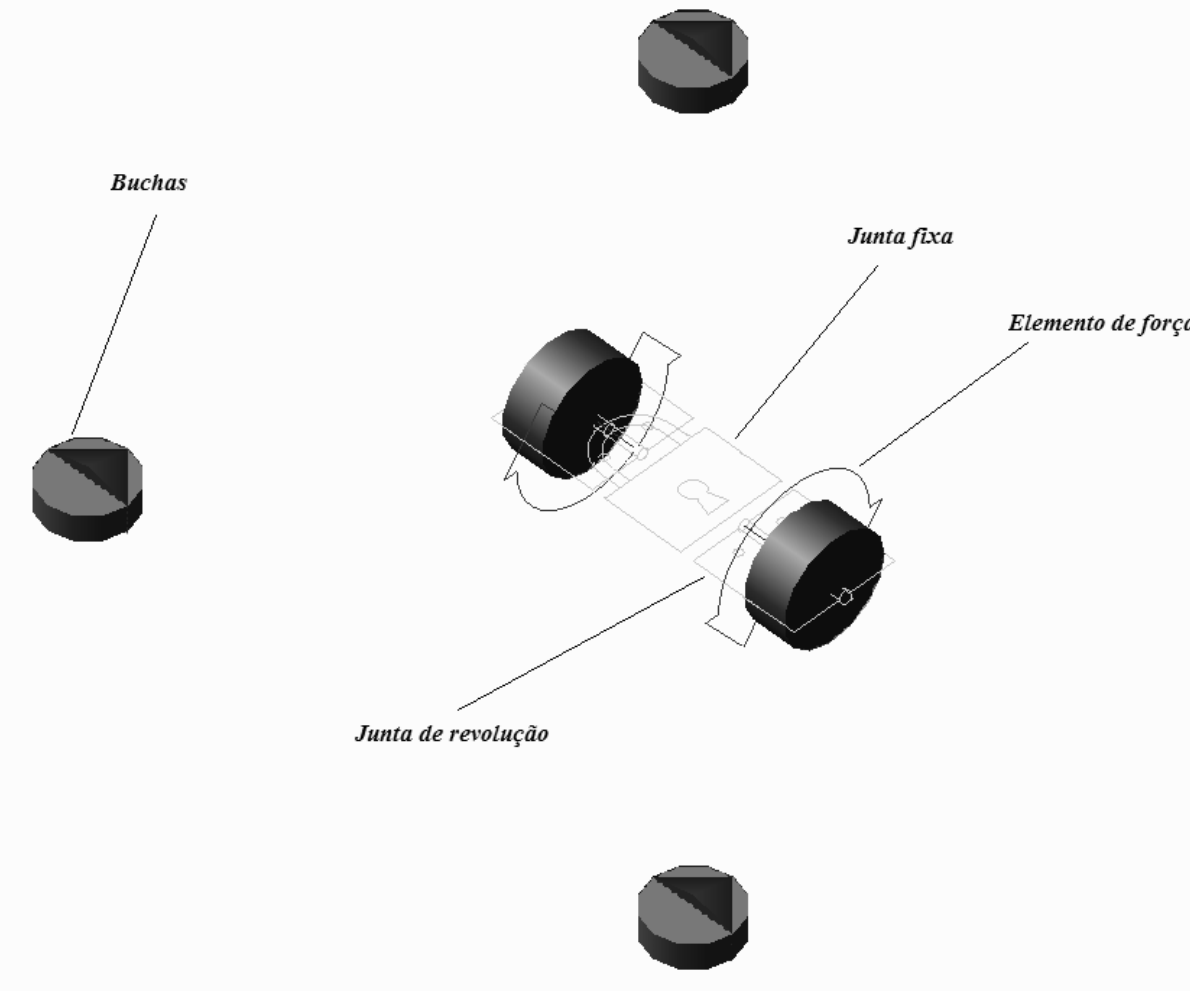

Figura 28 - Subsistema motor e transmissão.

A junta fixa apresentada na figura 27 conecta o motor ao chassi e a junta de revolução conecta o motor ao diferencial. O modelo do motor usa um mapa com, torque de saída do motor e a rotação de saída do motor.

\subsubsection{Subsistema barra anti-rolagem dianteira e traseira}

O subsistema barra anti-rolagem é composto por uma barra de torção, duas buchas e dois links, como mostra a figura 28. 


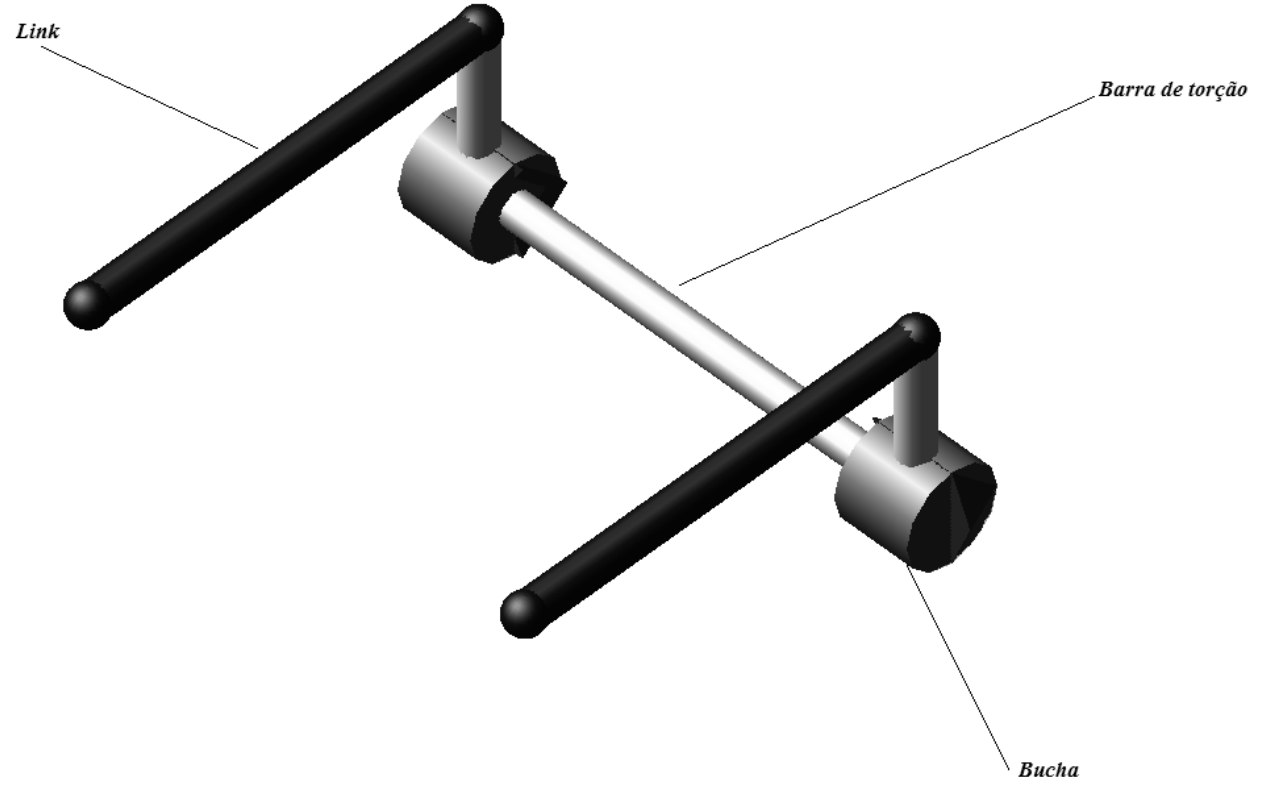

Figura 29 - Subsistema barra anti-rolagem.

No subsistema barra anti-rolagem a rigidez é modelada por uma mola de torção, assim desprezando a flexão da barra, como apresenta a figura 29.

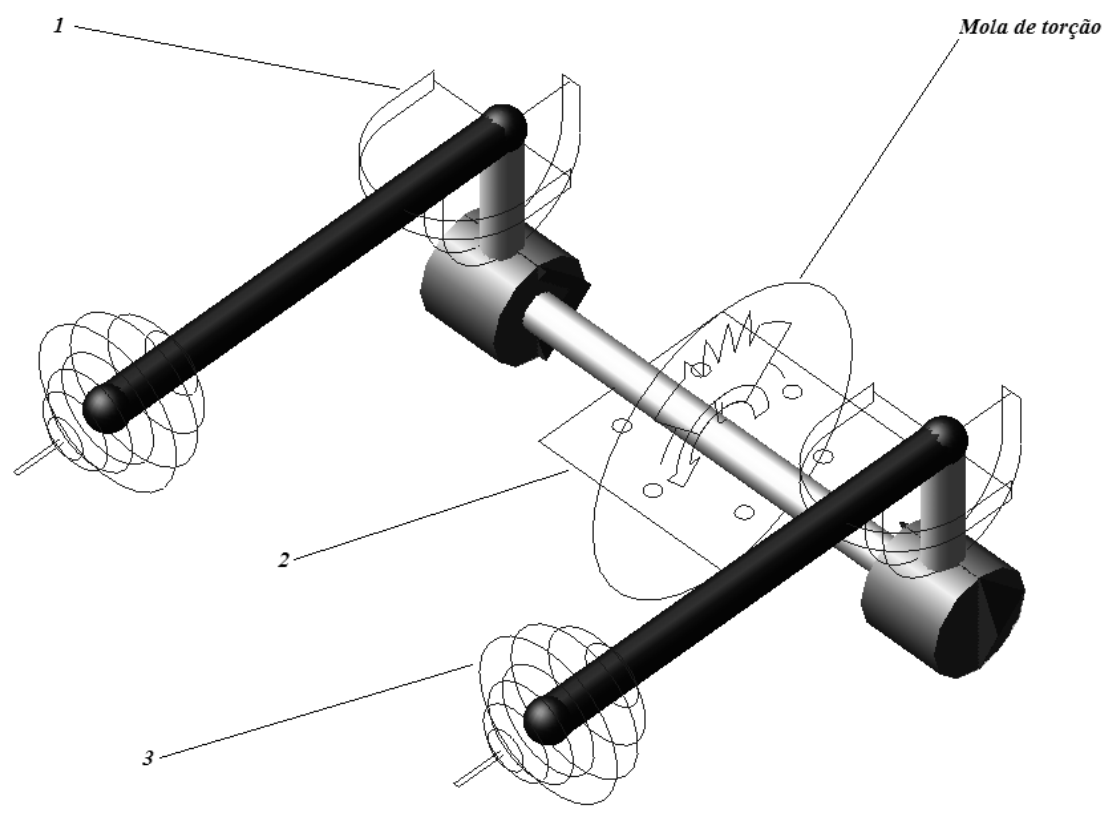

Figura 30 - Junta entre os corpos da barra anti-rolagem. 
Na tabela 7 são descritas as juntas do subsistema barra anti-rolagem.

Tabela 7 - Descrição das juntas do subsistema barra anti-rolagem.

\begin{tabular}{|l|l|}
\hline \multicolumn{2}{|l|}{ Juntas da barra anti-rolagem } \\
\hline 1 & Junta cruzeta para a conexão da barra de torção ao link. \\
\hline 2 & Junta de revolução para a conexão dos lados da barra de torção. \\
\hline 3 & Junta esférica para a conexão do link ao Bellcrank. \\
\hline
\end{tabular}

\subsubsection{Subsistema freio}

O subsistema freio representa um mecanismo que aplica uma resistência ao movimento do veiculo. A resistência ao movimento é obtida através do torque aplicado entre o rotor e o caliper. $\mathrm{O}$ torque de frenagem é expresso como função de um numero de parâmetros listados na tabela 8

Tabela 8 - Características do subsistema freio.

\begin{tabular}{|l|l|}
\hline \multicolumn{2}{|l|}{ Características do freio } \\
\hline Proporção de freio na dianteira & 0,6 \\
\hline Coeficiente de atrito entre o & 0,4 \\
rotor e o caliper & \\
\hline Raio efetivo do pistão & $135 \mathrm{~mm}$ \\
\hline Área do pistão & $2500 \mathrm{~mm}^{2}$ \\
\hline Largura do rotor & $25 \mathrm{~mm}^{2}$ \\
\hline Valor máximo de frenagem & 100 \\
\hline Largura do cubo do rotor & $40 \mathrm{~mm}$ \\
\hline
\end{tabular}


O caliper é montado na manga de suspensão e o rotor é montado na roda. . O subsistema freio é limitado pela interação entre o rotor e o caliper. O modelo do sistema de freio é apresentado na figura 30.

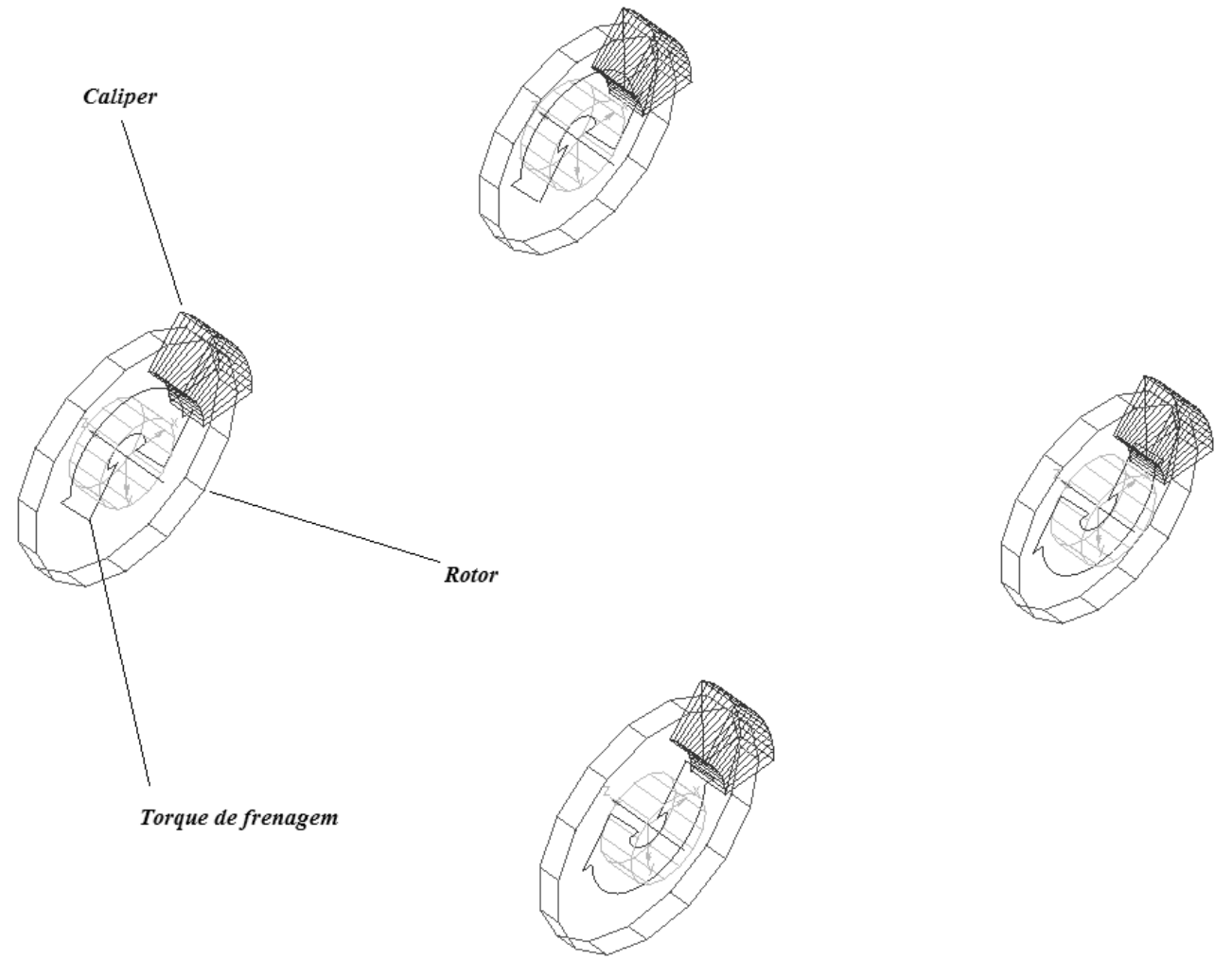

Figura 31 - Subsistema freio.

\subsection{Simulações em ADAMS}

As simulações efetuadas no trabalho estão divididas em duas partes principais sendo a primeira referente a suspensão e a segunda ao veiculo completo. $\mathrm{Na}$ análise da suspensão será efetuado o deslocamento paralelo das rodas variando $30 \mathrm{~mm}$ para cima e $30 \mathrm{~mm}$ para baixo, para a suspensão dianteira e traseira. Parâmetros como squat, lift, dive, 
equivalente trailing-arm, anti-squat, anti-lift, anti-dive, serão apresentados em função do deslocamento vertical do centro da roda.

$\mathrm{Na}$ análise do veiculo completo serão efetuadas duas manobras sendo uma de aceleração e uma de desaceleração. Considerando as ressalvas apresentadas por R. S. SHARP às simulações do veiculo completo não focaram um caso especifico. A manobra de aceleração foi feita com $40 \%$ de carga do motor em primeira marcha com velocidade inicial de zero, a manobra de desaceleração foi aplicada uma entrada rampa no sistema de freio a $120 \mathrm{~km} / \mathrm{h}$ quando o veiculo estava em quinta marcha. 


\section{Resultados e Análises}

O capitulo de resultados e análises está dividido em duas partes, sendo a primeira parte as analises das suspensões dianteira e traseira isoladas e na segunda parte as análises do veiculo completo. Na primeira parte são analisadas as características de dive, lift, squat, comprimento do equivalente trailing-arm e o ângulo do equivalente trailing-arm. Na segunda parte são analisados os deslocamentos das suspensões dianteira e traseira e os deslocamentos da massa suspensa, em aceleração e desaceleração.

\subsection{Análises das Suspensões}

Com o estudo separado do sistema de suspensão é possível verificar e determinar os prováveis problemas de projeto, antes mesmo de modelar o veiculo completo. As suspensões dianteira e traseira são analisadas para diferentes valores de anti-dive e anti-lift. Para determinar as características das suspensões foi feito o deslocamento paralelo do centro das rodas variar $30 \mathrm{~mm}$ para cima e $30 \mathrm{~mm}$ para baixo. 


\subsubsection{Dive e lift em frenagem}

Com a simulação da suspensão isolada é possível prever como será a característica do carro quando em frenagem. O gráfico 1 apresenta no eixo horizontal o deslocamento do centro da roda e no eixo vertical o deslocamento da suspensão quando o veiculo estiver freando a $1 \mathrm{~g}$ de desaceleração.

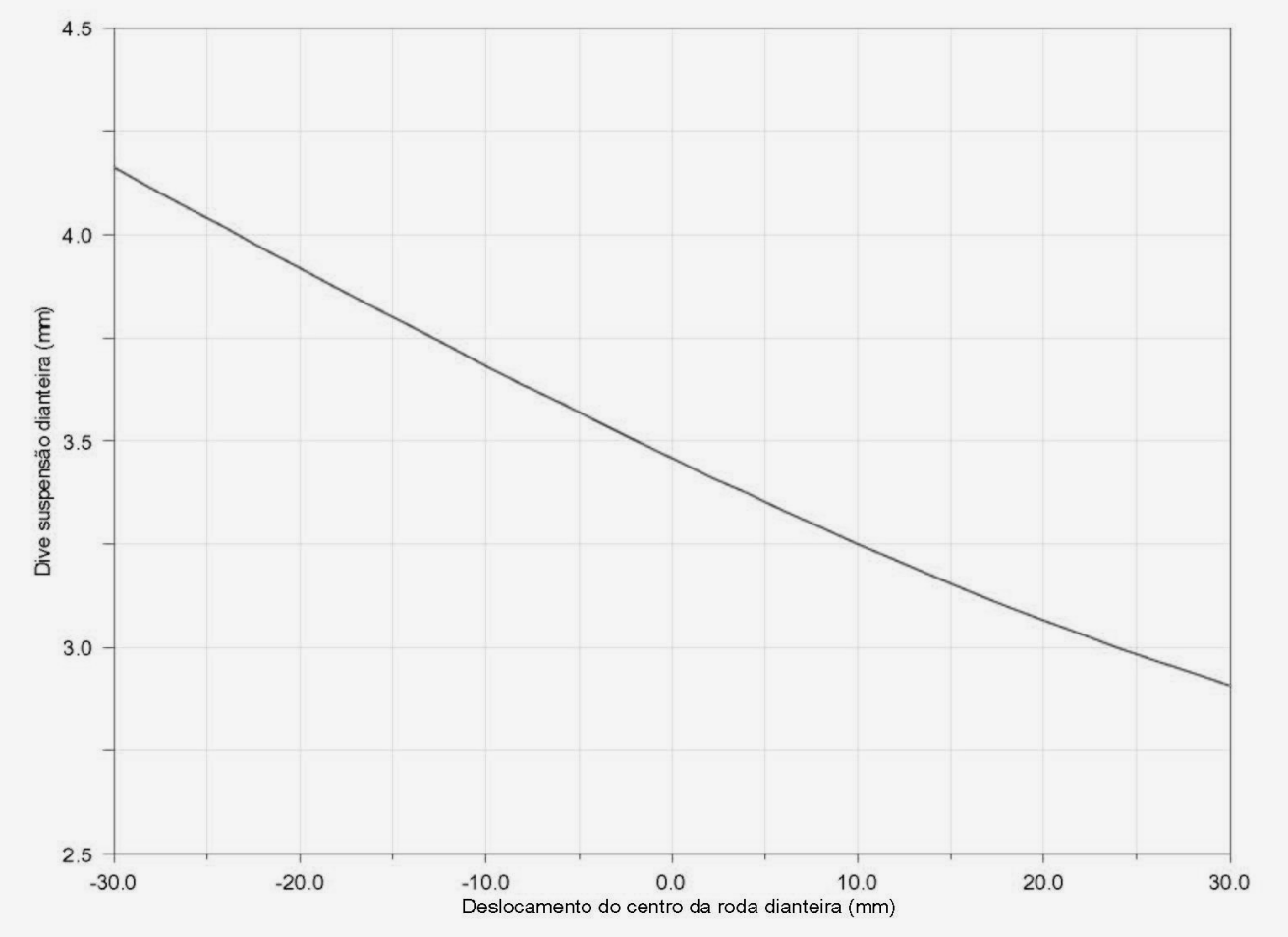

Gráfico 1. - Variação de dive na suspensão dianteira para $0 \%$ de anti-dive

Comparando os gráficos um e dois é possível verificar que com o aumento do percentual de anti-dive de $0 \%$ para $100 \%$, o deslocamento da suspensão para $1 \mathrm{~g}$ de desaceleração reduziu de aproximadamente de $3,5 \mathrm{~mm}$ para $0,105 \mathrm{~mm}$. 


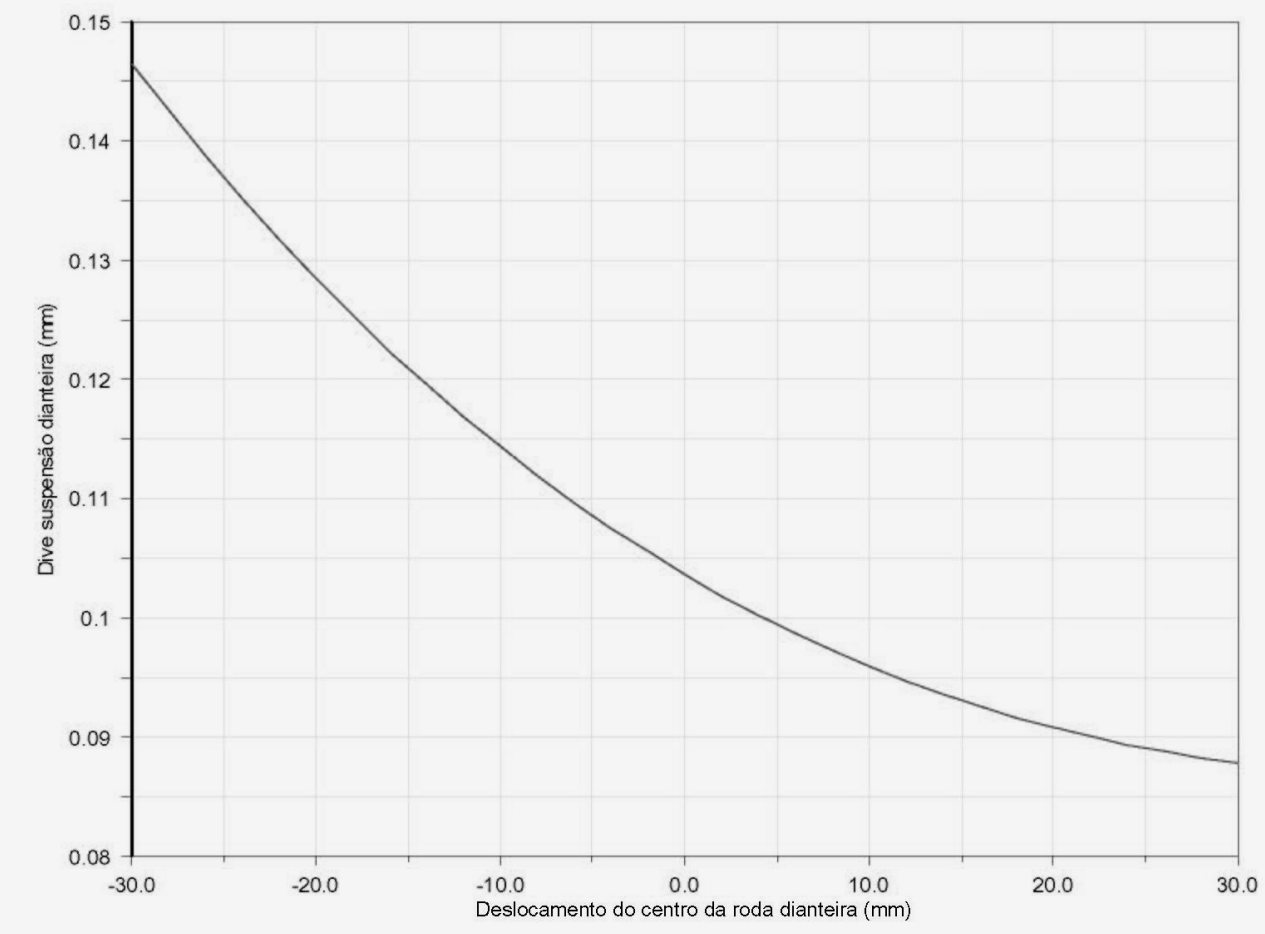

Gráfico 2- Variação de dive na suspensão dianteira para $100 \%$ de anti-dive.

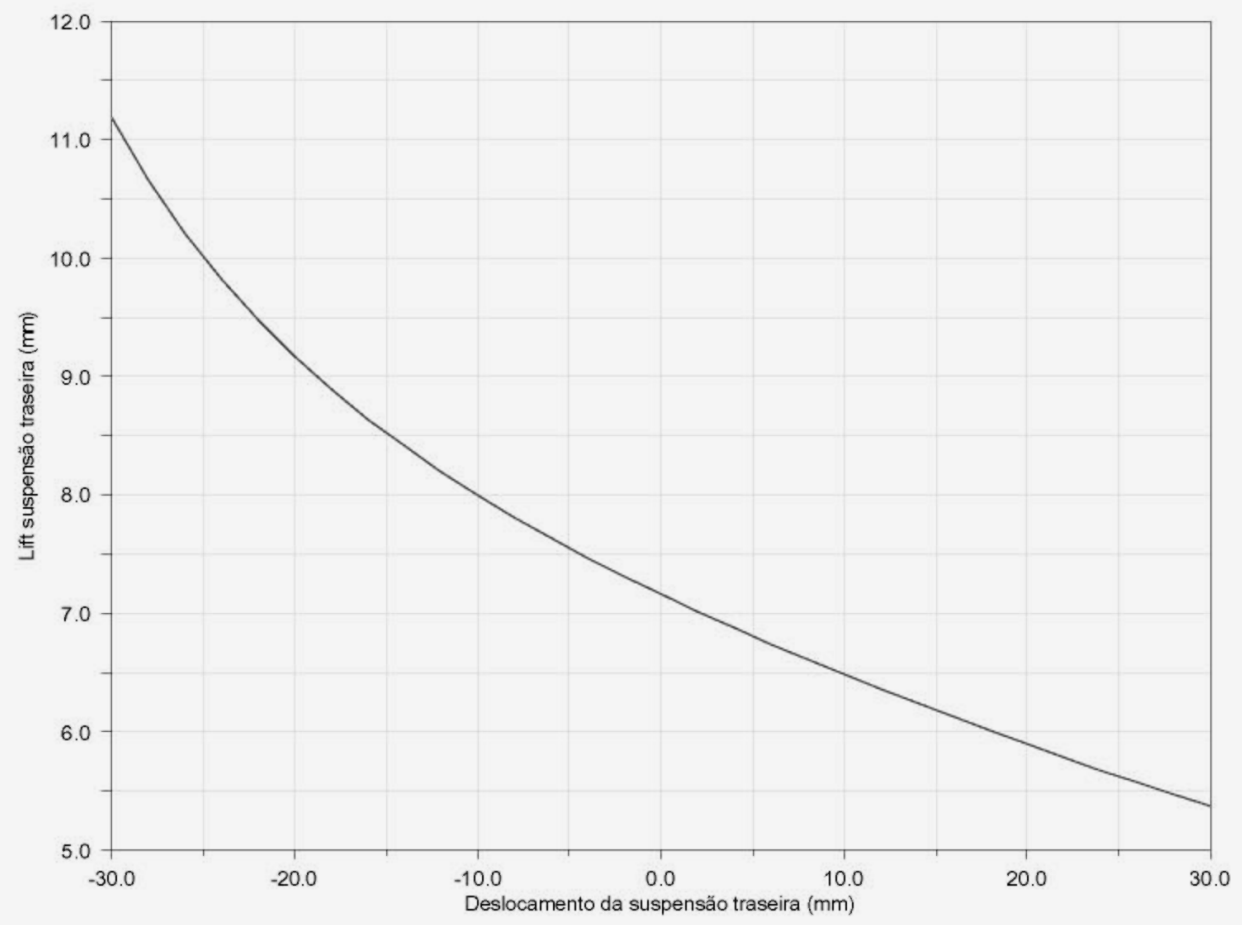

Gráfico 3- Variação de lift na suspensão traseira para $0 \%$ de anti-lift. 
No gráfico (3) é possível observar o deslocamento da suspensão traseira para $1 \mathrm{~g}$ desaceleração quando possuir $0 \%$ de percentual de anti-lift. No estudo de lift da suspensão traseira foram verificados problemas quando a suspensão possuía altos percentuais de anti-lift.

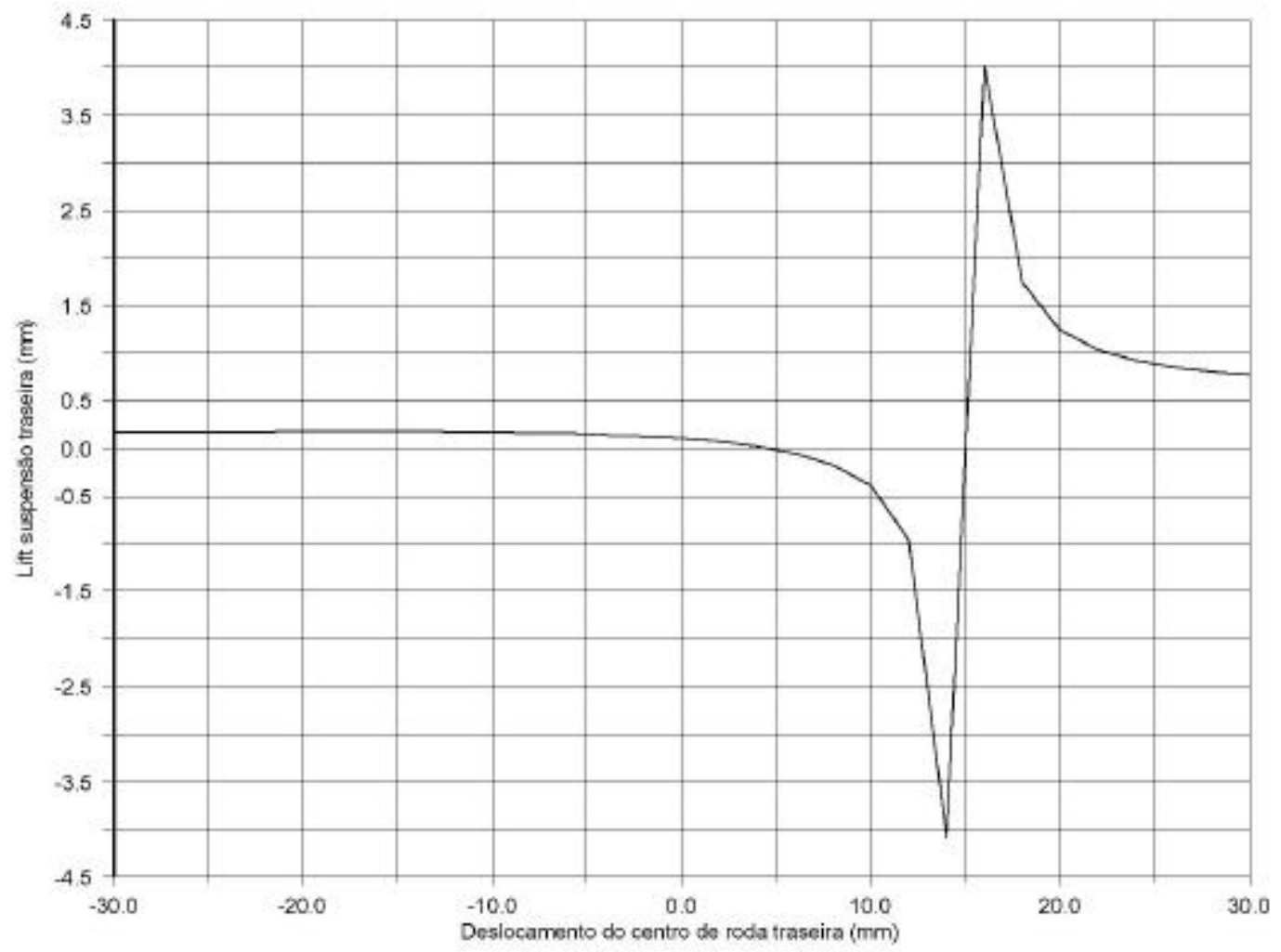

Gráfico 4- Variação de lift na suspensão traseira para $100 \%$ de anti-lift.

No gráfico (4) a suspensão possui $100 \%$ de anti-lift e apresenta uma indeterminação quando a suspensão traseira desloca em seu curso positivo, essa indeterminação pode causar diferentes reações ao veiculo e sensação de desconforto ao condutor. 


\subsubsection{Squat em aceleração}

Em aceleração será estudado somente o efeito de squat na suspensão traseira, pois não faz sentido o estudo do lift em aceleração na suspensão dianteira devido o veiculo não possui tração dianteira.

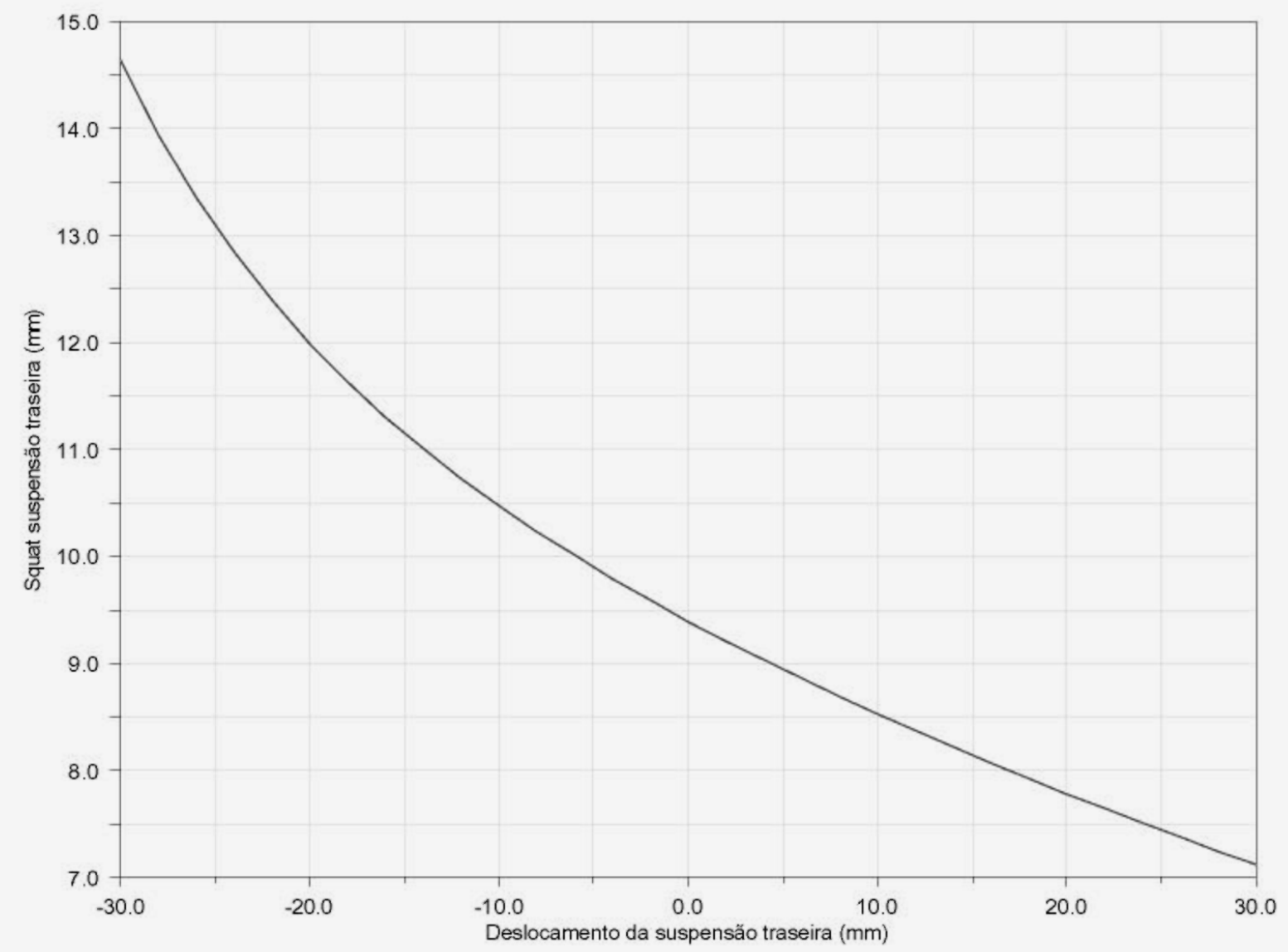

Gráfico 5- Variação de squat na suspensão traseira para $0 \%$ de anti-lift.

É possível observar o mesmo problema encontrado no estudo de lift, onde as suspensões com maior percentual de anti-squat possuem indeterminação ao longo do seu deslocamento, como mostra o gráfico (6). 


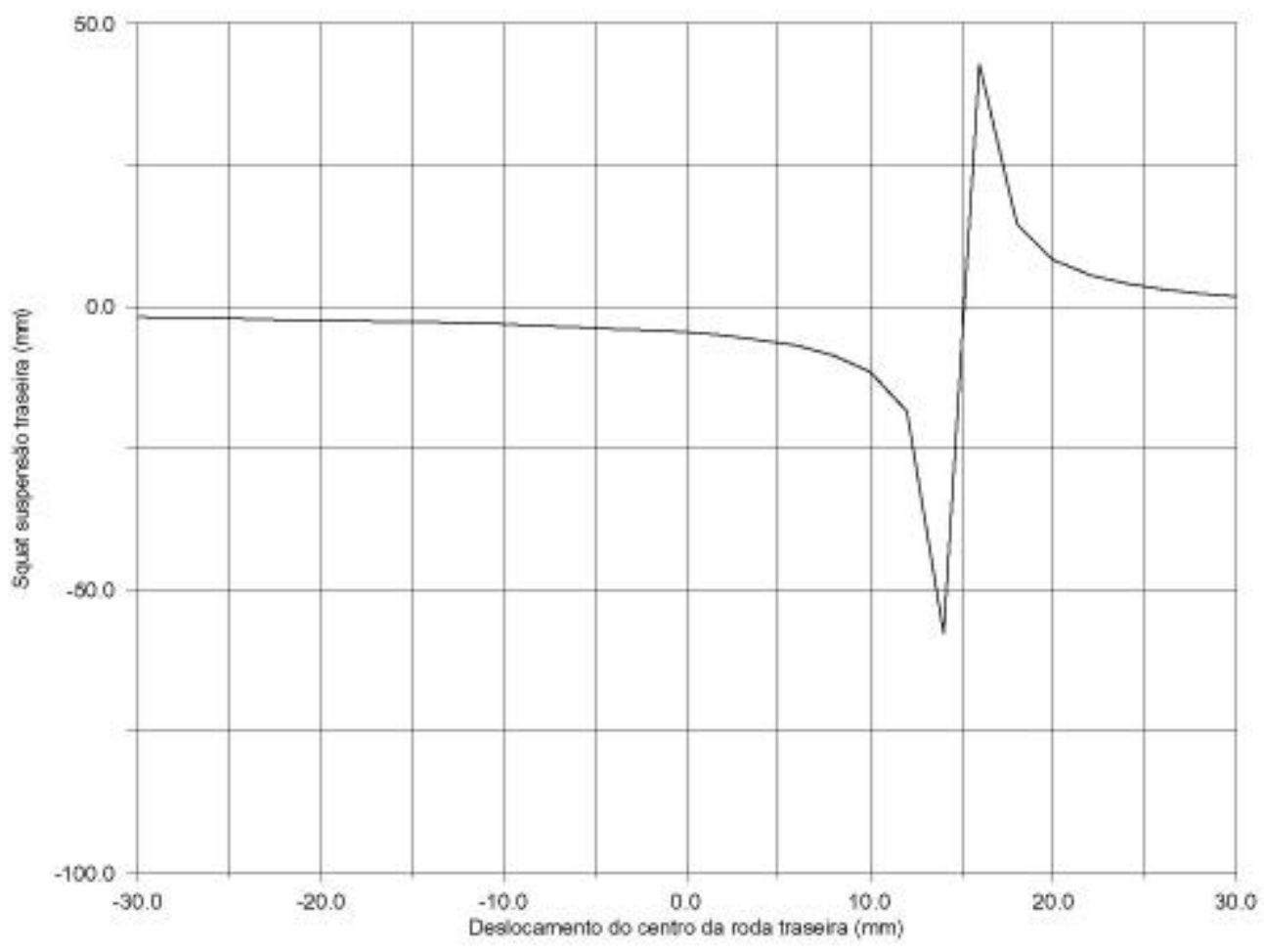

Gráfico 6- Variação de squat na suspensão traseira para $100 \%$ de anti-lift.

Procurando entender e solucionar o problema foram revisados os ângulos de suspensão e os ângulos do push-rod e foi verificado que alterando os ângulos da barra do push-rod essa indeterminação desaparecia.

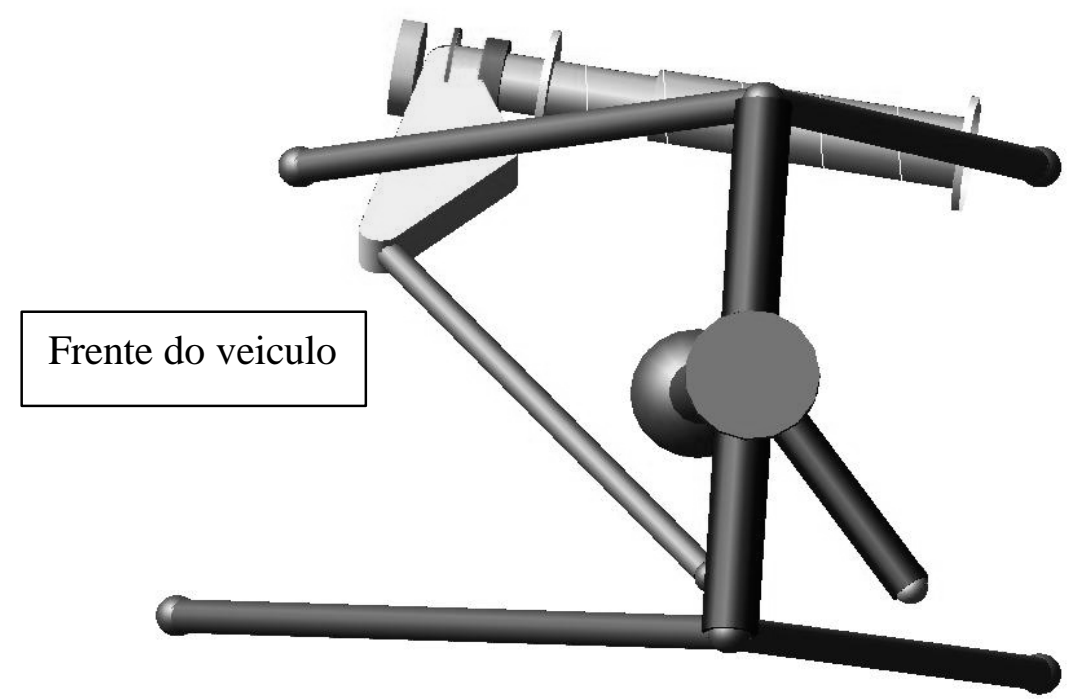

Figura 32- Sistema de suspensão push-rod antigo. 


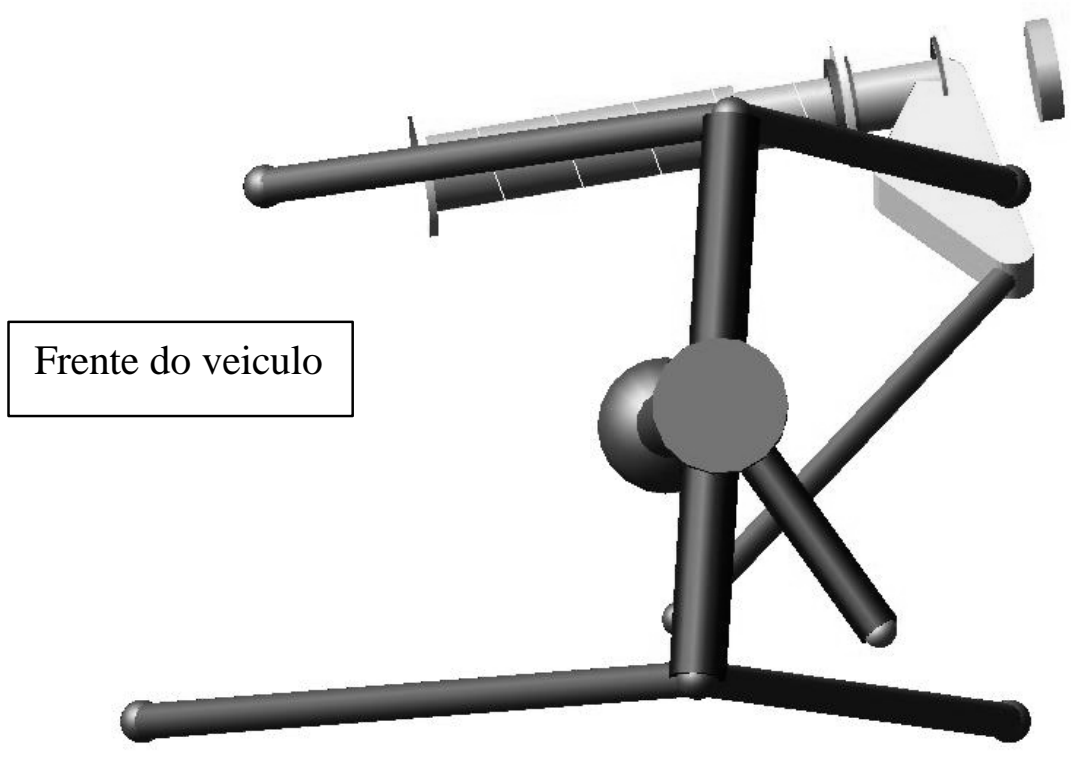

Figura 33- Sistema de suspensão push-rod novo.

Observando as figuras anteriores, o sistema de suspensão push-rod com a barra do push-rod a frente do centro da roda traseira possuía indeterminação vista nos gráficos anteriores figura (32). O problema foi resolvido passando a barra do push-rod para traz do centro da roda traseira figura (33). Cabe salientar que esse tipo de problema não é abordado pelos livros, onde somente os ângulos de suspensão em vista lateral são considerados.

Os gráficos para a nova fixação do sistema de push-rod não apresentam nenhuma indeterminação, e segue as tendências apresentadas nos livros onde com o aumento do ângulo de anti-squat ocorre à redução do deslocamento da suspensão traseira para $1 \mathrm{~g}$ de aceleração. 


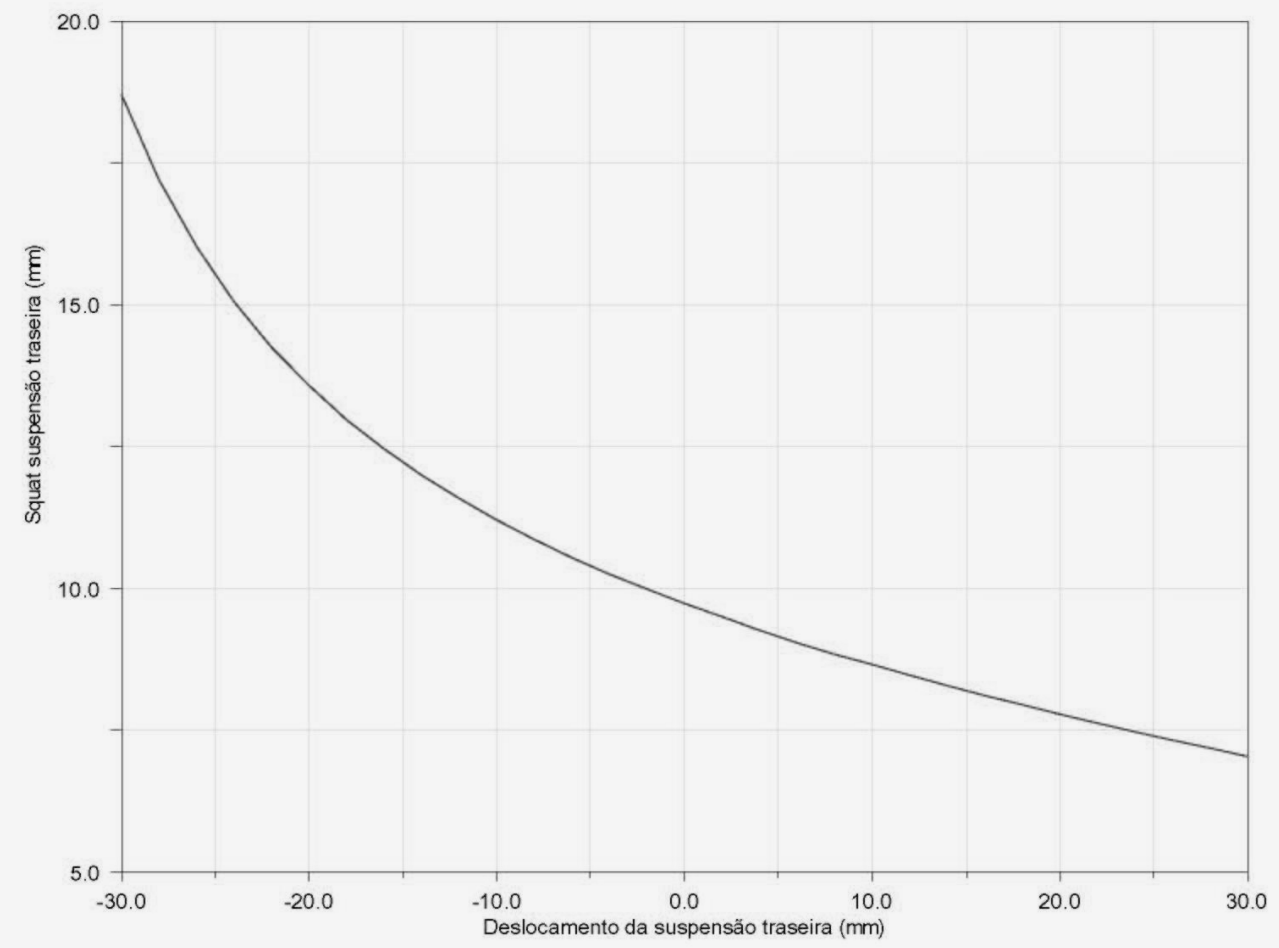

Gráfico 7- Variação de squat na nova suspensão traseira para $0 \%$ de anti-lift.

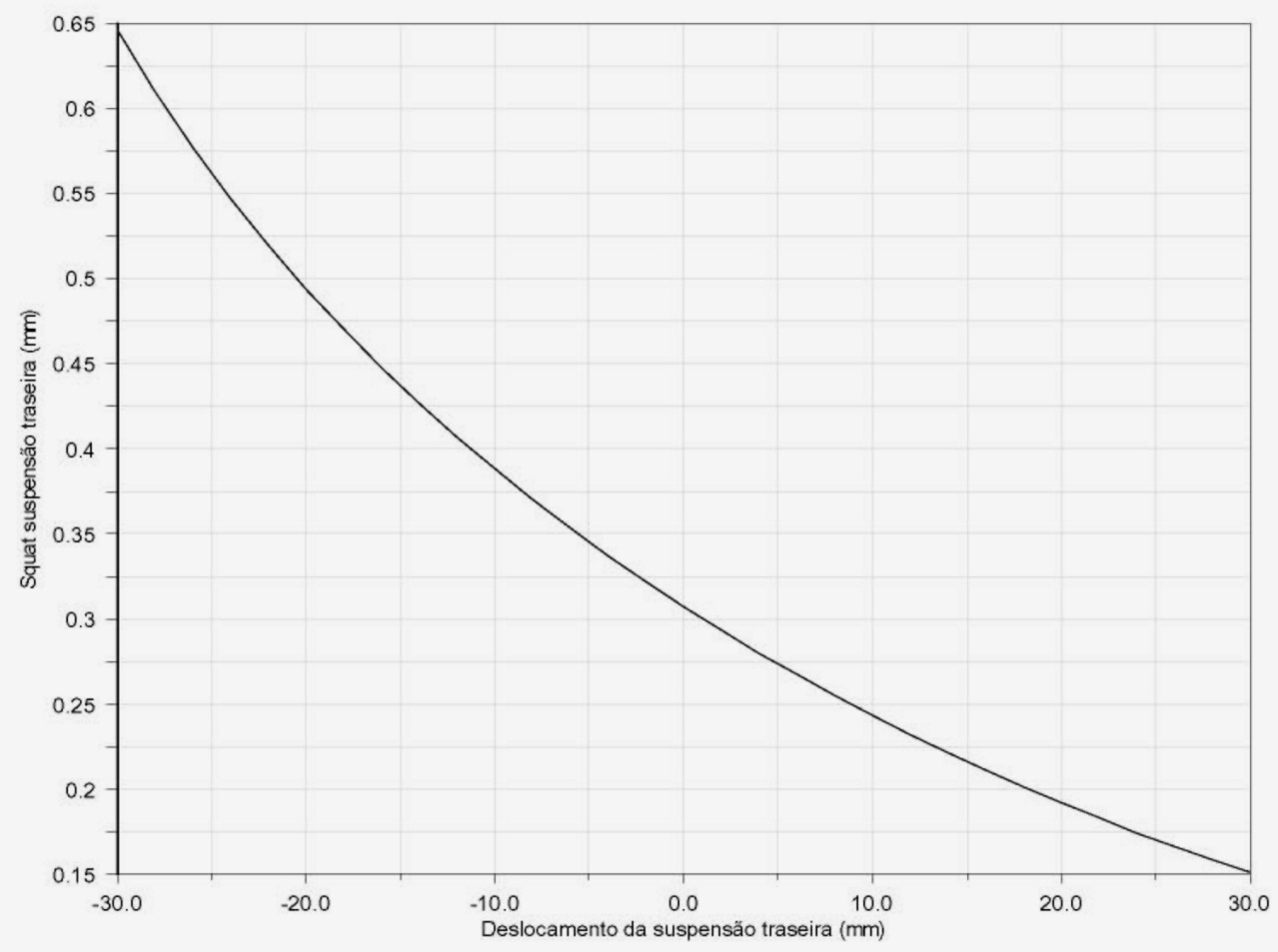

Gráfico 8- Variação de squat na nova suspensão traseira para $100 \%$ de anti-lift. 


\subsubsection{Comprimento e ângulo de equivalente trailing-arm}

Foram feitos os gráficos do comprimento e do ângulo do equivalente trailing-arm para as suspensões dianteira e traseira variando os percentuais de anti-dive e anti-lift (Anexo B). As indeterminações encontradas nos gráficos de squat, na suspensão traseira, podem ser encontradas nos gráficos do comprimento do equivalente trailing-arm. O gráfico (9), quando a suspensão traseira não possui anti-lift, não possui nenhuma indeterminação no curso da suspensão, mas quando a suspensão traseira tem um percentual de anti-lift muito alto é possível verificar uma variação muito brusca no comprimento do equivalente trailing-arm, gráfico (10).

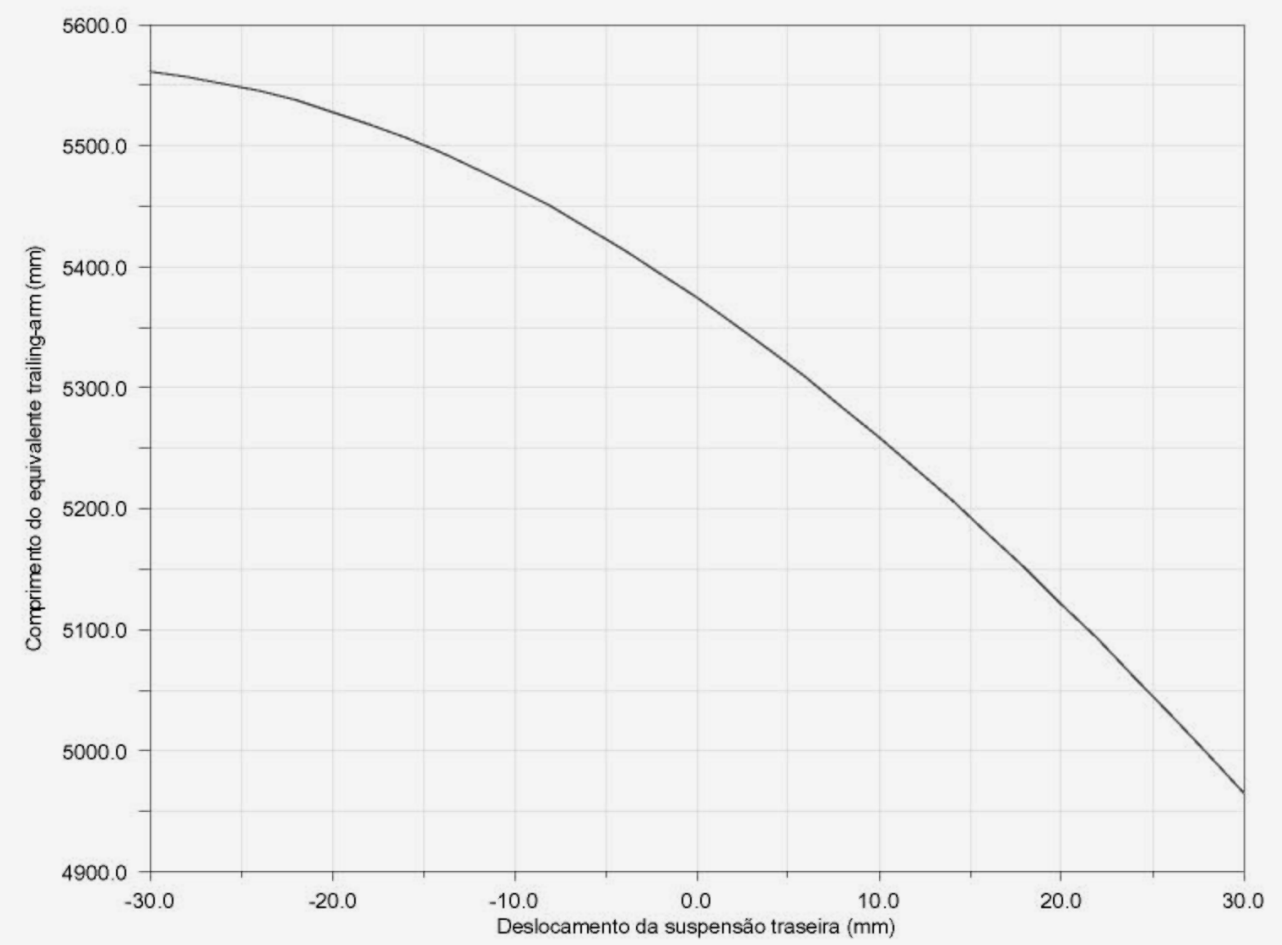

Gráfico 9- Variação do comprimento do equivalente trailing-arm para $0 \%$ de anti-lift. 


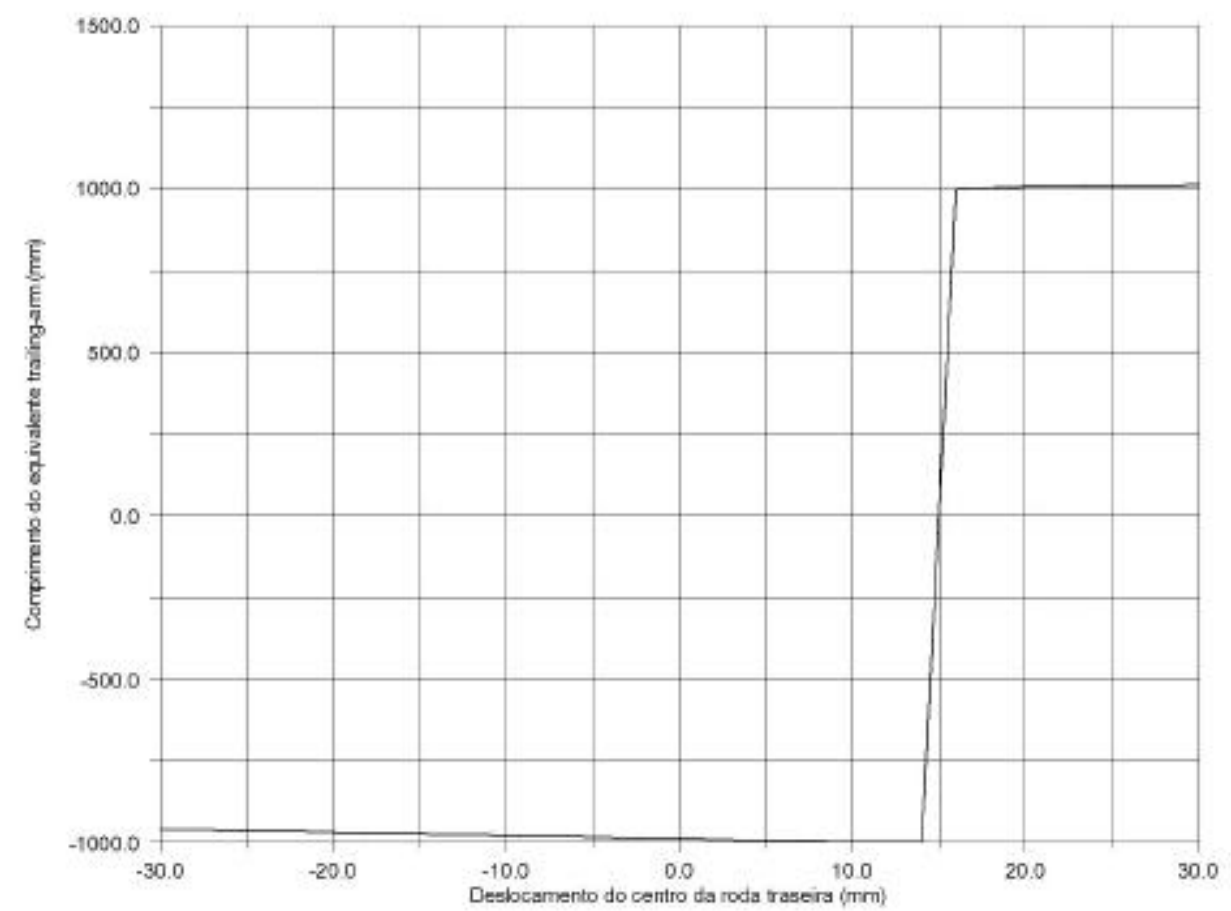

Gráfico 10- Variação do comprimento do equivalente trailing-arm para $100 \%$ de anti-lift.

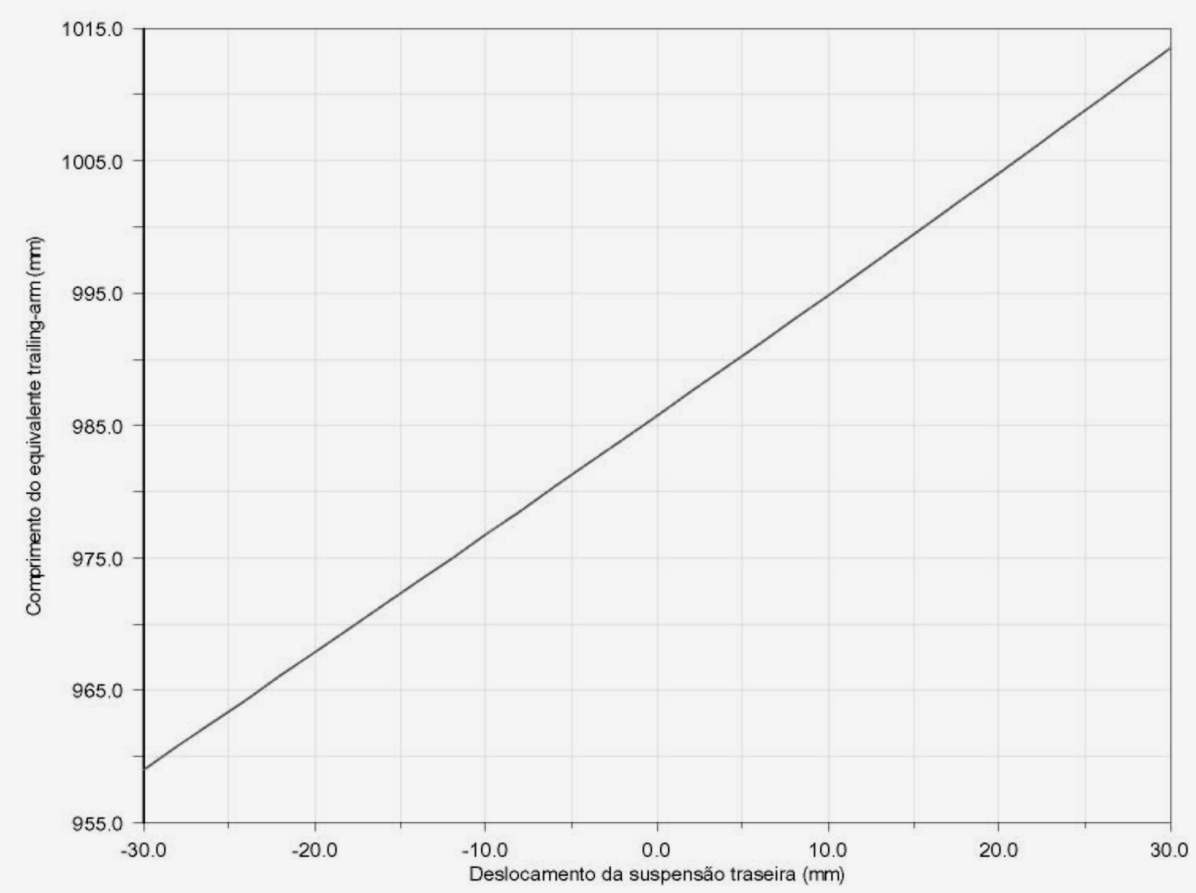

Gráfico 11- Variação do comprimento do equivalente trailing-arm para $100 \%$ de anti-lift para a nova fixação do push-rod. 
Com a alteração feita no sistema do push-rod na suspensão traseira, a mudança brusca do comprimento do equivalente trailing-arm desaparece, gráfico (11).

\subsection{Análises do Veículo Completo}

O estudo do veiculo completo foi dividido em duas partes principais onde na primeira serão apresentas os gráficos referentes aos deslocamentos da massa suspensa quando o veiculo estiver em aceleração ou desaceleração. As manobras de aceleração e de desaceleração foram escolhidas como citado no capitulo anterior.

\subsubsection{Deslocamentos da massa suspensa}

Para a massa suspensa serão analisados dois deslocamentos, angular "pitch" e o linear vertical, esses deslocamentos serão obtidos através de simulações dinâmicas. Será feito um paralelo sobre os dois tipos de suspensão traseira apresentados anteriormente. As suspensões dianteira e traseira terão o mesmo percentual de geometria, por exemplo, o modelo 50_50 tem 50\% de anti-dive na suspensão dianteira e 50\% de anti-lift na suspensão traseira.

O modelo que possui suspensão traseira com a barra do push-rod à frente do centro da roda, seus resultados em aceleração são apresentados nos gráficos 12 e 13. No gráfico 12 é possível observar que o movimento de pitch do veiculo aumenta a medida que aumenta o percentual de anti-squat indo contra aos conceitos apresentados no capitulo 3. 


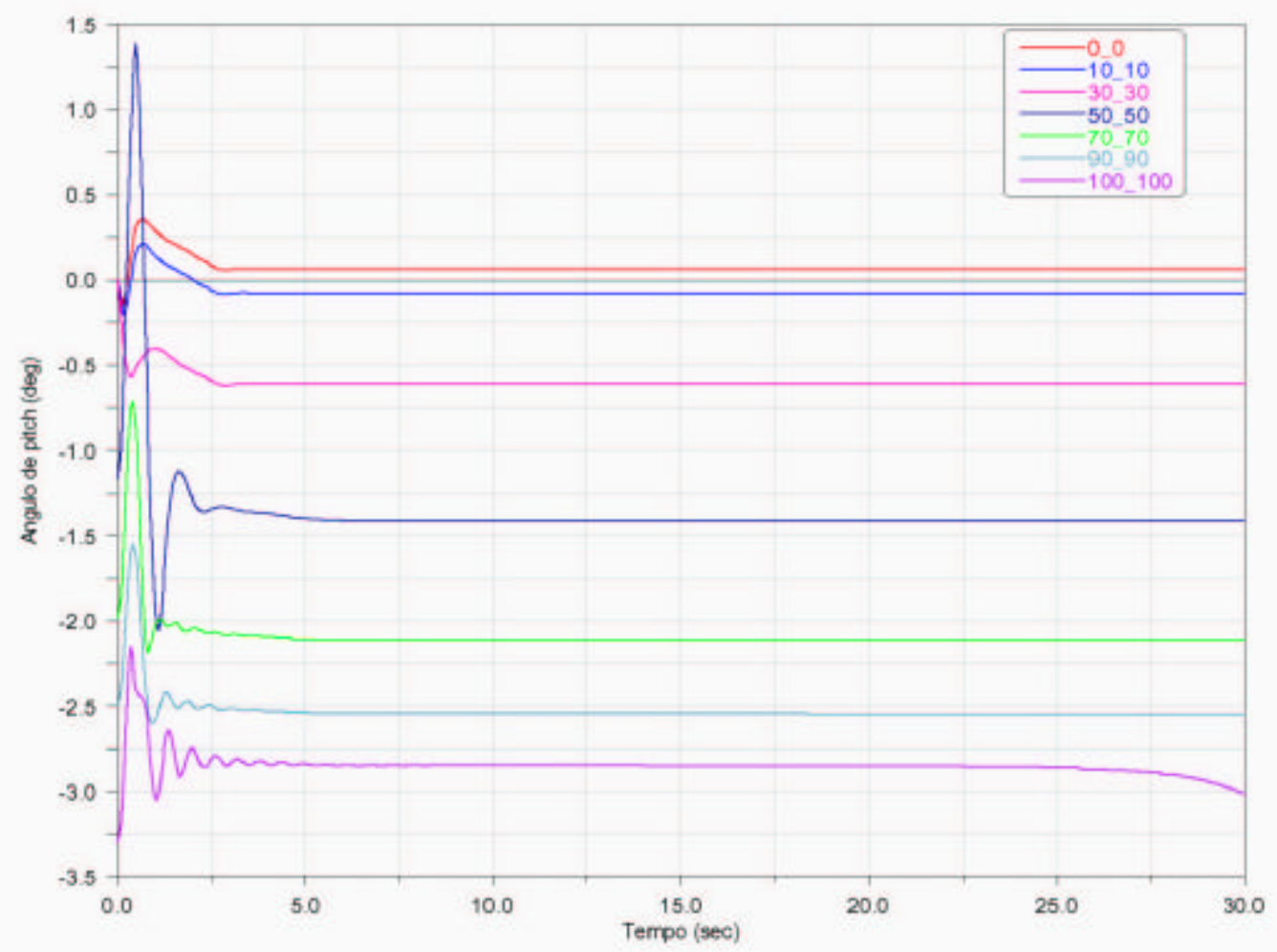

Gráfico 12 - Deslocamento angular do veiculo em aceleração.

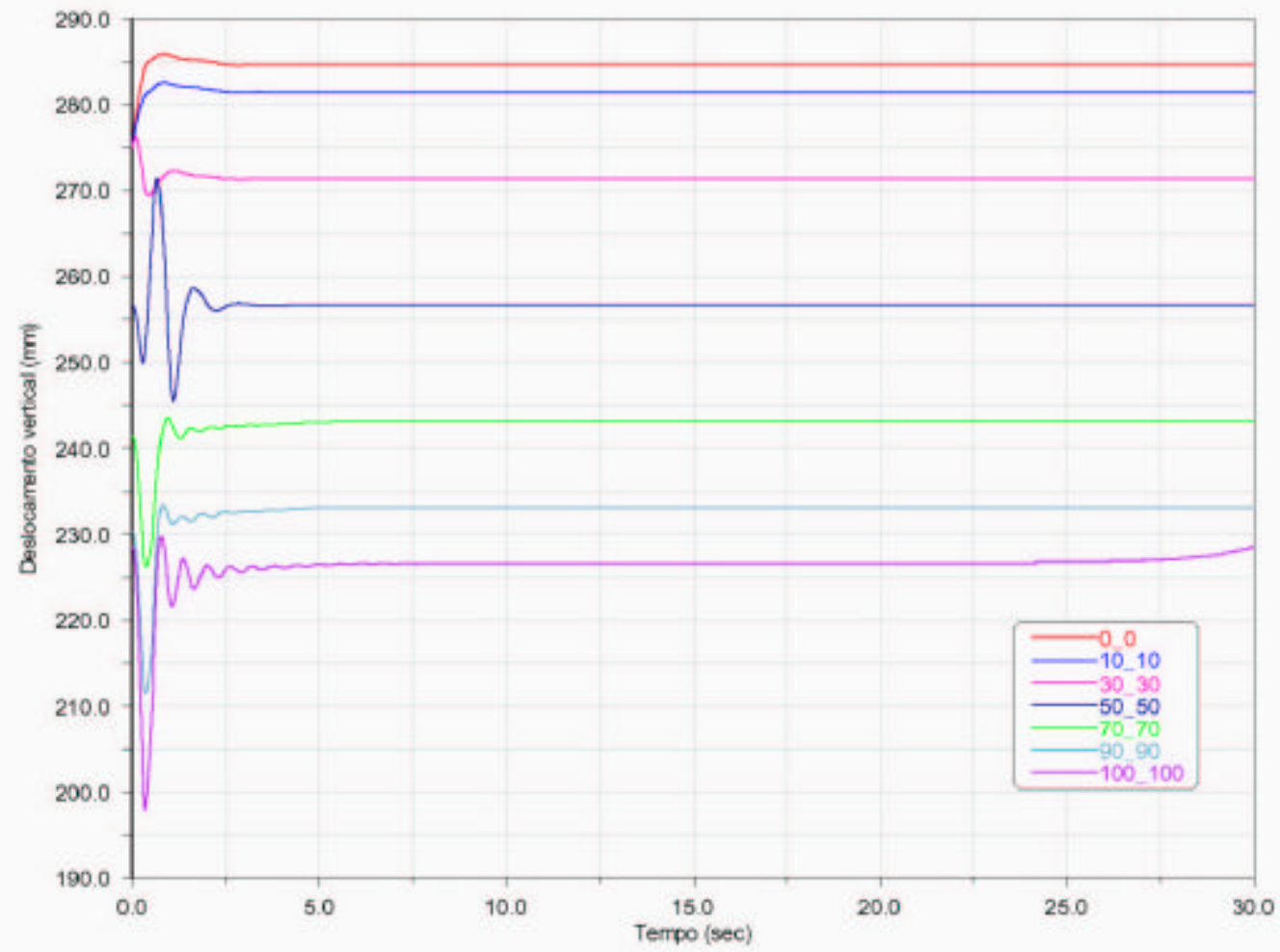

Gráfico 13 - Deslocamento vertical do veiculo em aceleração. 
No gráfico 13 é possível verificar que a distância vertical do veiculo com o solo diminui quando o percentual de anti-squat aumenta. A redução da altura do solo é provavelmente devido à compressão da suspensão traseira, essa afirmação poderá ser verificada com o estudo do deslocamento da suspensão.

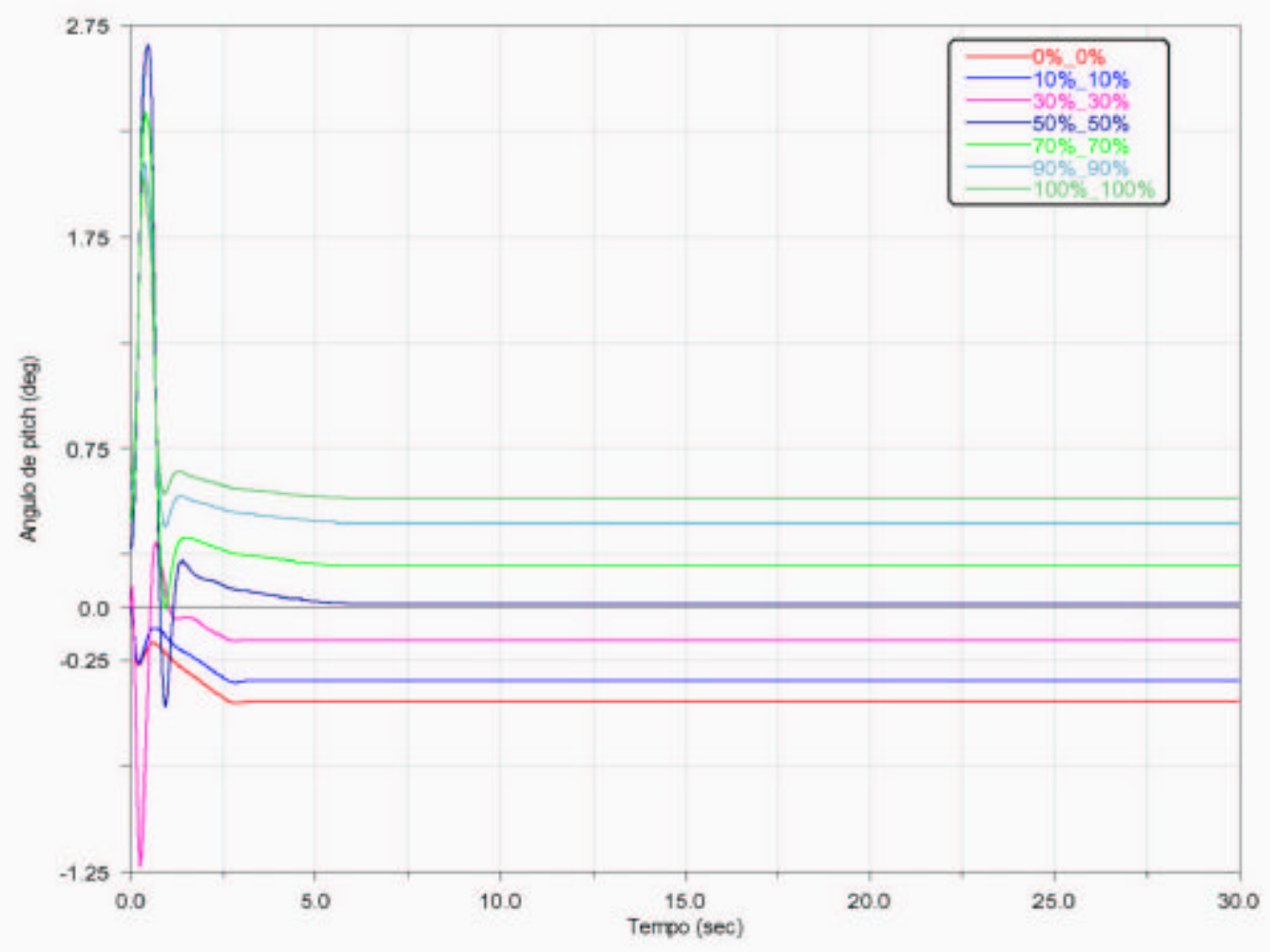

Gráfico 14- Deslocamento angular para o veiculo em aceleração com nova fixação do push-rod.

Os gráficos 14 e 15 apresentam os deslocamentos da massa suspensa para o modelo com suspensão traseira alterada, a fixação do push-rod atrás do centro da roda traseira.

Diferente do gráfico 12, o gráfico 14 apresenta as características esperadas, com o aumento do percentual de anti-squat ocorreu à redução do deslocamento angular, caracterizando a influência da suspensão traseira nos resultados encontrados. 


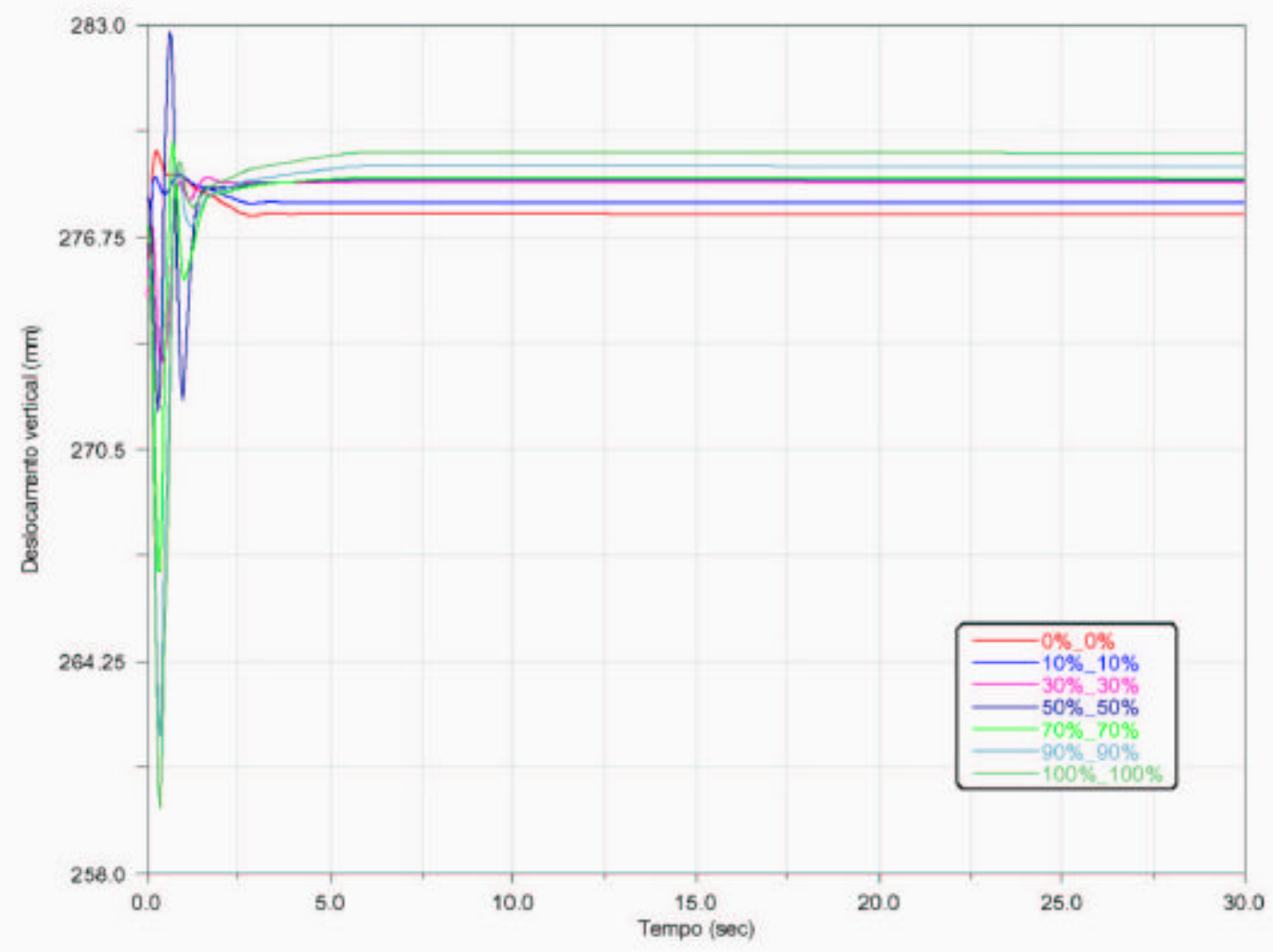

Gráfico 15 - Deslocamento angular para o veiculo em aceleração com nova fixação do push-rod.

No gráfico 15 é possível verificar as características citadas por R.S. Sharp, a medida em que é aumentado o percentual de anti-squat a massa suspensa é deslocada para cima aumentando sua distância ao solo.

Os gráficos 16 e 17 apresentam o movimento da massa suspensa para o veiculo em desaceleração, eles são referentes ao modelo com que possui a barra do push-rod à frente do centro da roda traseira.

É notável que os gráficos 16 e 17 não apresentam as características esperadas, pois ocorre o aumento no movimento angular e a redução da altura como o solo, quando a suspensão possui altos percentuais de anti-dive e anti-lift. 


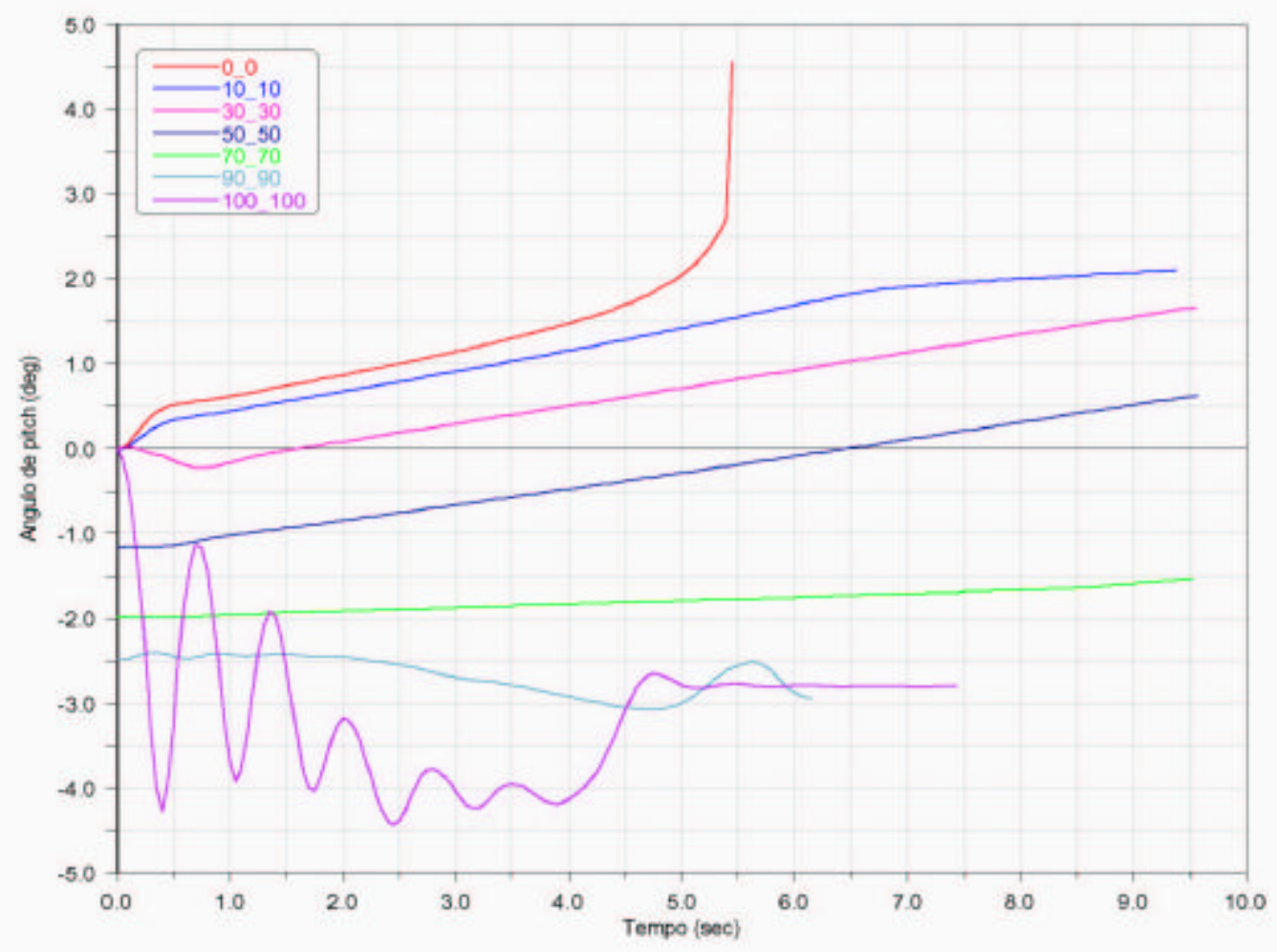

Gráfico 16 - Deslocamento angular para o veiculo em desaceleração.

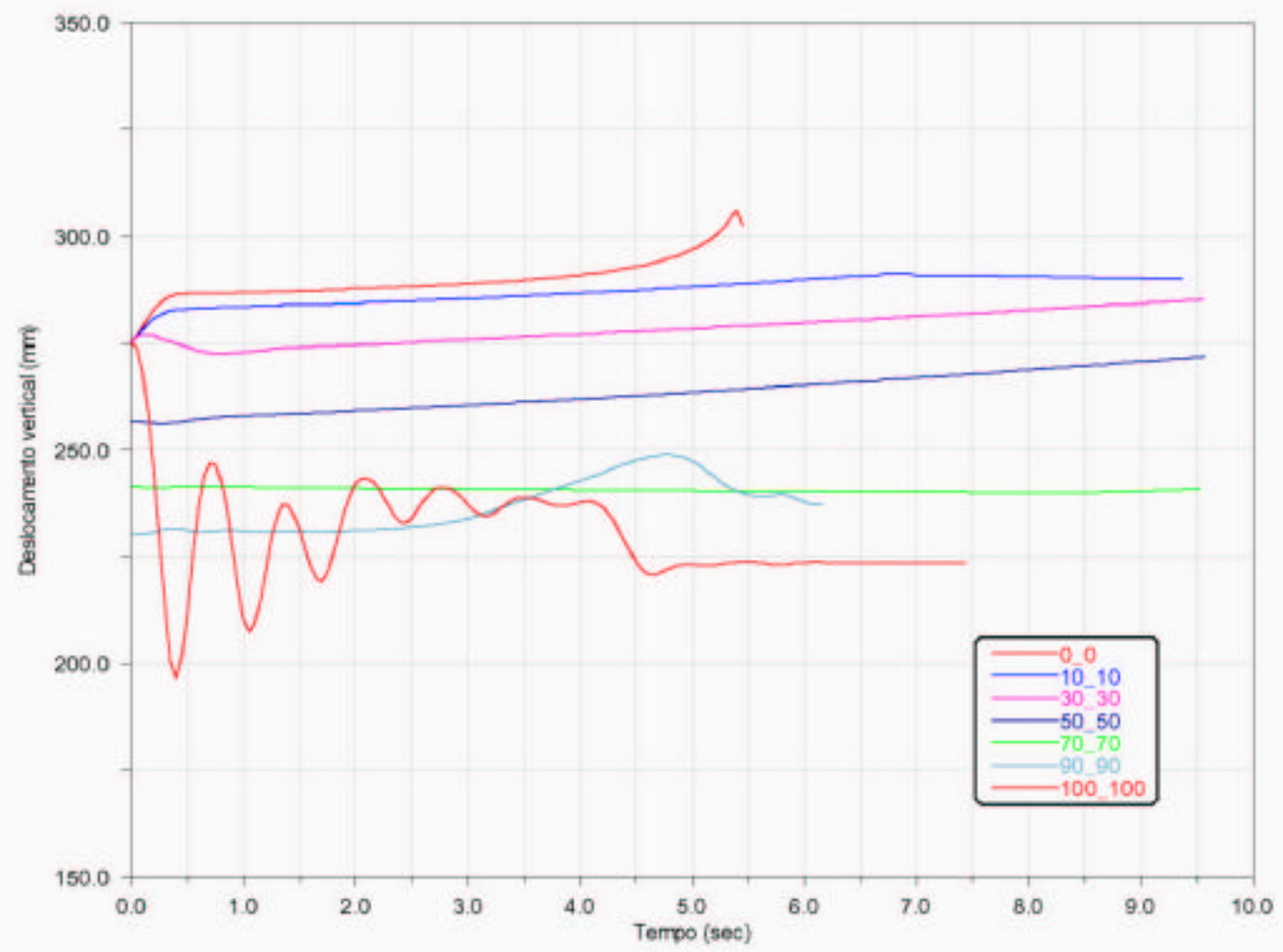

Gráfico 17 - Deslocamento vertical para o veiculo em desaceleração. 


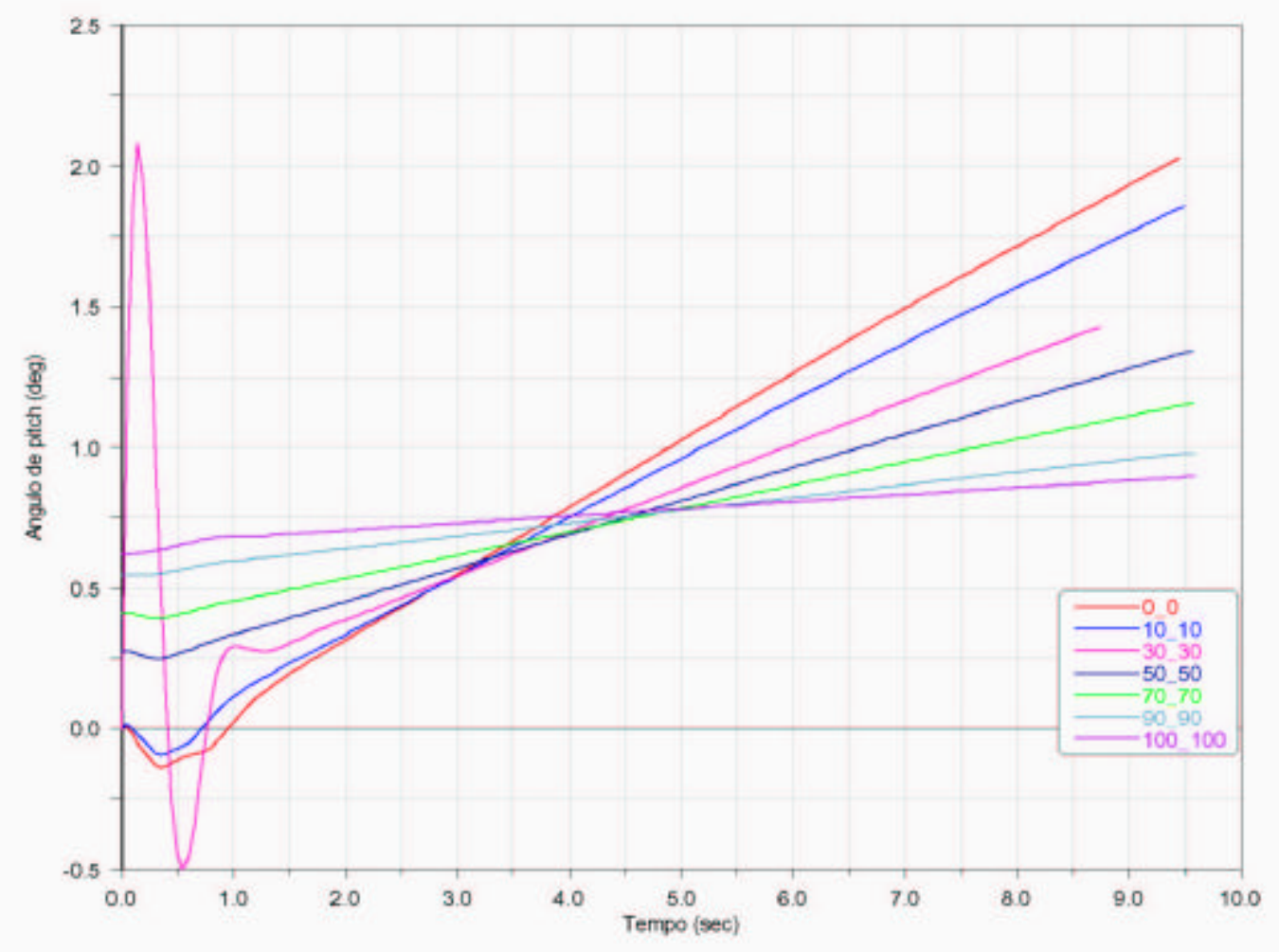

Gráfico 18- Deslocamento angular para o veiculo em desaceleração com nova suspensão.

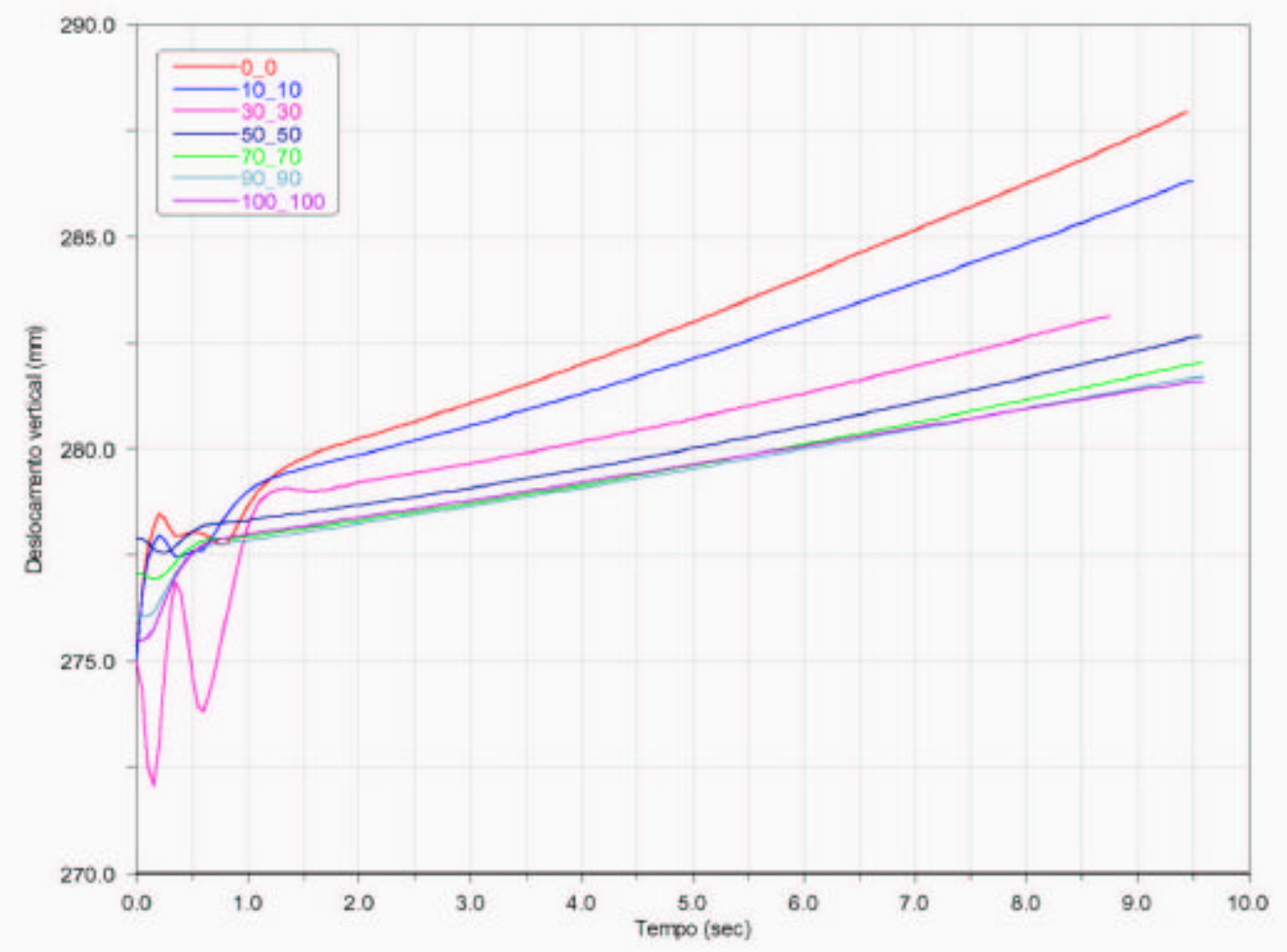

Gráfico 19- Deslocamento vertical para o veiculo em desaceleração com a nova suspensão. 
Para a nova suspensão traseira com a barra do push-rod atrás do centro da roda traseira é possível verificar que o deslocamento angular durante o tempo diminui, quando a suspensão possui altos percentuais de anti-lift. Comparando os gráficos 17 e 19 é possível verificar que com a nova fixação a variação da altura vertical torna-se muito menor.

\subsubsection{Deslocamentos das suspensões}

Alguns gráficos na parte anterior do capitulo apresentaram características diferentes das comuns, para procurar entender essa diferença uma análise do deslocamento das suspensões são feitas. Conhecendo previamente as indeterminações encontradas nos gráficos da suspensão traseira será focado seu deslocamento quando o veiculo estiver em aceleração e desaceleração.

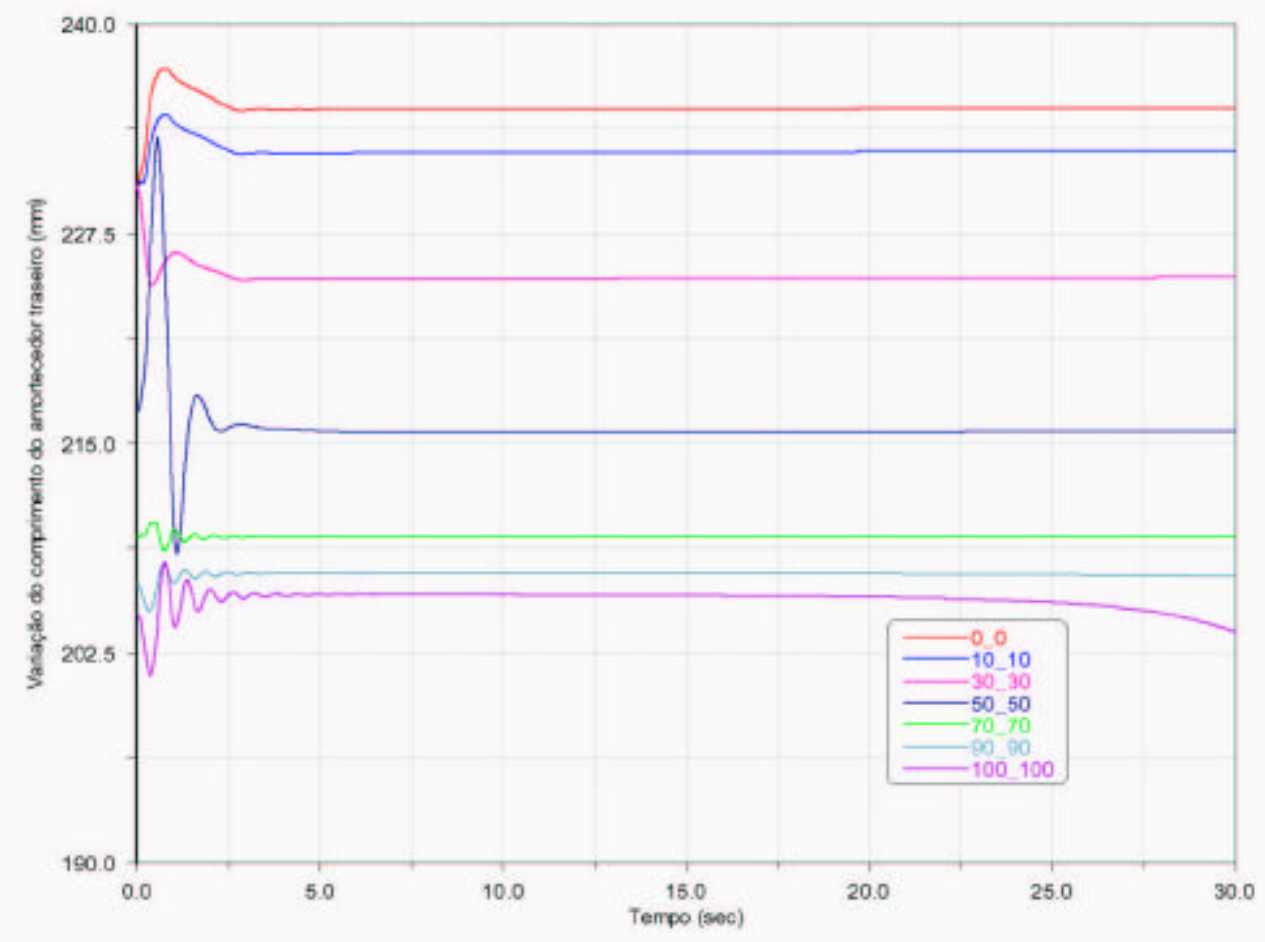

Gráfico 20 - Variação do comprimento do amortecedor traseiro em aceleração. 


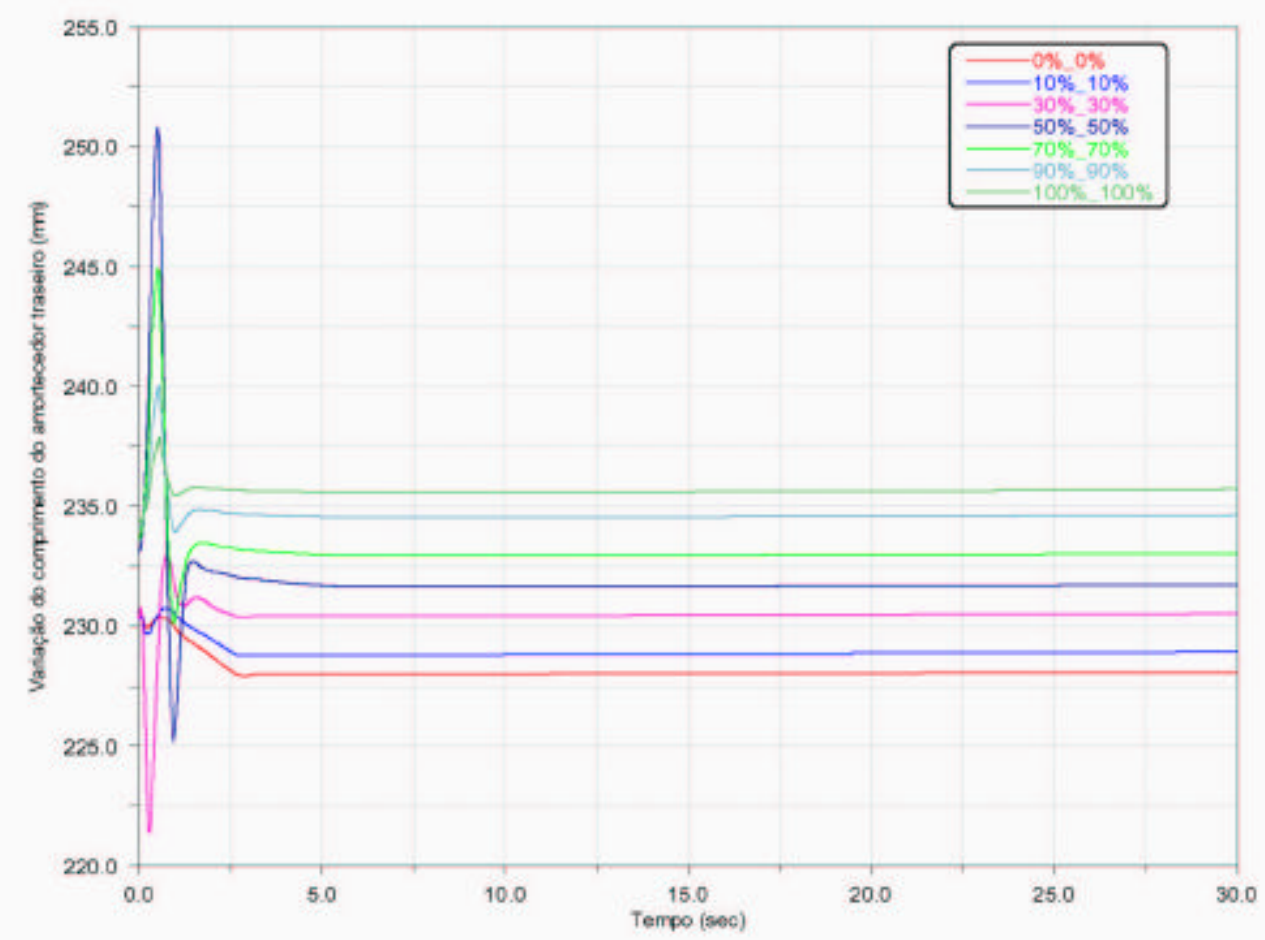

Gráfico 21 - Variação do comprimento do amortecedor traseiro em aceleração, com a nova suspensão.

No gráfico 20 é possível verificar que, a medida que o percentual de anti-squat aumenta o comprimento do amortecedor traseiro diminui. Essa característica foi observada quando foi feito o estudo da suspensão em separado, e pode explicar os gráficos 16 e 17 onde o deslocamento angular aumentava e a altura do vertical com o solo diminuía quando aumentava o percentual de anti-squat. Assim a medida que aumentava o percentual de antisquat, a suspensão traseira comprimia e assim diminuía a altura vertical com o solo e gerava um movimento angular maior.

Para a suspensão traseira com a fixação do push-rod atrás do centro da roda traseira, gráfico 21, é notável que a variação do comprimento do amortecedor traseiro é menor e que com o aumento do percentual de anti-squat sua variação é menor. 


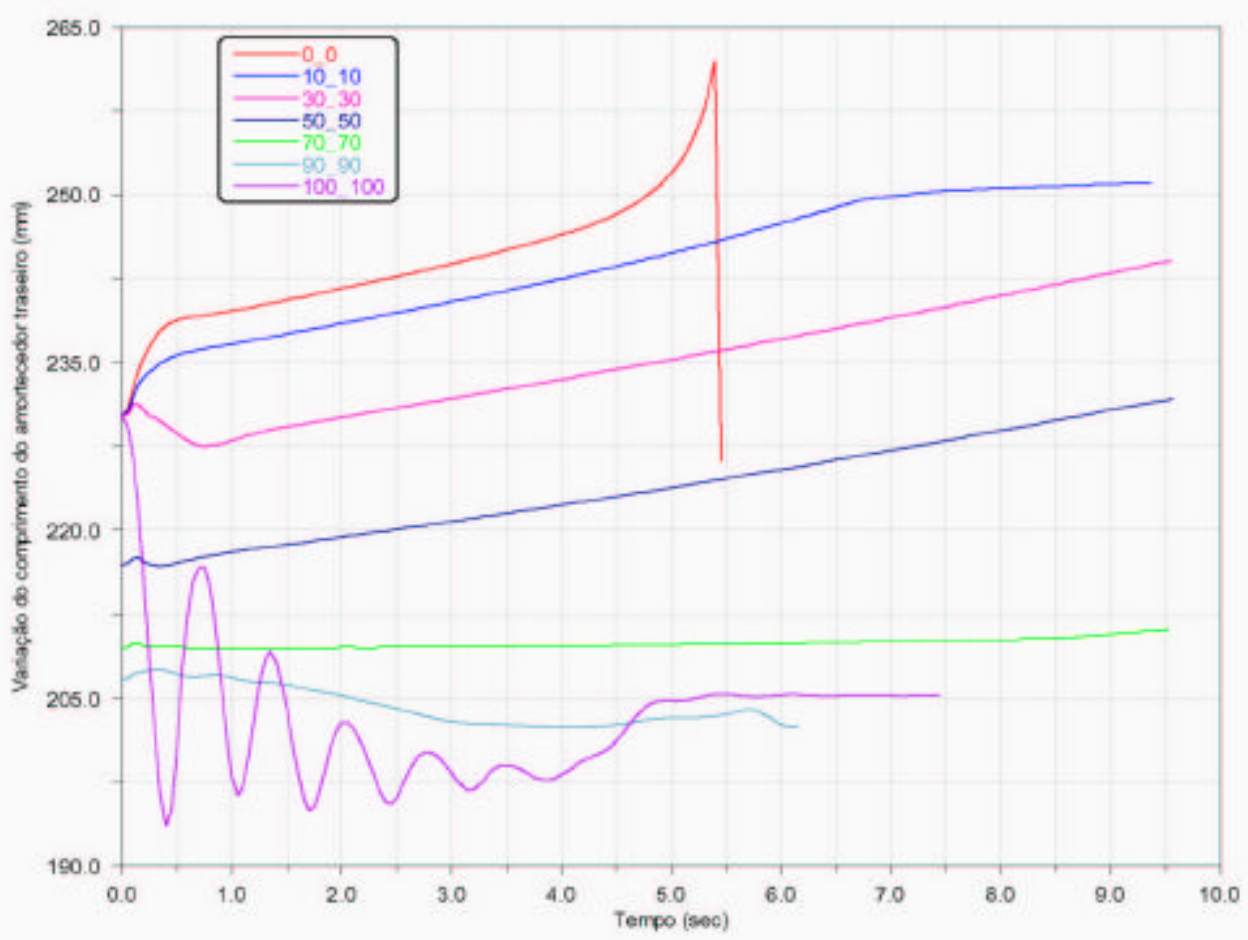

Gráfico 22 - Variação do comprimento do amortecedor traseiro em desaceleração.

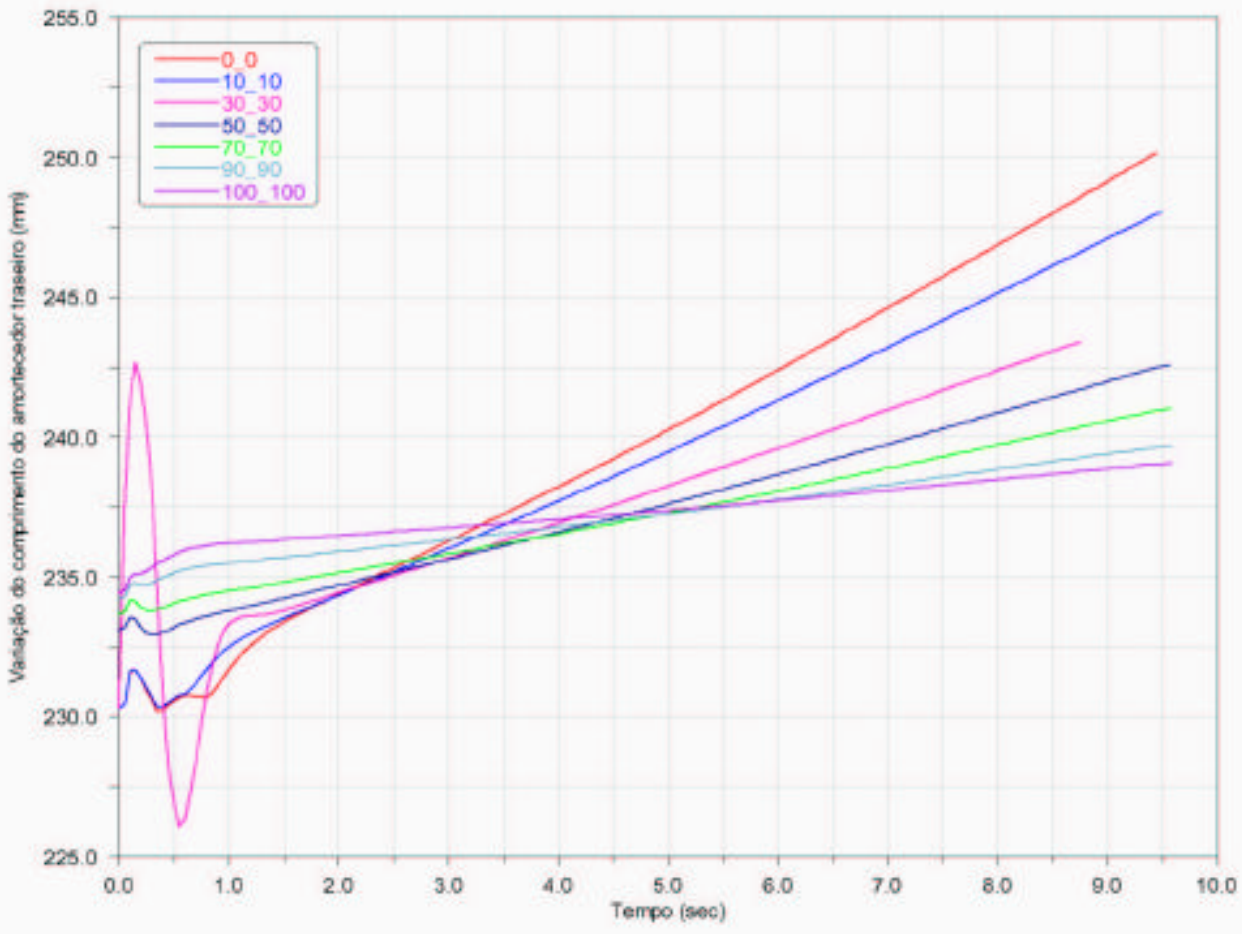

Gráfico 23 - Variação do comprimento do amortecedor traseiro em desaceleração, com a nova suspensão. 
Analisando o gráfico 22 é possível constatar uma variação muito grande no comprimento do amortecedor traseiro, e mesmo em desaceleração onde a reação da suspensão traseira seria a extensão a suspensão responde com compressão para altos percentuais de antilift.

Para o gráfico 23 é saliente a variação do comprimento do amortecedor traseiro é muito menor e que a medida em que aumenta o percentual anti-lift a variação do comprimento diminui durante a manobra. Outro ponto interessante é que no gráfico 23 por volta de dois a três segundos do tempo da manobra, todas as curvas possuem uma área em comum, que também é encontrada no movimento de pitch, gráfico 18 , por volta de três a quatro segundos da manobra. 


\section{Conclusões e Sugestões}

Após apresentar os resultados no capitulo anterior é possível verificar as falhas nas teorias apresentadas no começo do trabalho, capitulo dois. Uma análise simplificada onde somente a geometria da suspensão é estudada não atendeu as necessidades, pois quando era aumentado o percentual de anti-squat na suspensão traseira o veiculo respondia de forma inversa.

O modelo de F.W. Chang, que podem ser verificadas as características dinâmicas, não atendeu as necessidades para o estudo do veiculo, pois, a simplificação feita no modelo não permite o estudo de suspensões mais complexas, como as de veículos esportivos ou de competição.

Porém com o modelo da suspensão completo e do veiculo completo em um software de análise de multicorpos foi possível encontrar problemas não esperados e não citados, assim devido a possibilidade de possíveis problemas serem encontrados quando o veiculo possuir sistemas de suspensão mais complexos torna-se necessário o uso desse tipo de softwares.

Como continuação do trabalho seria interessante a calibração do modelo do veiculo completo no ADAMS. Outro ponto a ser estudado seria verificar em que ponto a 
fixação do push-rod em relação ao centro de giro da roda inverte o efeito de anti-squat na suspensão. E para finalizar seria interessante verificar se para veículos de passeio com suspensão convencional esses problemas podem aparecer devido a deformação dos elementos elásticos da suspensão. 


\section{Referências Bibliográficas}

ADAMS/Car Documentation User's Reference Manual - Version 12.0 (2002), Mechanical Dynamics Inc., Ann Arbor, MI, USA.

ALVARENGA, M. A. F. P.; COUTO ROSA, M. V. F. P. Apontamentos de Metodologia para a Ciência e Técnicas de Redação Científica. 2. ed. Porto Alegre: 2001. 181p.

BASTOW, D. (1993). Car suspension and handling. 3ed, Society of Automotive Engineers, ISBN 07273 0318-x.

BARBIERE, F. A. A. Prototipagem Virtual: Modelagem, Simulação, Controle e Otimização de Dinâmica Veicular.(2002) Tese (Doutorado) Universidade de Engenharia de São Carlos USP.

CANALE, A. C. (1989) Automobilística: Dinâmica e Desempenho. São Paulo. Ed. Érica.

CANALE, A. C.; RUFFINO, R. T. (1992) A study of the braking performance of road vehicles using the "static equilibrium" or "center of gravity range" technique. SAE technical paper 921438. 
COSTA NETO, A. (1991). Application of multibody system (MBS) techniques to automotive vehicle chassis simulation for motion control studies. Tese (Doutorado). Universidade de Warwick, Inglaterra.

COSTA NETO, A. (1994). Dinâmica Veicular. Notas de aula. Escola de Engenharia de São Carlos, Universidade de São Paulo, São Carlos.

CRAHAN, T. C. Modeling Steady-State Suspension Kinematics an Vehicles Dynamics of Road Racing Cars - Part I: Theory and Methodology. Motor Sport Engineering Conference Proceedings. v. 1, n. 942505, p.179-212, dec. 1994.

CRAHAN, T. C. Modeling Steady-State Suspension Kinematics an Vehicles Dynamics of Road Racing Cars - Part II: Examples. Motor Sport Engineering Conference Proceedings. v. 1, n. 942506, p.213-234, dec. 1994.

CUNHA, R. H. (1998). Modelagem e análise da dinâmica longitudinal de veículos automotivos. Dissertação (Mestrado). Universidade de Engenharia de São Carlos - USP.

CUNHA, R. H. (1994). Modelagem de sistema de freio de veículo automotivo, baseado em programa computacional já existente. São Carlos. Relatório (Iniciação Científica) - Escola de Engenharia de São Carlos, Universidade de São Paulo.

CUNHA, R. H. (1995a). Modelagem de sistema de freio de veículo automotivo, baseado em programa computacional já existente. São Carlos. Relatório (Iniciação Científica) - Escola de Engenharia de São Carlos, Universidade de São Paulo. 
CUNHA, R. H. (1995b). Modelagem de sistema de freio de veículo automotivo, baseado em programa computacional já existente. São Carlos. Relatório (Iniciação Científica) - Escola de Engenharia de São Carlos, Universidade de São Paulo.

DIXON, J.C. (1996). Tires, suspension and handling. 2 ed., Society of Automotive Engineers, ISBN 1-56091-831-4.

DOEBELIN, E. O. (1980). System Modeling and Response Theoretical and Experimental Approaches. 1ed., John Wiley \& Sons, Inc, ISBN 0471 03211-5.

GILLESPIE, T. (1992). Fundamentals of vehicle dynamics. Warrendale: Society of Automotive Engineers, ISBN 1-56091-199-9.

LEE, S.; CHRSTOS, J. P.; GUENTHER, D.A. (1995) Modeling of Dynamics Characteristics of Tire Lateral and Longitudinal Forca Responses to Dynamics Inputs. SAE technical paper 950314.

MCGUIRE, M. K.; GUENTHER D. A. (1993) Longitudinal Suspension Compliance Modeling with ADAMS. SAE technical paper 930764.

MILLIKEN, W.F.; MILLIKEN, D.L. (1995). Race car vehicle dynamics. Society of Automotive Engineers, ISBN 1-56091-526-9. 
PRADO, M. Desenvolvimento de um modelo não linear de três graus de liberdade para a análise da dinâmica lateral de um ônibus com suspensão a ar.(2003) Tese (Doutorado) Universidade de Engenharia de São Carlos - USP.

REIMPELL, J. (2001). The automotive chassis: engineering principles. 2 ed., Society of Automotive Engineers, ISBN 0768006570.

SHARP R. S. Influences of Suspension Kinematics on Pitching Dynamics of Cars in Longitudinal Maneuvering. Vehicle System Dynamics Supplement, v.1, n.33, p.23-36, 1999.

SOHN, H. S.; LEE, S. C.; SUH, M. W.; SONG, Y. M. (1994) The Influences of Chassis Geometric Characteristics on Vehicle Dynamics Performance.

TABOREK, J. J. (1957). Mechanics of Vehicles. Cleveland, Tow motor Corp.

WANG F. C. (2001). Design and Synthesis of Active and Passive Vehicle Suspensions. Tese (Doutorado). University of Cambridge. 


\section{Anexos}

\section{A.1 Desenvolvimento do modelo trailing-arm}

\section{A.1.1 Geometria Anti-squat (freio Inboard)}

Para o desenvolvimento do modelo são adotadas as seguintes coordenadas, figura (12).

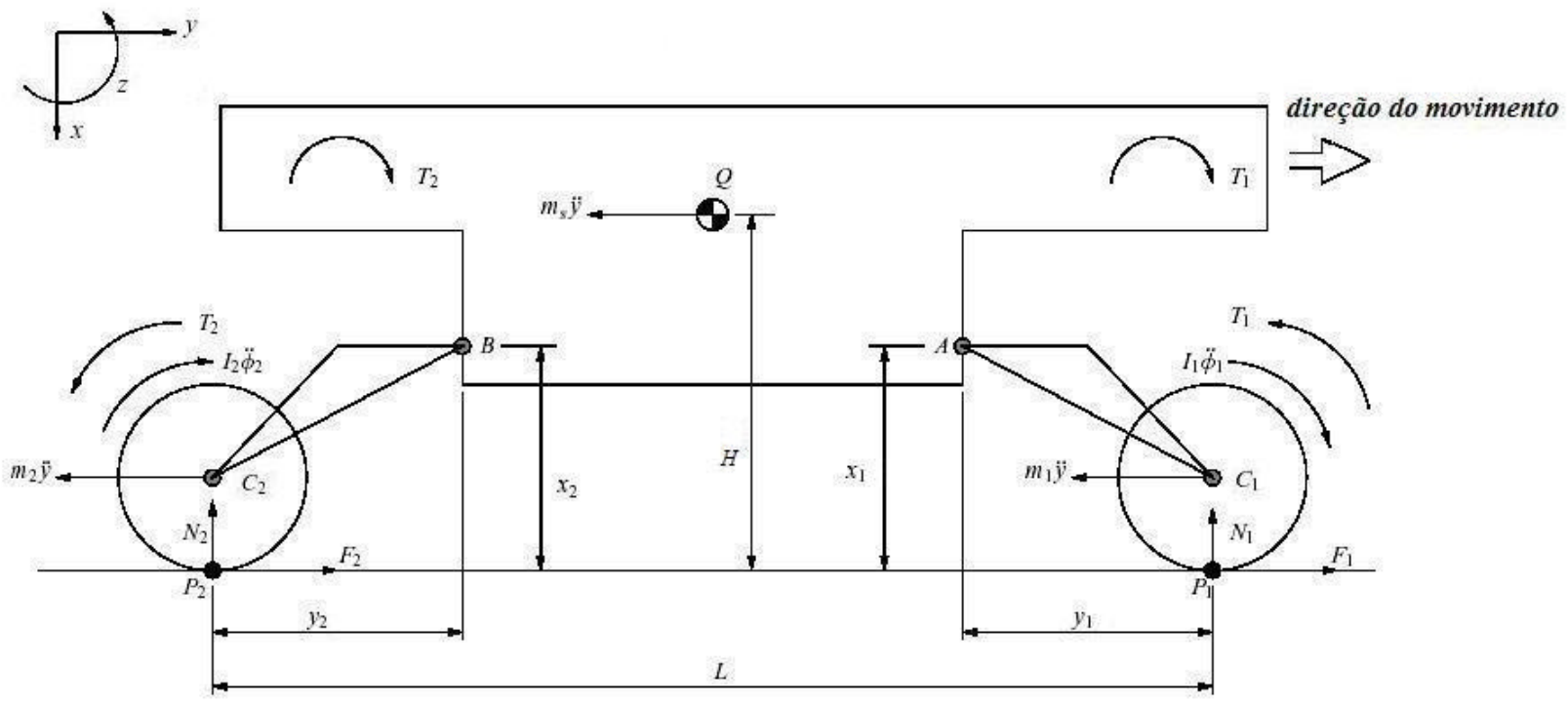

Figura 34 - Coordenadas do modelo trailing-arm. 
Referente a figura (12) deixe $Q=x \vec{x}+y \vec{y}$ em relação ao sistema fixo de coordenada, aonde $\vec{x}$ e $\vec{y}$ são vetores unidades paralelos ao eixo de coordenadas. Assim é possível escrever a coordenada de alguns pontos:

$$
\begin{gathered}
A=\left(x+\left(H-x_{1}\right) \cos \phi_{3}-a \sin \phi_{3}\right) \vec{x}+\left(y+\left(H-x_{1}\right) \sin \phi_{3}+a \cos \phi_{3}\right) \vec{y} \\
B=\left(x+\left(H-x_{2}\right) \cos \phi_{3}+b \sin \phi_{3}\right) \vec{x}+\left(y+\left(H-x_{2}\right) \sin \phi_{3}-b \cos \phi_{3}\right) \vec{y} \\
C_{1}=\left(x+\left(H-x_{1}\right) \cos \phi_{3}-a \sin \phi_{3}+l_{4} \cos \phi_{4}\right) \vec{x}+\left(y+\left(H-x_{1}\right) \sin \phi_{3}+a \cos \phi_{3}+l_{4} \sin \phi_{4}\right) \vec{y}(\mathrm{~A} \\
C_{2}=\left(x+\left(H-x_{2}\right) \cos \phi_{3}+b \sin \phi_{3}+l_{5} \cos \phi_{5}\right) \vec{x}+\left(y+\left(H-x_{2}\right) \sin \phi_{3}-b \cos \phi_{3}-l_{5} \sin \phi_{5}\right) \vec{y}(\mathrm{~A}
\end{gathered}
$$

Analisando o diagrama de corpo livre, figura (13), é possível escrever as equações de movimento para cada elemento.

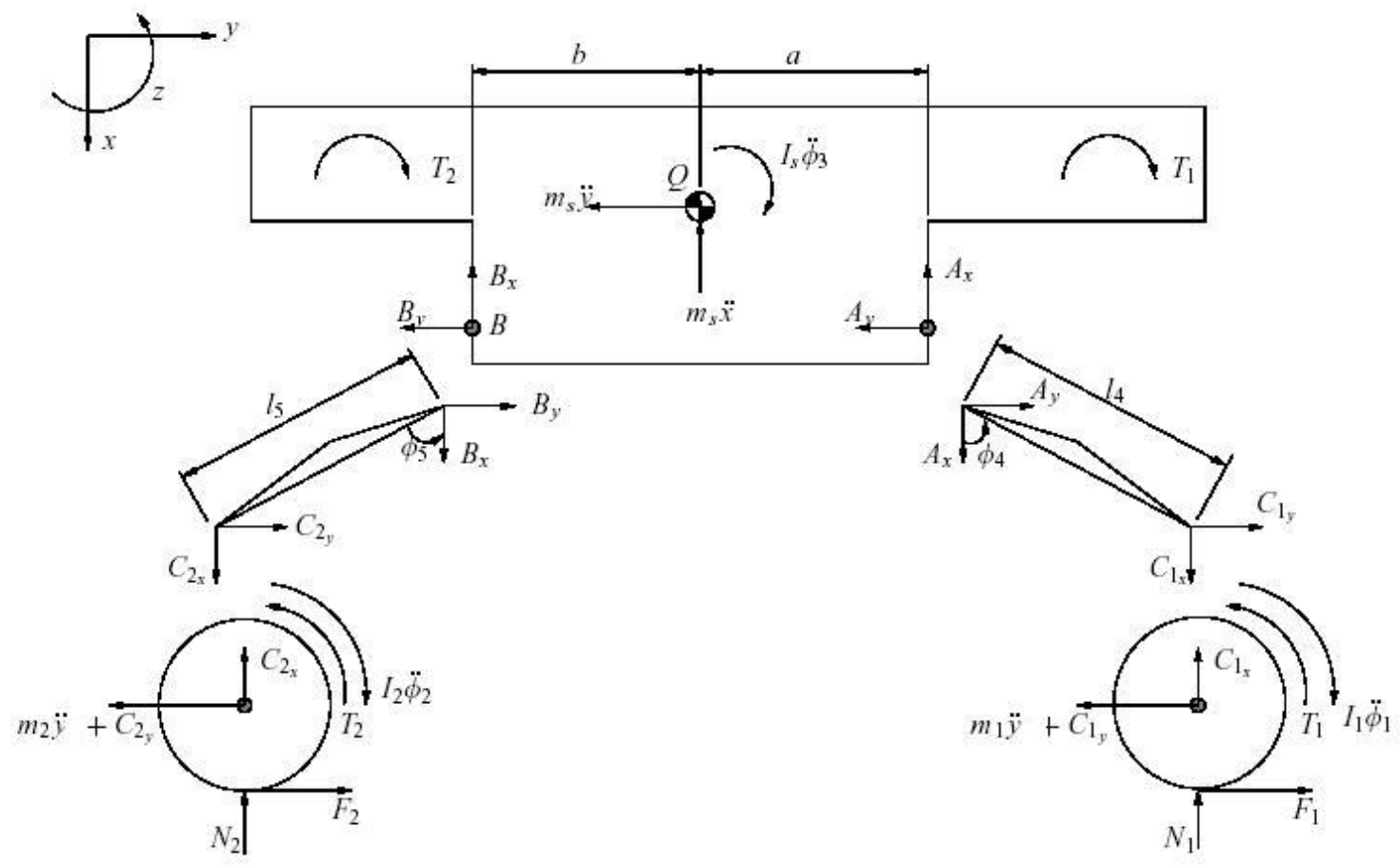

Figura 35 - Diagrama de corpo livre.

Para a massa suspensa tem-se: 


$$
\begin{gathered}
m_{s} \ddot{x}+A_{x}+B_{x}=0 \\
m_{y} \ddot{y}+A_{y}+B_{y}+m_{s} \ddot{y}=0 \\
-I_{s} \ddot{\phi}_{3}-T_{1}-T_{2}+A_{x}\left(\left(H-x_{1}\right) \sin \phi_{3}+a \cos \phi_{3}\right)-A_{y}\left(\left(H-x_{1}\right) \cos \phi_{3}-a \sin \phi_{3}\right) \\
+B_{x}\left(\left(H-x_{2}\right) \sin \phi_{3}-b \cos \phi_{3}\right)-B_{y}\left(\left(H-x_{2}\right) \cos \phi_{3}+b \sin \phi_{3}\right)=0
\end{gathered}
$$

Para o trailing-arm dianteiro:

$$
\begin{gathered}
A_{x}+C_{1 x}=0 \\
A_{y}+C_{1 y}=0 \\
-C_{1 x} l_{4} \sin \phi_{4}+C_{1 y} l_{4} \cos \phi_{4}=0
\end{gathered}
$$

Para o trailing-arm traseiro:

$$
\begin{gathered}
B_{x}+C_{2 x}=0 \\
B_{y}+C_{2 y}=0 \\
C_{2 x} l_{5} \sin \phi_{5}+C_{2 y} l_{5} \cos \phi_{5}=0
\end{gathered}
$$

Para a roda dianteira:

$$
\begin{gathered}
N_{1}+C_{1 x}=0 \\
C_{1 y}+m_{1} \ddot{y}-F_{1}=0 \\
T_{1}+F_{1} r_{1}-I_{1} \ddot{\phi}_{1}=0
\end{gathered}
$$

Para a roda traseira:

$$
\begin{gathered}
N_{2}+C_{2 x}=0 \\
C_{2 y}+m_{2} \ddot{y}-F_{2}=0 \\
T_{2}+F_{2} r_{2}-I_{2} \ddot{\phi}_{2}=0
\end{gathered}
$$

Para a condição de não escorregamento: 


$$
\begin{aligned}
& y=-r_{1} \phi_{1} \\
& y=-r_{2} \phi_{2}
\end{aligned}
$$

Vínculos geométricos podem ser derivados das coordenadas $\mathrm{C}_{1}$ e $\mathrm{C}_{2}$.

$$
\begin{aligned}
& \left(x+\left(H-x_{1}\right) \cos \phi_{3}-a \sin \phi_{3}+l_{4} \cos \phi_{4}\right)=H-r_{1} \\
& \quad\left(y+\left(H-x_{1}\right) \sin \phi_{3}+a \cos \phi_{3}+l_{4} \sin \phi_{4}\right)=y+a+y_{1} \\
& \left(x+\left(H-x_{2}\right) \cos \phi_{3}+b \sin \phi_{3}+l_{5} \cos \phi_{5}\right)=H-r_{2} \\
& \quad\left(y+\left(H-x_{2}\right) \sin \phi_{3}-b \cos \phi_{3}-l_{5} \sin \phi_{5}\right)=y-b-y_{2}
\end{aligned}
$$

Das equações anteriores é possível determinar a forças que atuam sobre suspensão trailing-arm:

$$
\begin{gathered}
C_{1 x}=-A_{x}=-N_{1} \\
C_{2 x}=-B_{x}=-N_{2} \\
C_{1 y}=-A_{y}=F_{1}-m_{1} \ddot{y} \\
C_{2 y}=-B_{y}=F_{2}-m_{2} \ddot{y} \\
T_{1}=-F_{1} r_{1}-\frac{I_{1}}{r_{1}} \ddot{y} \\
T_{2}=-F_{2} r_{2}-\frac{I_{2}}{r_{2}} \ddot{y}
\end{gathered}
$$

\section{A.1.2 Geometria Anti-dive (freio Outboard)}

As equações para a geometria anti-dive ou para freios outboard são similares as para o caso do anti-squat. As equações dinâmicas são iguais exceto (60), (63) e (66) que ficam respectivamente: 


$$
\begin{gathered}
-I_{s} \ddot{\phi}_{3}+A_{x}\left(\left(H-x_{1}\right) \sin \phi_{3}+a \cos \phi_{3}\right)-A_{y}\left(\left(H-x_{1}\right) \cos \phi_{3}-a \sin \phi_{3}\right) \\
+B_{x}\left(\left(H-x_{2}\right) \sin \phi_{3}-b \cos \phi_{3}\right)-B_{y}\left(\left(H-x_{2}\right) \cos \phi_{3}+b \sin \phi_{3}\right)=0 \\
-C_{1 x} l_{4} \sin \phi_{4}+C_{1 y} l_{4} \cos \phi_{4}-T_{1}=0 \\
C_{2 x} l_{5} \sin \phi_{5}+C_{2 y} l_{5} \cos \phi_{5}-T_{2}=0
\end{gathered}
$$




\section{B.1 Resultados (Gráficos)}

\section{B.1.1 Dive}

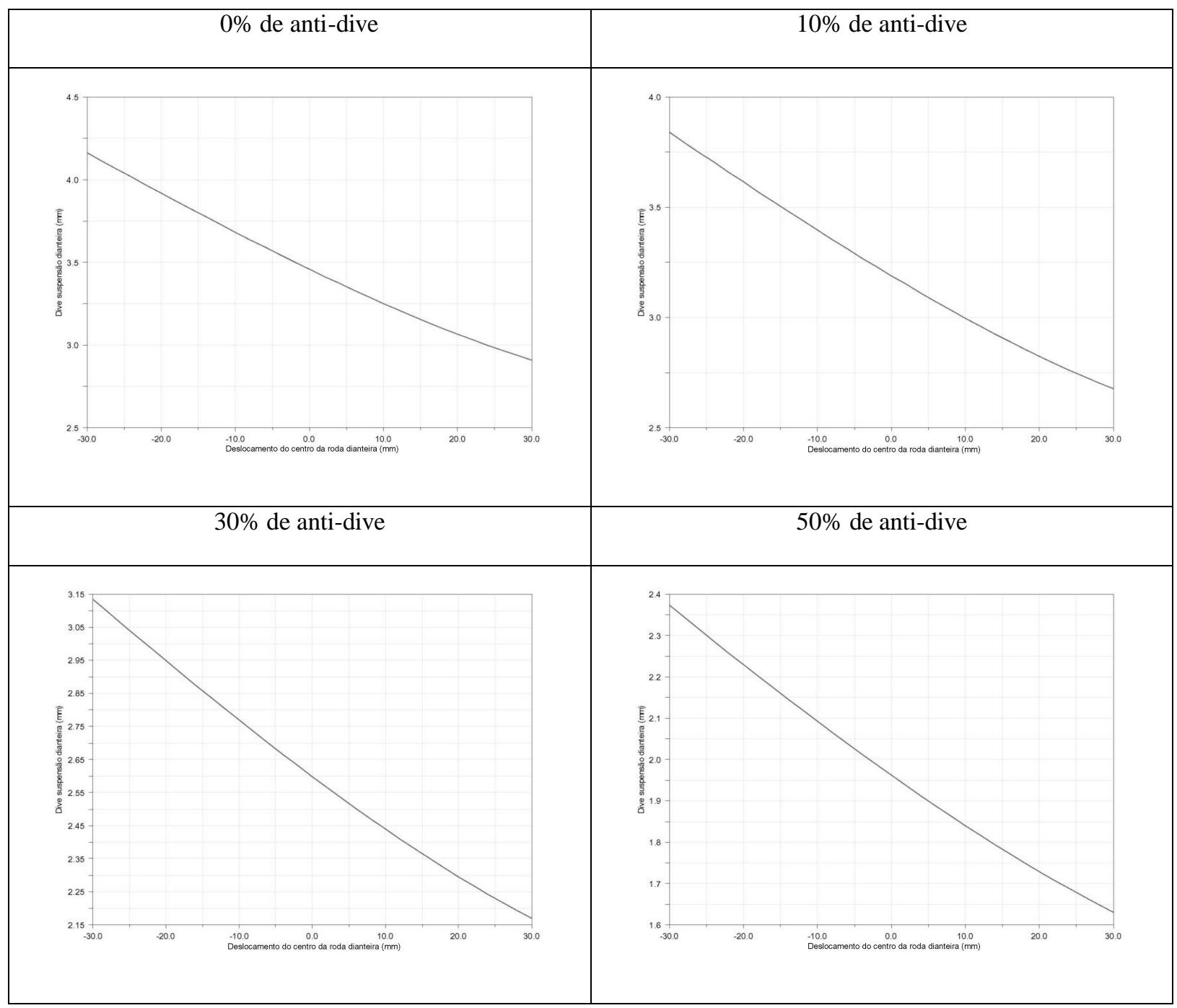




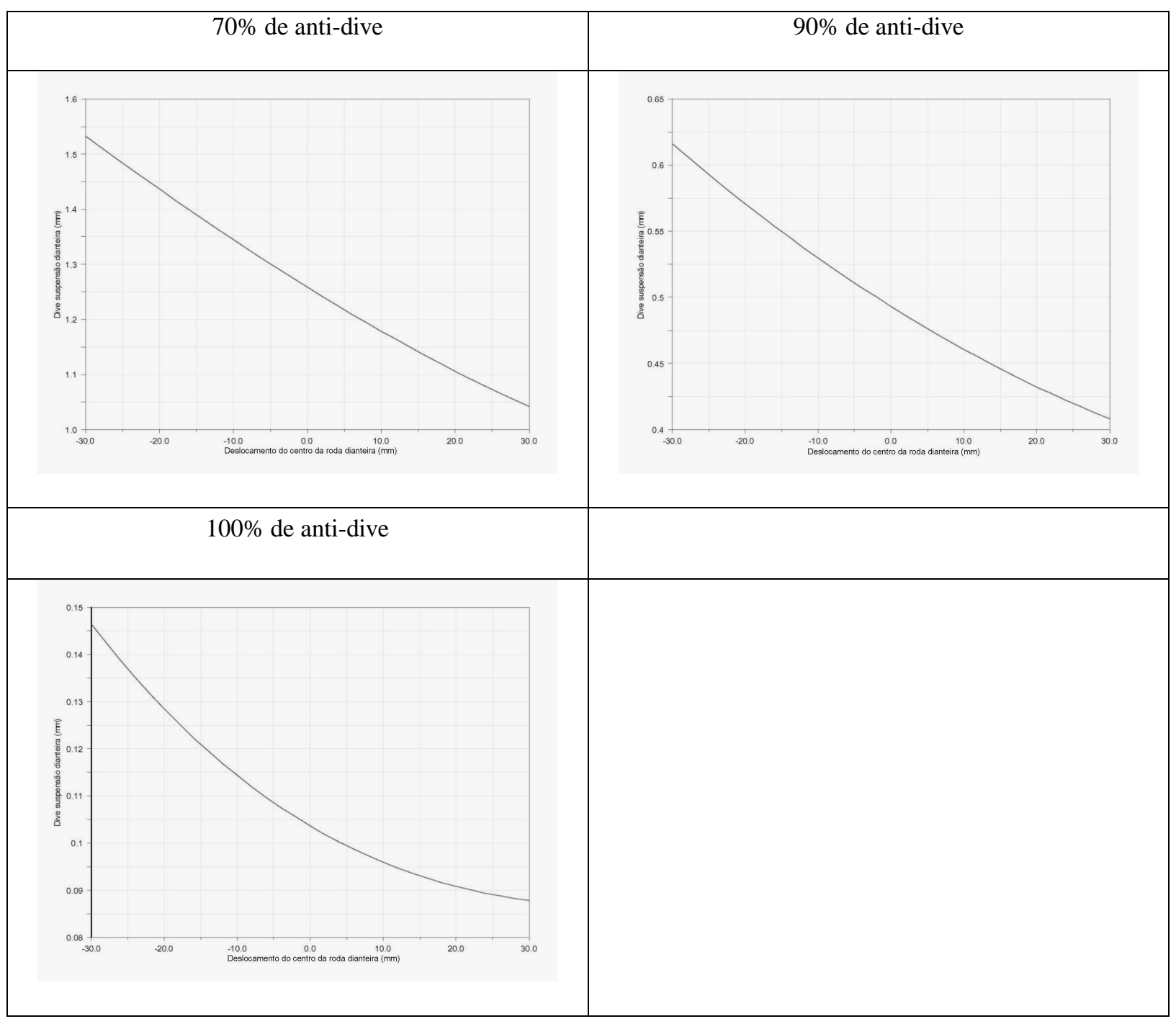

\section{B.1.2 1 Squat (Suspensão original)}

\begin{tabular}{|c|c|c|c|c|}
\hline & $0 \%$ de anti-lift & & & \\
\hline & & & \\
\hline
\end{tabular}




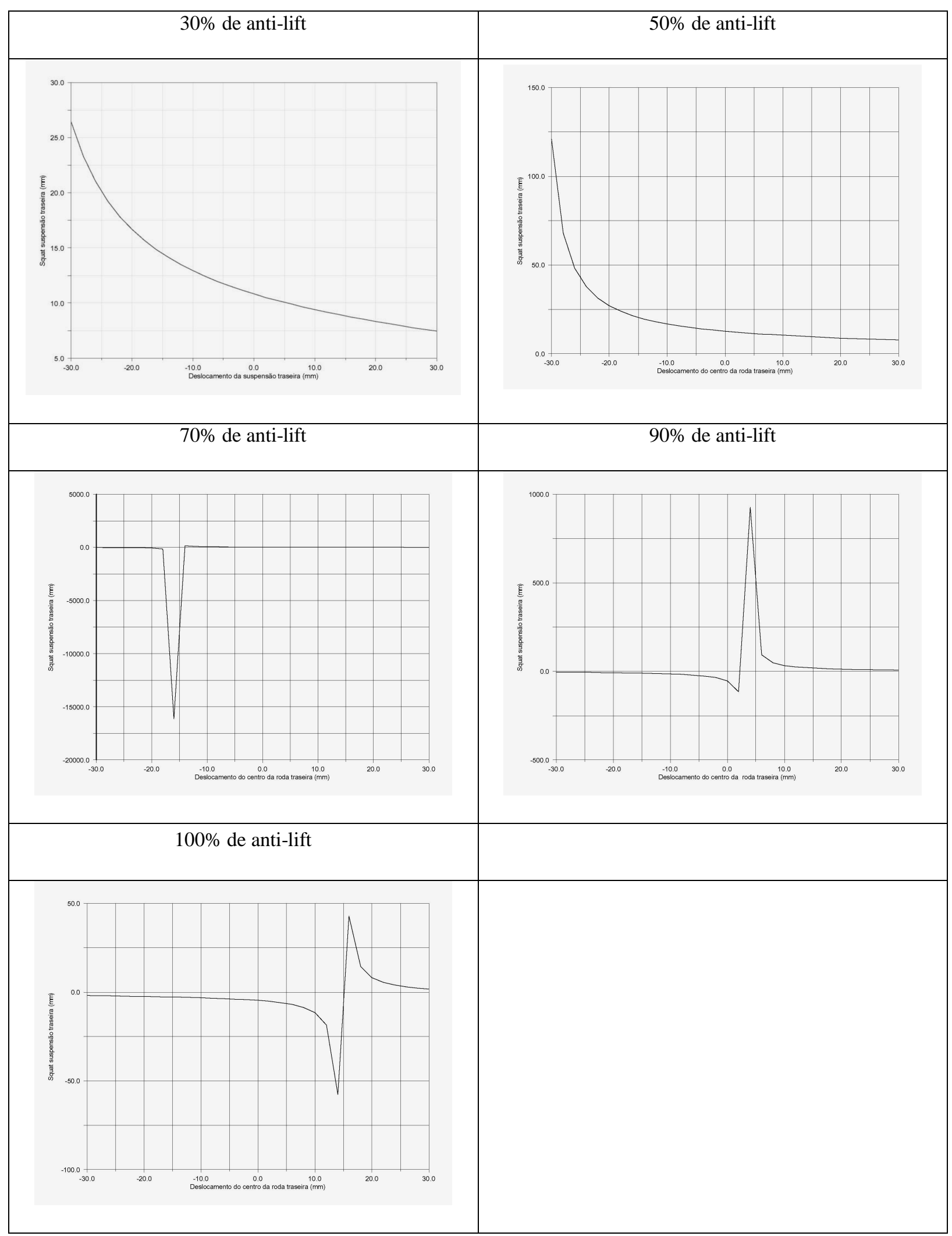




\section{B.1.2.2 Squat (Suspensão com alteração no push-rod)}

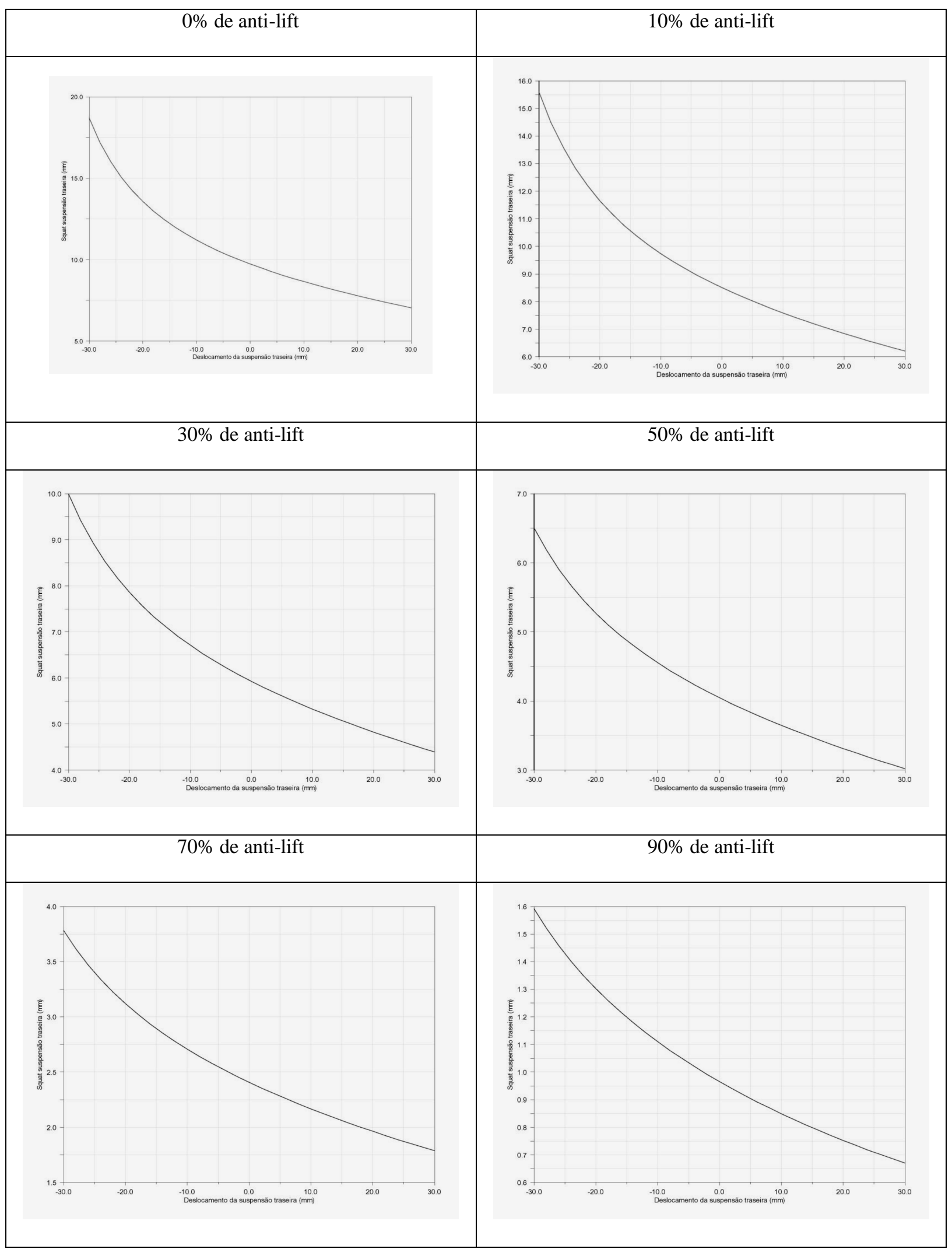




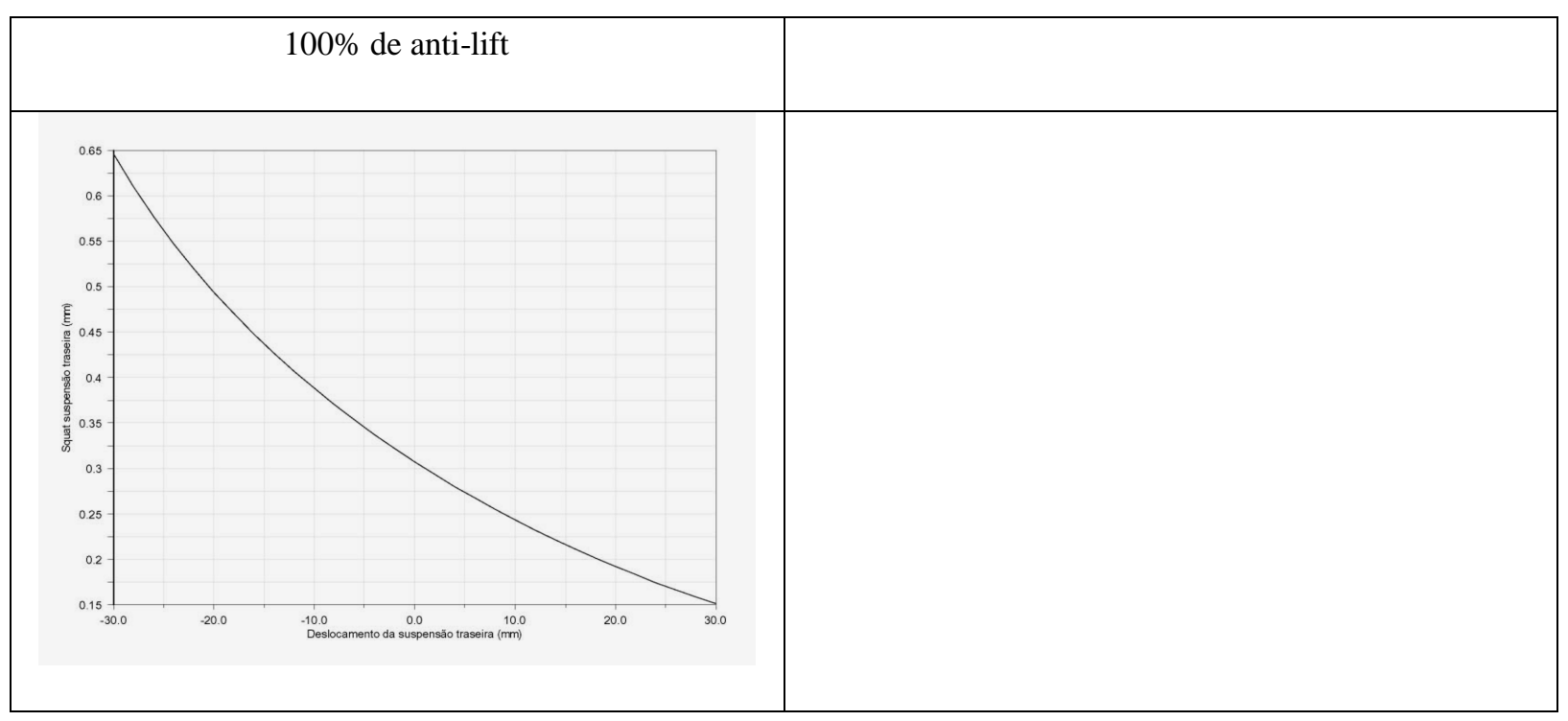

\section{B.1.3 Lift (Suspensão original)}

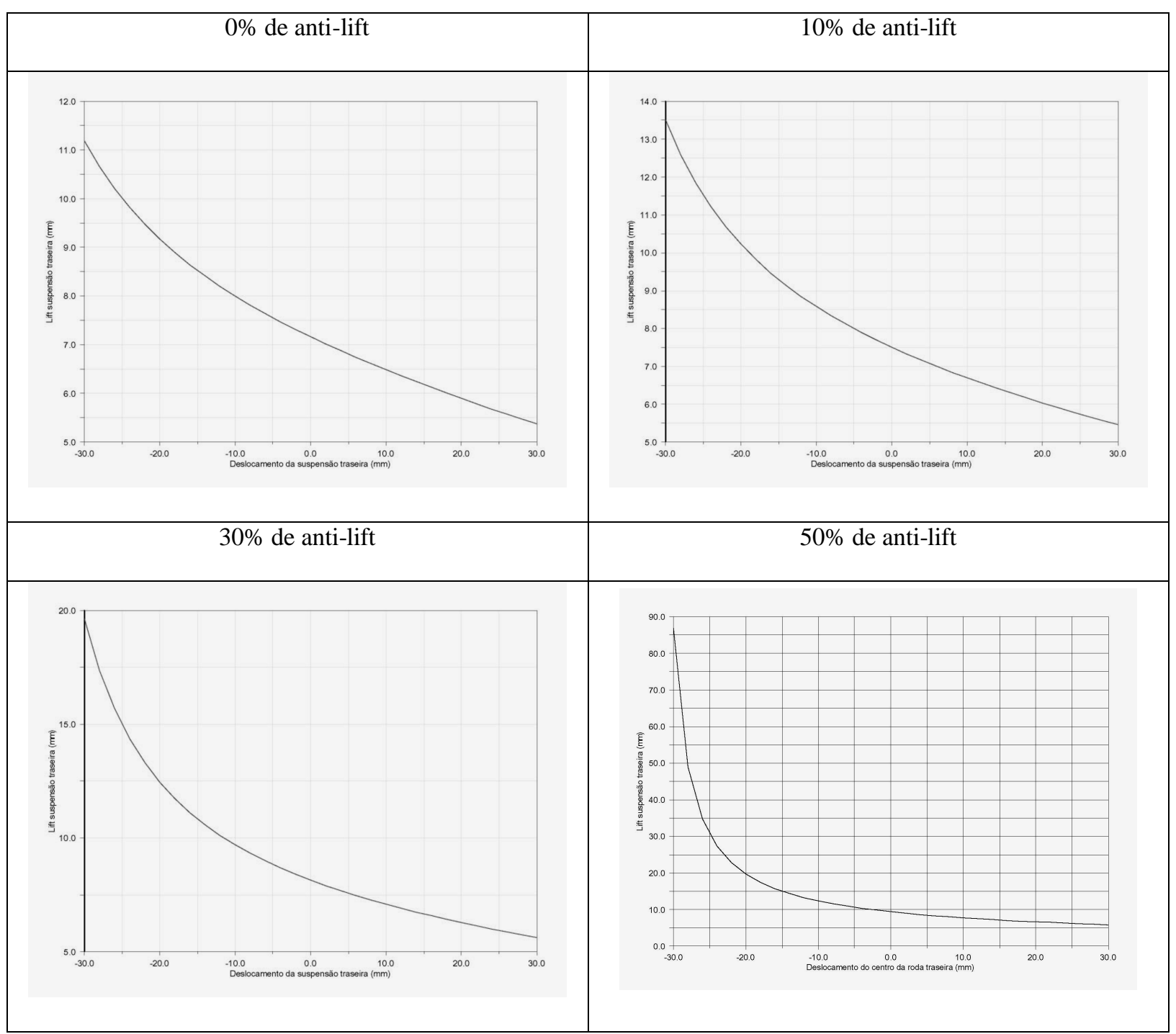




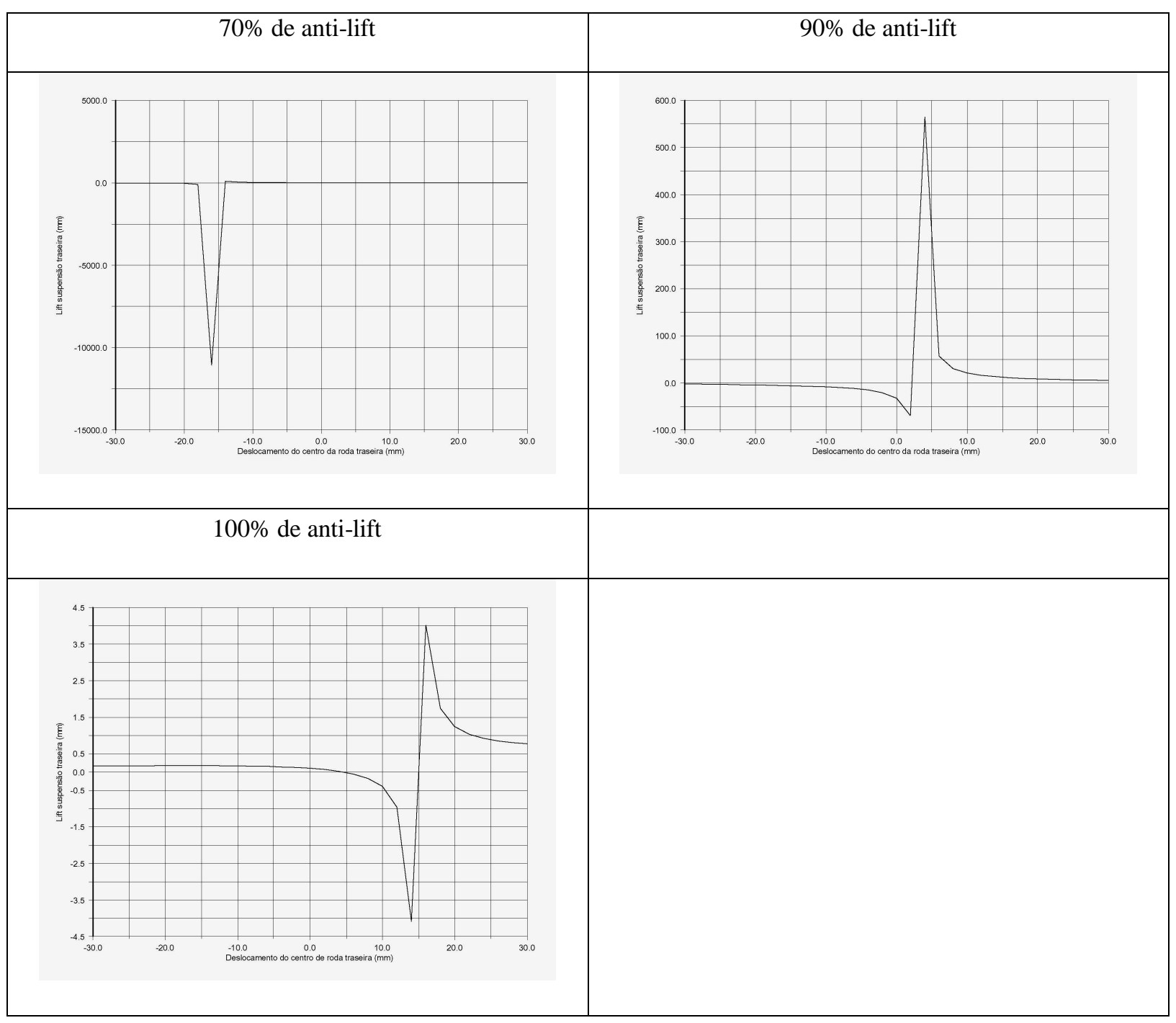

\section{B.1.4 Anti-dive}

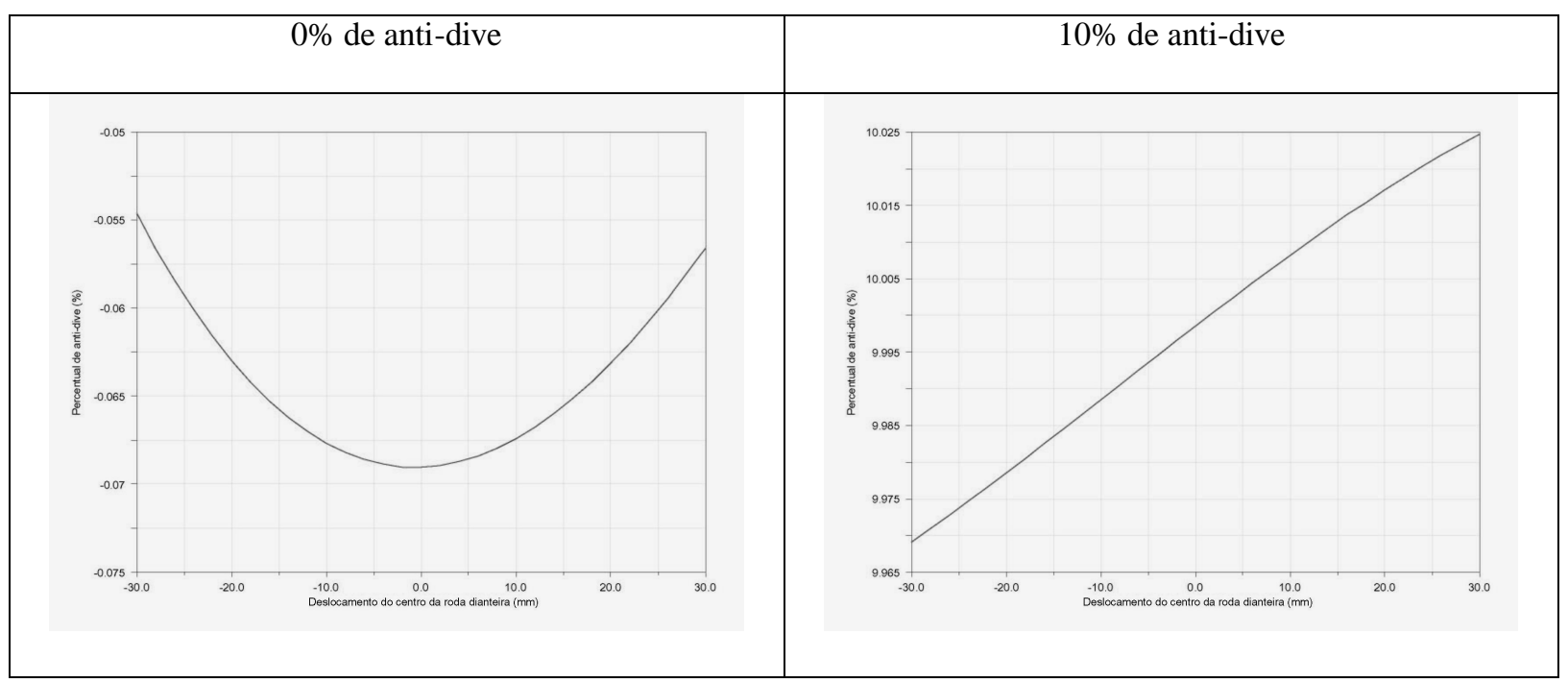




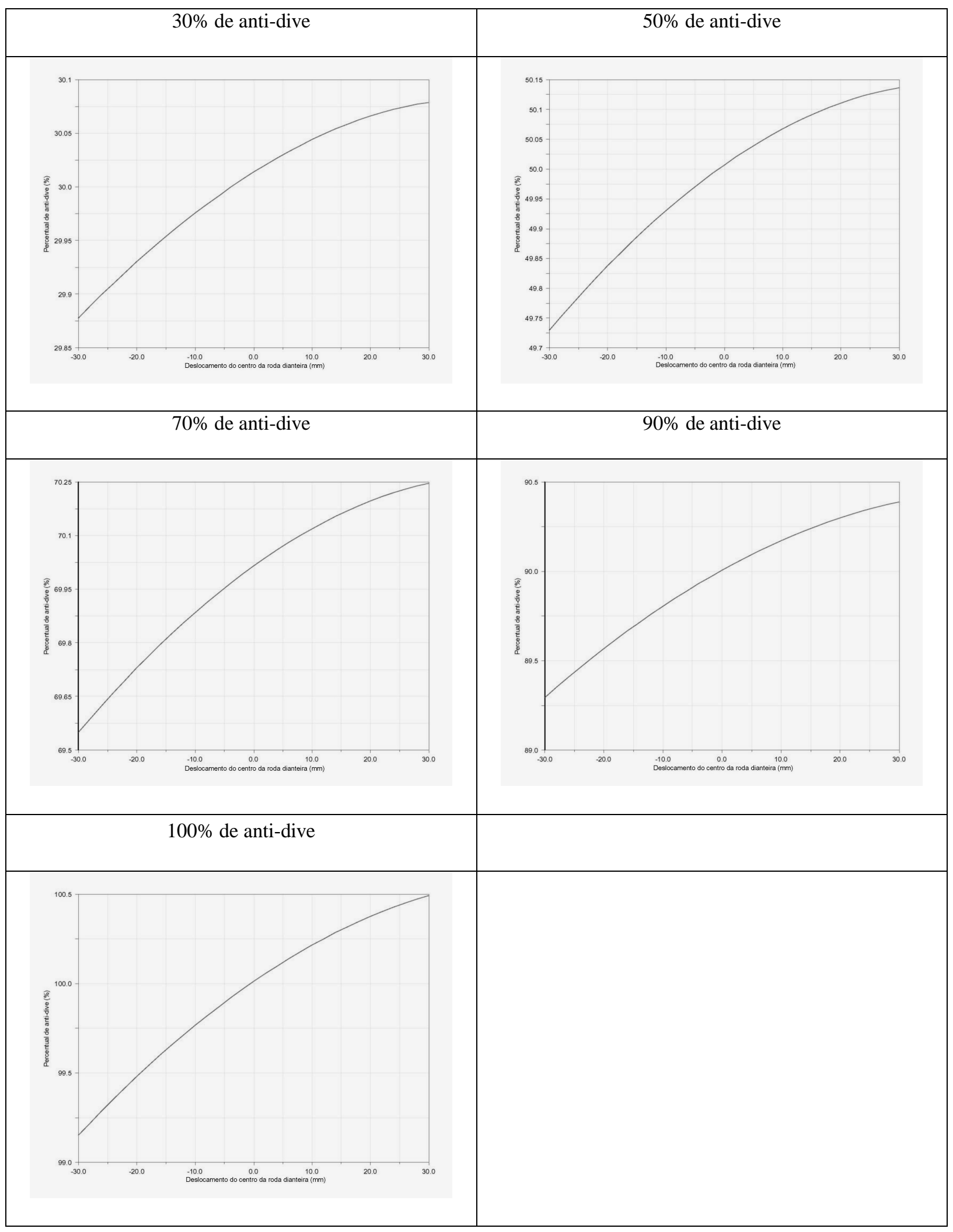




\section{B.1.5 Anti-Squat}

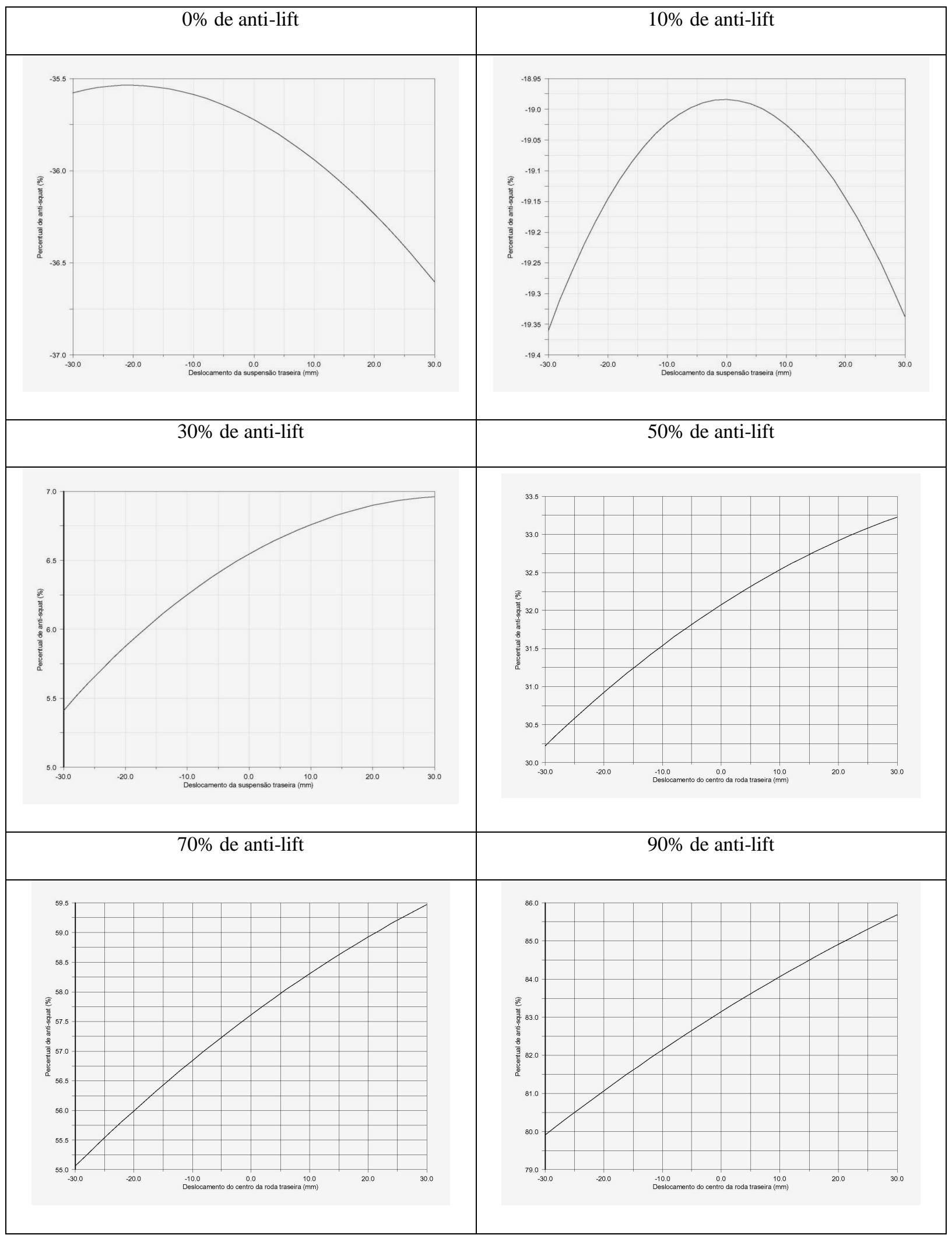




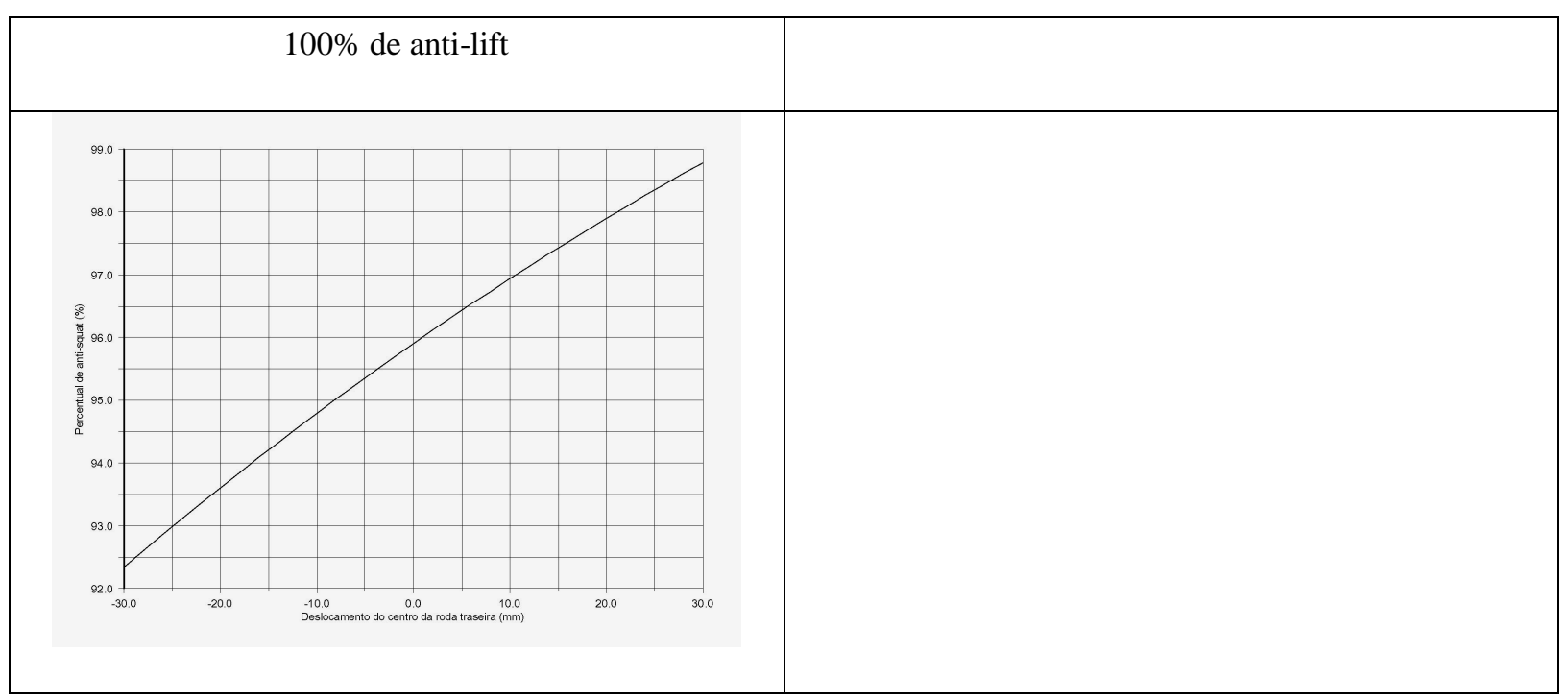

\section{B.1.6 Anti-Lift}

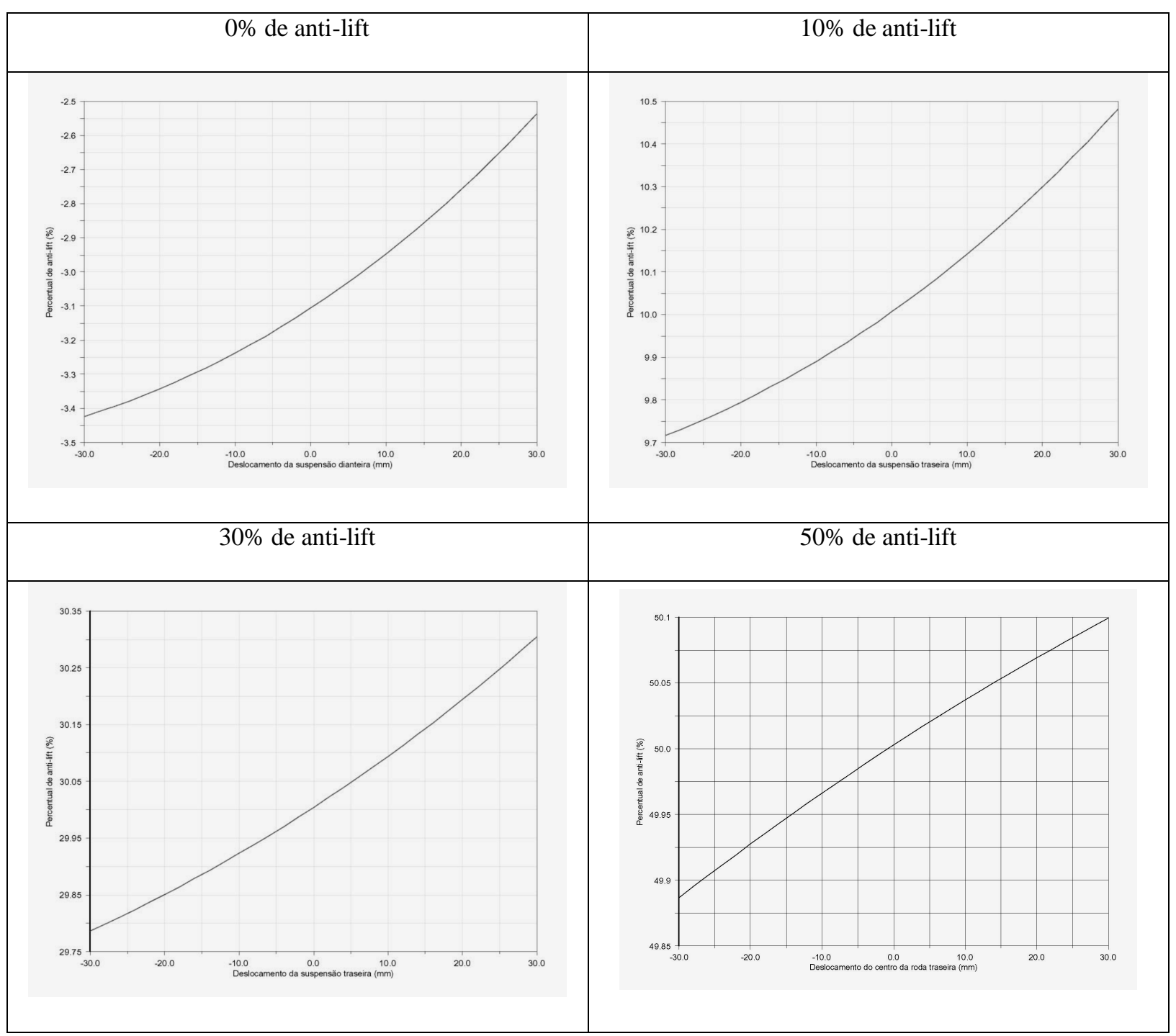




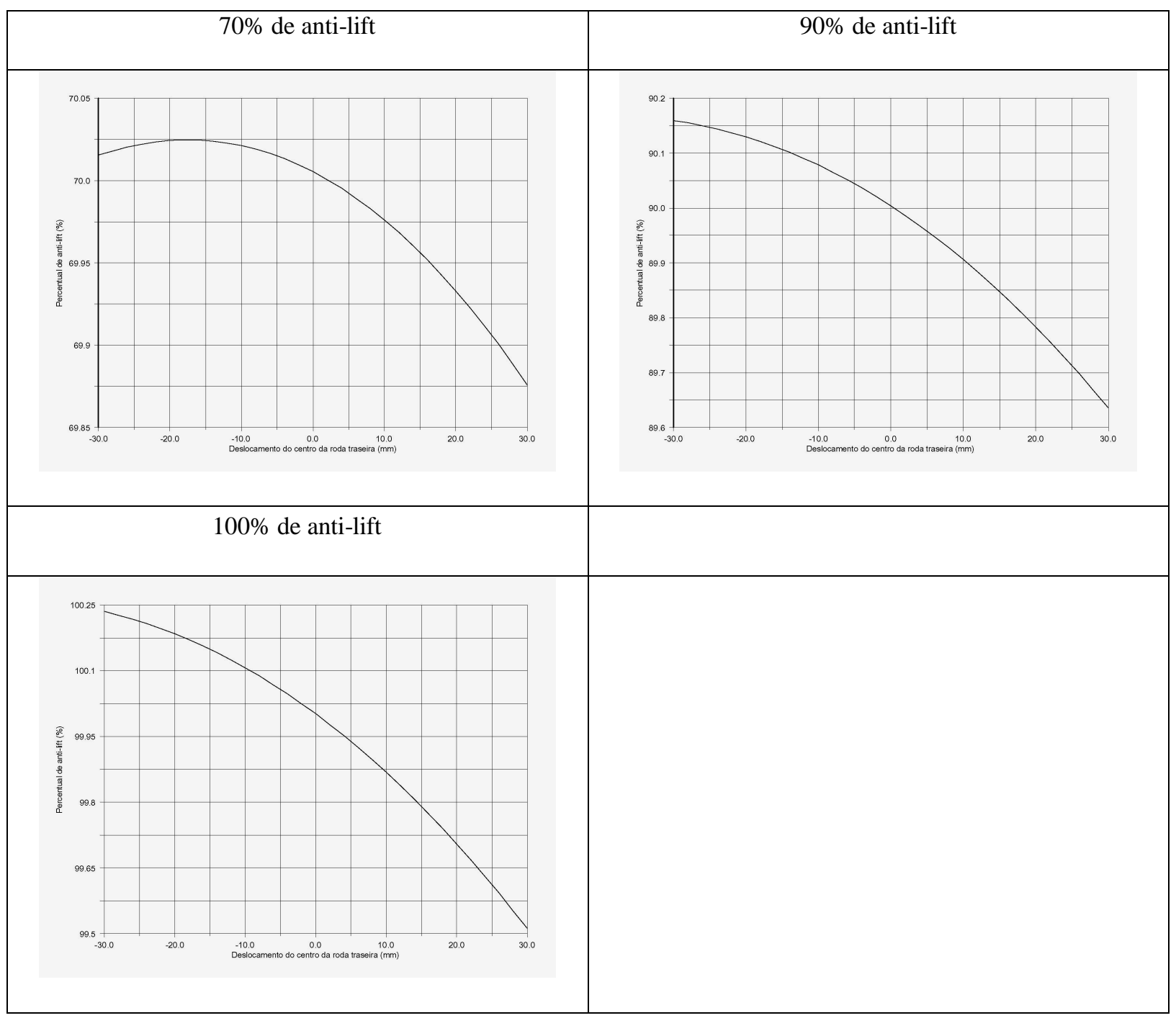

B.1.7 Ângulo do Equivalente trailing-arm (suspensão traseira original)

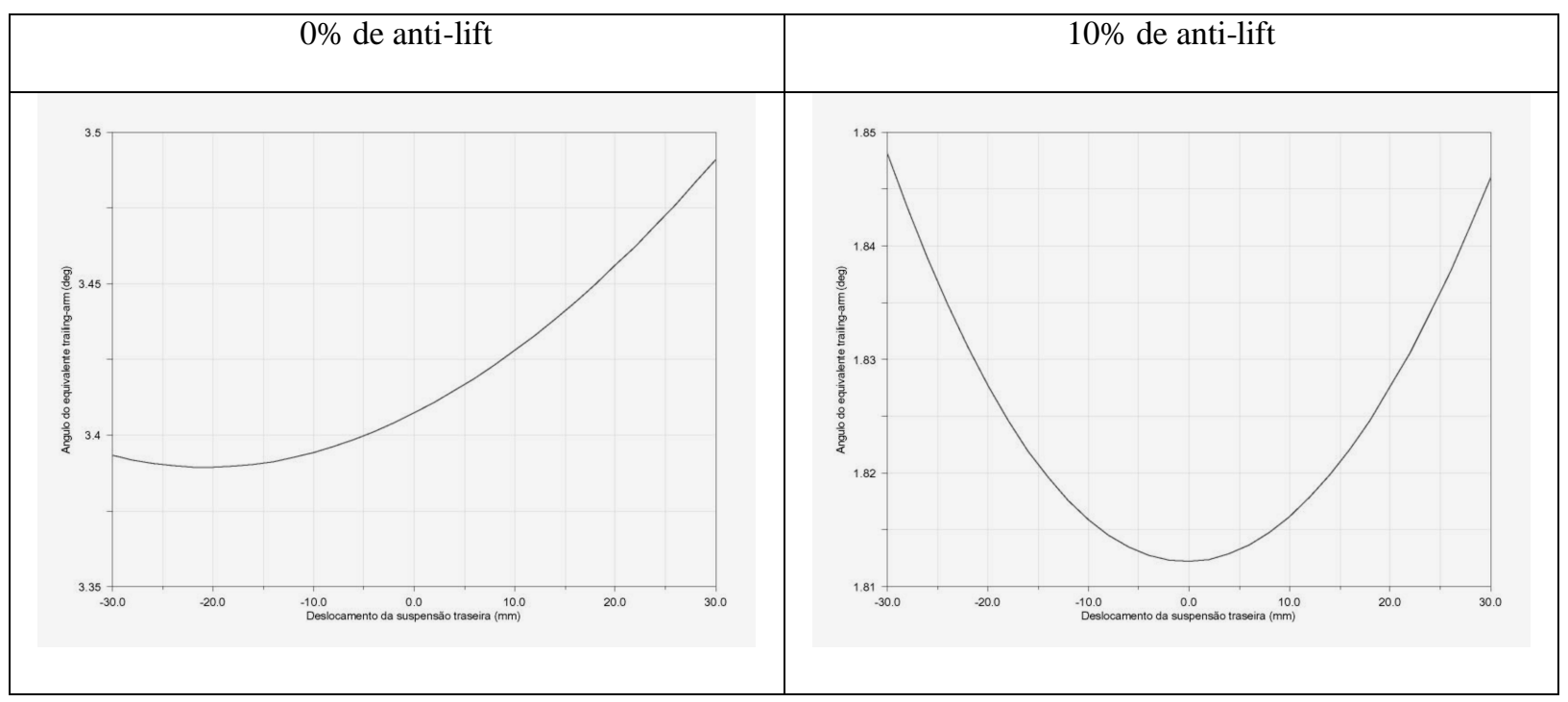




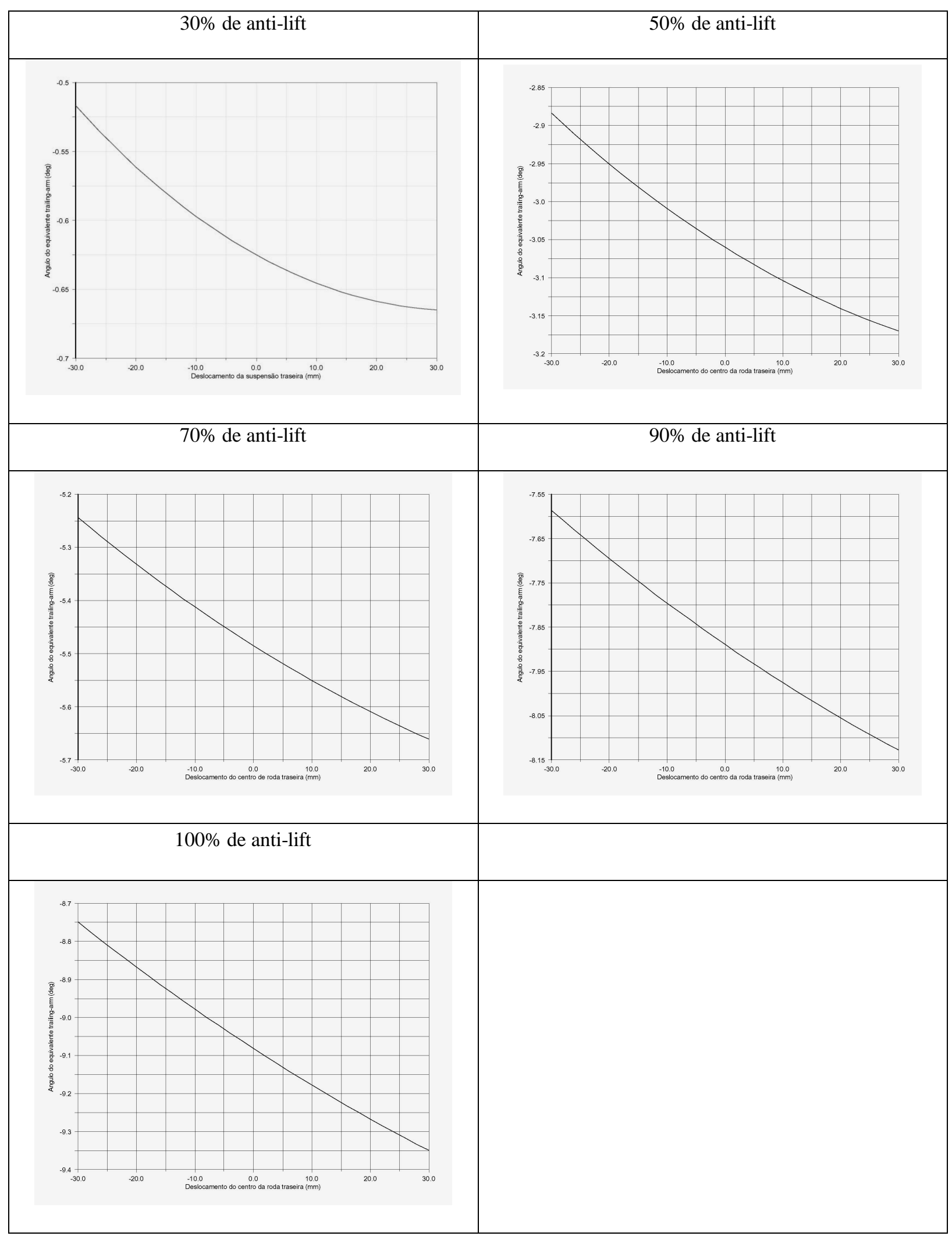


B.1.8 Ângulo do Equivalente trailing-arm (suspensão traseira com alteração no push-rod)

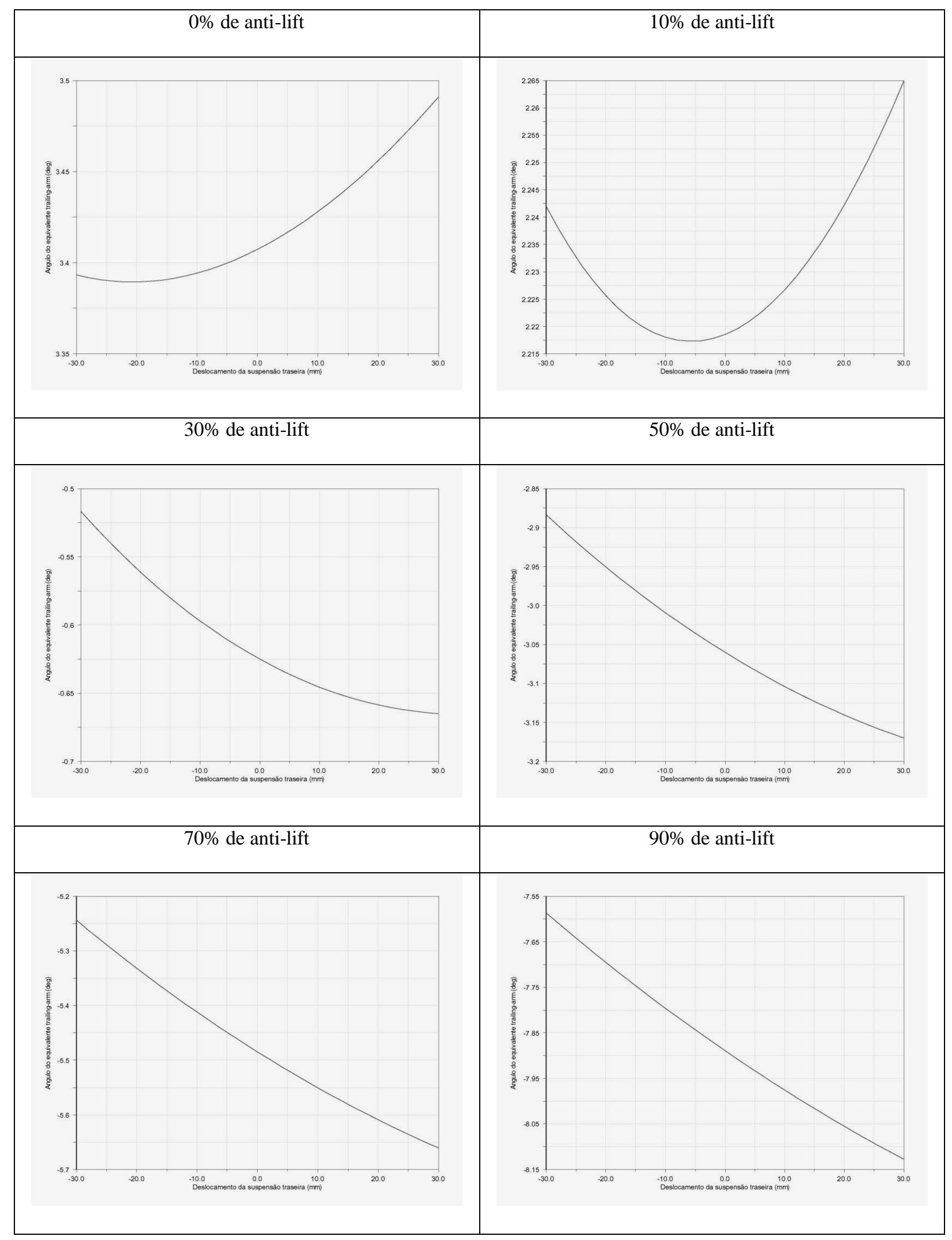




\begin{tabular}{|l|l|l|}
\hline $100 \%$ de anti-lift & \\
\hline & & \\
\hline
\end{tabular}

\section{B.1.9 Comprimento do Equivalente trailing-arm (suspensão traseira original)}

\begin{tabular}{|l|l|l|l|l|}
\hline & $0 \%$ de anti-lift & & \\
\hline & & & \\
\hline
\end{tabular}




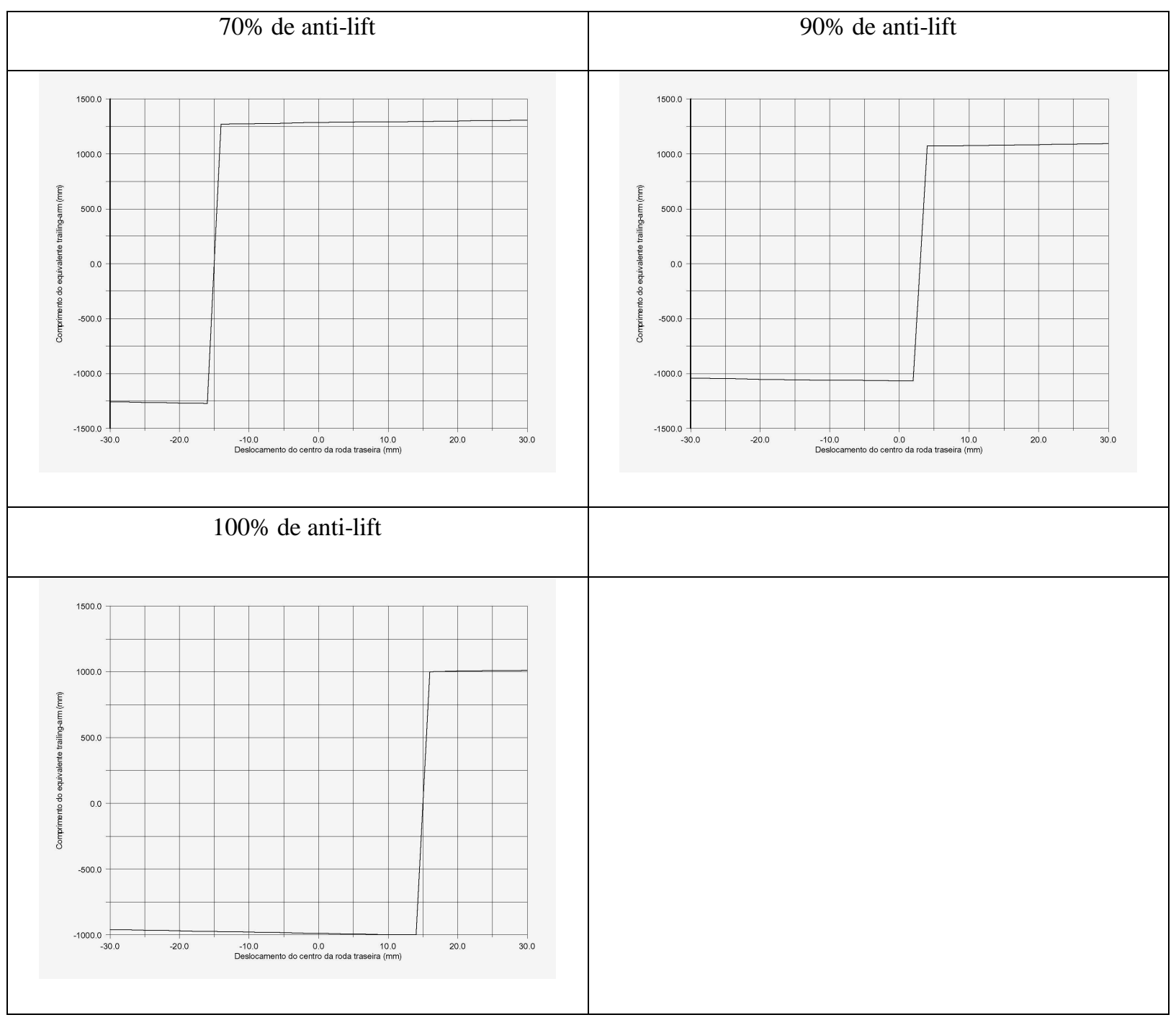

B.1.10 Comprimento do Equivalente trailing-arm (suspensão traseira com alteração no push-rod)

\begin{tabular}{|l|l|l|l|l|}
\hline & $0 \%$ de anti-lift & & \\
\hline & & & \\
\hline
\end{tabular}




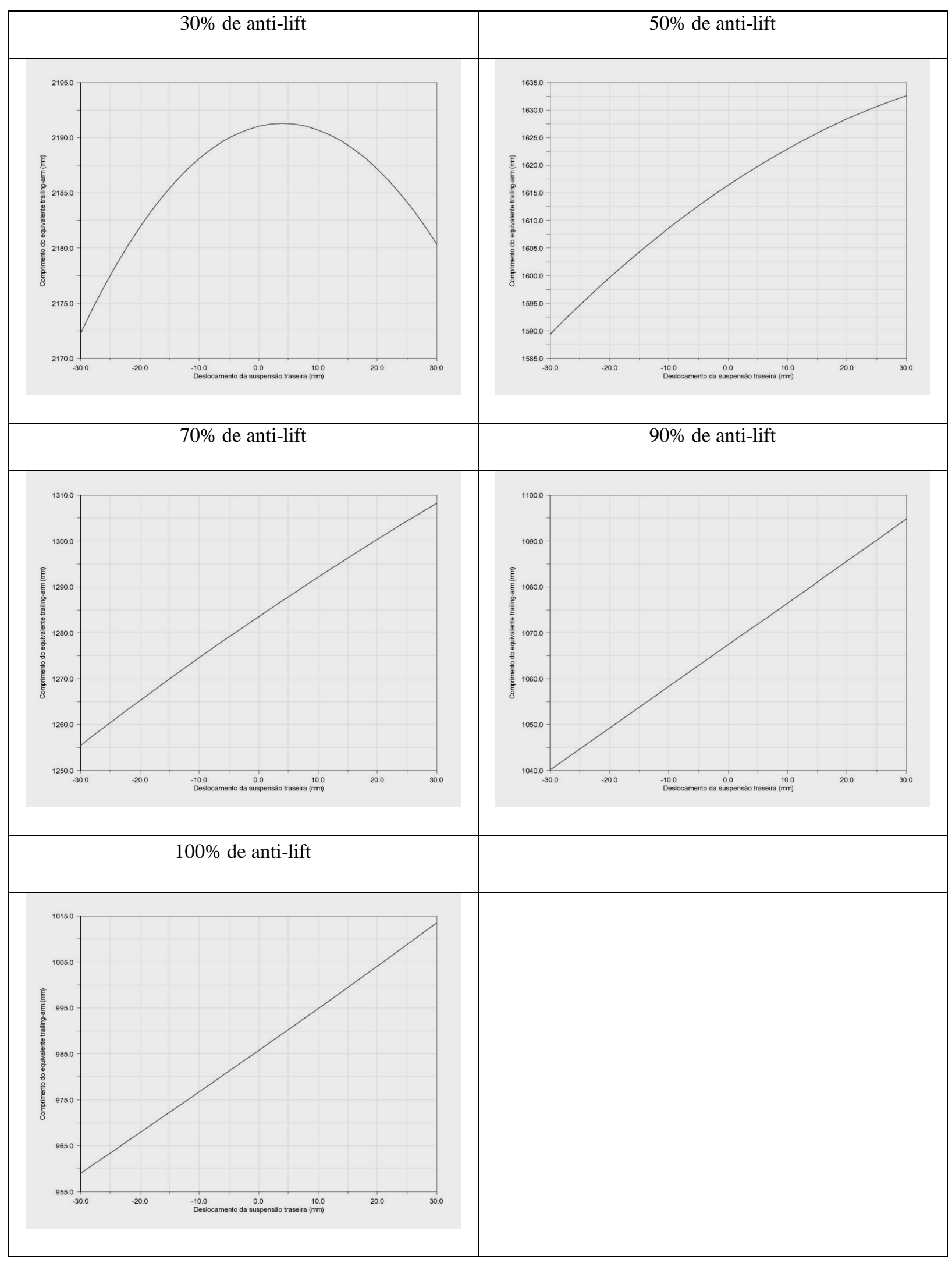


